Portland State University

PDXScholar

5-6-1993

\title{
Assessing the Impact of an ESL/Bilingual Program by Means of Instrumental Variable Estimation
}

John Akanbi Babatunde

Portland State University

Follow this and additional works at: https://pdxscholar.library.pdx.edu/open_access_etds

Part of the Urban Studies and Planning Commons

Let us know how access to this document benefits you.

\section{Recommended Citation}

Babatunde, John Akanbi, "Assessing the Impact of an ESL/Bilingual Program by Means of Instrumental Variable Estimation" (1993). Dissertations and Theses. Paper 4608.

https://doi.org/10.15760/etd.6492

This Thesis is brought to you for free and open access. It has been accepted for inclusion in Dissertations and Theses by an authorized administrator of PDXScholar. Please contact us if we can make this document more accessible: pdxscholar@pdx.edu. 
AN ABSTRACT OF THE DISSERTATION OF John Akanbi Babatunde for the Doctor of Philosophy in Urban Studies presented May 6, 1993.

Title: Assessing the Impact of an ESL/bilingual Program by Means of Instrumental Variable Estimation.

APPROVED BY THE MEMBERS OF THE DISSERTATION COMMITTEE:

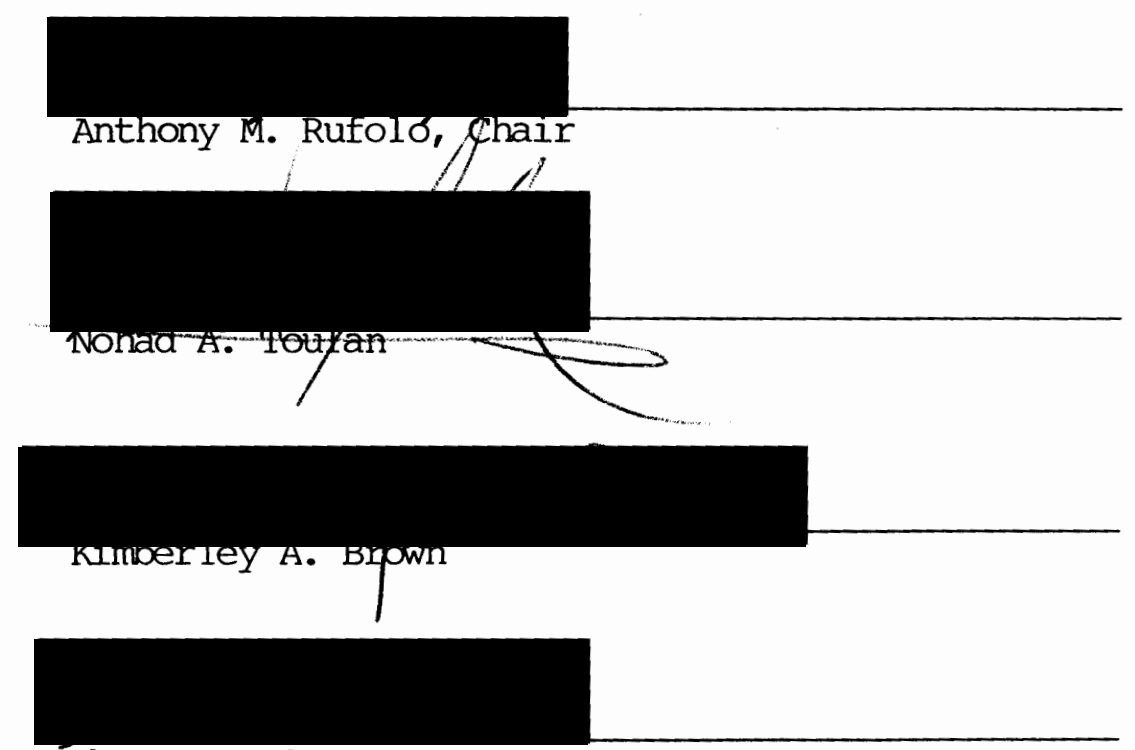

Thomas R. Owens

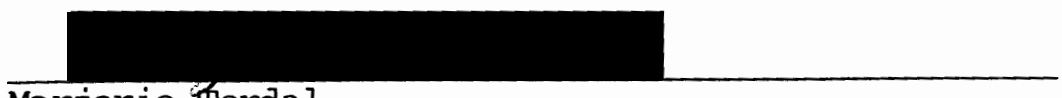

Marjorie Terdal

The purpose of this study was to assess the impact of the Portland (Oregon) public school district's ESL/bilingual program on the academic performance of limited English proficiency (IEP) students. 
The study attempted to correct a statistical bias that might lead to underestimating the effectiveness of ESL/bilingual programs. This statistical bias is caused by a negative correlation between student achievement and the characteristics which result in a student being placed in the ESL/bilingual program. Several variables and proxies representing characteristics of the school, the neighborhood, and the student's personal background were examined for their contribution to explaining the academic progress of LEP students in reading, mathematics, and English language usage.

This dissertation attempts to answer the following major questions:

1. Is the Portland school district's ESL/bilingual education approach effective in increasing LEP students' academic progress in reading, mathematics, and English language usage?

2. Does the amount of ESL/bilingual instruction influence the academic achievement of IEP students in reading, mathematics, and English language usage?

3. Do the personal background characteristics of LEP students influence their academic gains in reading, mathematics, and English language usage?

4. Do neighborhood factors influence LEP students' gains in reading, mathematics, and English language usage?

Achievement gains of LEP students in Grades 3-11 from the Portland (Oregon) Public School district were examined. Data on pertinent characteristics relating to school, neighborhood, and personal background information were collected. The data were analyzed using 
multiple regression analysis and instrumental variable estimation. Instrumental variable (IV) estimation was found to be appropriate to deal with the serious problem of "selection bias" in evaluating achievement gains of LEP students in ESL/bilingual programs. The problem of selection bias occurs when learners are selected for a program or for evaluation study because of characteristics which will also influence their scores on a test. Subsequent effects of this type of selection, and possible solutions to this type of problem, are discussed.

The findings suggest that the ESL/bilingual education approach had a strong and statistically significant impact in improving mathematics achievement. The program's impact on language usage achievement was weak, and it showed no consistent results relating to reading achievement. The findings indicate that the greatest impacts are in academic areas rather than in language areas.

The results were not strong, but the ESL/bilingual program appeared to have some positive benefits in terms of achievement gain in mathematics and language usage which simpler statistical techniques tend not to show. However, because of the statistical problems and the methods used to address them, confidence in estimates of the specific parameters is not great. Studies covering different geographic areas and longer periods of time are recommended. 
ASSESSTNG THE IMPACT OF AN ESL/BILINGUAL PROGRAM BY MEANS OF INSTRUMENTAL VARIABLE ESTIMATION

by

JOHN AKANBI BABATUNDE

A dissertation submitted in partial fulfillment of the requirements for the degree of

\author{
DOCTOR OF PHILOSOPHY \\ in \\ URBAN STUDIES
}

Portland State University

(c) 1993 
TO THE OFFICE OF GRADUATE STUDIES:

The members of the Committee approve the dissertation of John Akanbi Babatunde presented May 6, 1993.
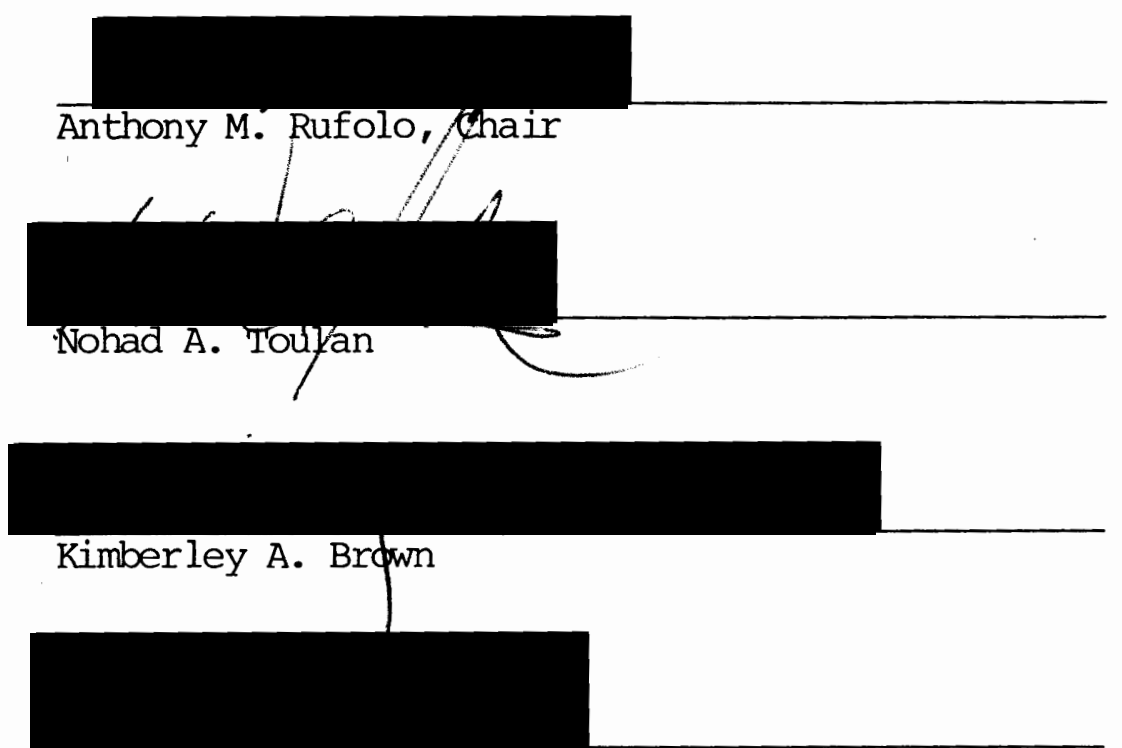

Thamas R. Owens
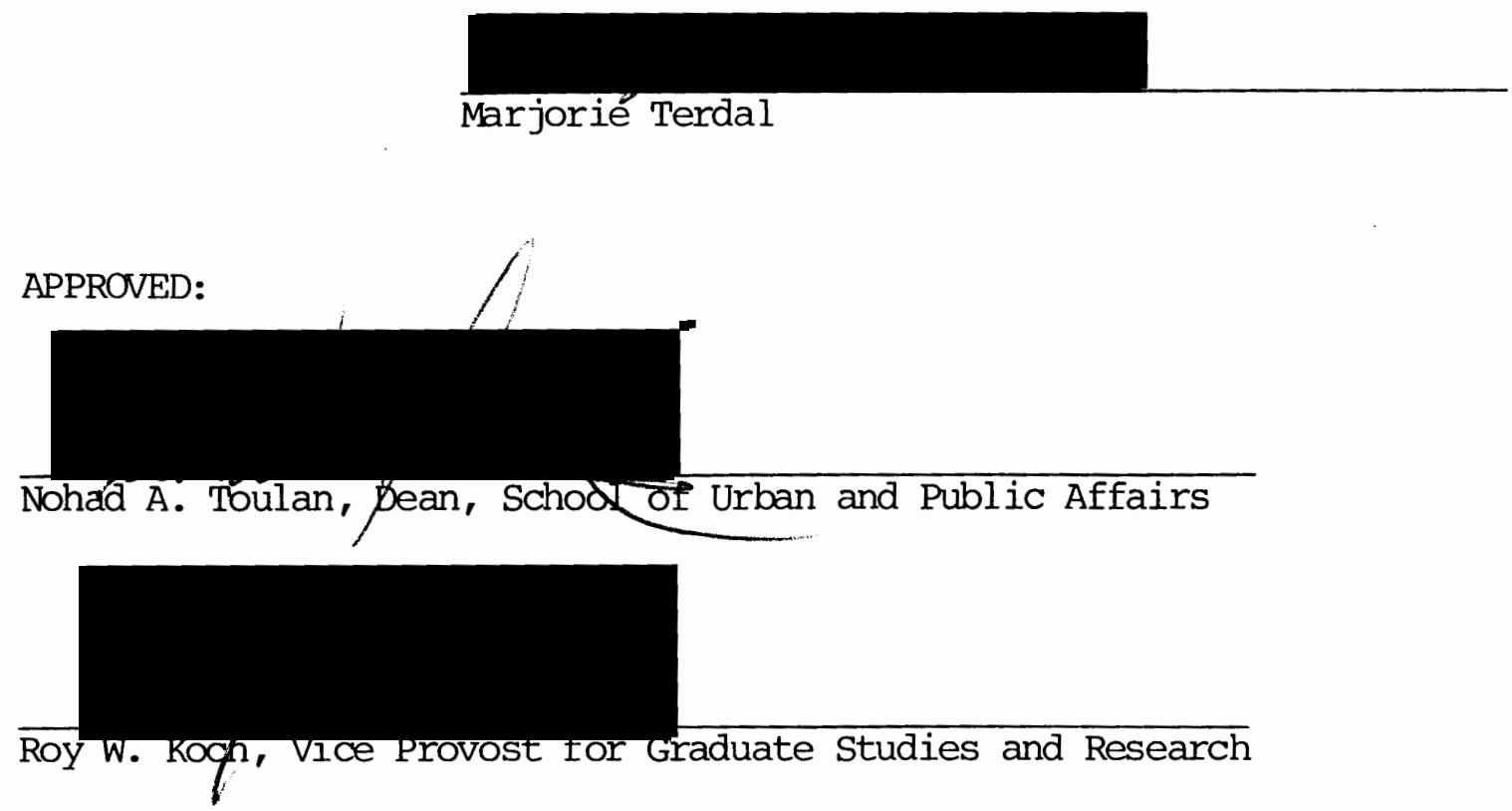


\section{DEDICATION}

I wish to dedicate this dissertation to my parents, (late) Amodu and Mariama Babatunde, whose love and support I have always received. 


\section{ACKNOWLEDGEMENTS}

This study could not have been completed without the gracious assistance of the members of my committee. I am immeasurably indebted to Dr. Anthony Rufolo, adviser and chair of my dissertation committee, for his patience, toleranœ, and understanding at a time when the prospect of finishing seemed remote. His guidance, prodding, enoouragement, and unending optimism were invaluable in seeing this dissertation to completion.

I am extremely grateful to Dr. Kimberley Brown, who guided and redirected my focus through the earlier parts of the project. A debt of gratitude is owed to $\mathrm{Dr}$. Marjorie Terdal for meticulously reading the earlier drafts and making constructive criticisms and valuable suggestions. I am extremely grateful to Dr. Thomas Owens for his assistance and encouragement not to abandon the pursuit. Sincere gratitude is expressed to Dr. Nohad Toulan for his understanding and patience. His support over the years is greatly appreciated.

I thank the Portland Public Schools for their data, the ESL/bilingual Education Department, the Evaluation Department, and the Plant Operations Department for their support.

My gratitude to my wife, Adun; my daughters, Ayo and Joke; and my son, Fikayo, is inestimable. Their patience and moral support were valuable during what might have seemed an interminable period of time. 
TABLE OF CONTENIS

PAGE

ACKNOWLEDGEMENTS . . . . . . . . . . . . . .

LIST OF TABLES .......................... ix

LIST OF FIGURES . . . . . . . . . . . . . . xii

CHAPTER

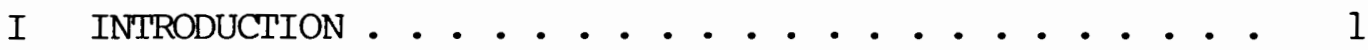

Background .................. 1

Statement of the Problem ........ 5

Objectives of the Study ......... 8

The Importance of the Study . . . . . . . . 10

Brief Definitions and Discussion of

Relevant Terms .......... 14

Limited English Proficiency . . . . . 14

Home Language or First Language (Ll) • . 14

Bilingual Education ........ 15

Transitional Bilingual Education .... 15

Bilingualism .......... 15

Additive Bilingualism ....... 15

subtractive Bilingualism ...... 16

Elementary and Secondary Education

Act Title VII . . . . . . . 16

Lau Category . . . . . . . . 16

English-as-a-Second-Language .... . 17

Pull-out ESL Approach . . . . . . . 17

Immersion Programs ........ 17

The Goals of ESL/bilingual Education .... . . 18 
Funding and Federal Support .......... 22

Population Characteristics and Data Sources . . . 25

Population Characteristics . . . . 25

Data Sources . . . . . . . . 27

Organization of the Study . . . . . . . 29

II REVIEW OF THE LTTERATURE . . • . • . . . . . . . 30

Theories and Issues Relevant to

ESL/bilingual Education . . . . . . . . 30

The Equilibrium Paradigm . . . . . 30

The Evolutionary Theory . . . . . . 32

Structural-Functional Theory . . . . . 33

Social and Cultural Factors Affecting

Education of IEP Students . . . . . . 34

Cummins's Developmental Interdependence

Theory ........... . . 39

Brief Historical Perspectives of

ESL/bilingual Education . . . . . . . 41

The Impact of Legislative and Judicial Actions

on ESL/bilingual Education . . . . . . 43

Lau Remedies . . . . . . . . . . 44

Oregon Laws Relevant to ESL/bilingual

Education .. . . . . . . . 45

Estimating the Number of LEP

School-aged Children . . . . . . . . 46

Language Planning Perspectives . . . . . . 48

Relevant Research on the Effectiveness of

ESL/bilingual Education . . . . . . . 53

Early Exit in ESL/bilingual Programs . . 61

Summary . . . . . . . . . . . . 67

III Methodology . . . . . . . . . . . . 70

Introduction . . . . . . . . . . . 70

Statistical Problem . . . . . . . . . 70

Error Structure .......... 71 
Research Design . . . . . . . . 76

Frequency Distribution .. . . . . 76

Breakdown Analysis ........ . 76

Regression Assumptions .. . . . . 76

Identification of Variables . . . . . . . 77

The Dependent Variables . . . . . 78

The Independent Variables . . . . . . 79

Description of ESL/bilingual

Instructional Variants . . . . 86

Measures of Progress in the PPS System . . . • . 87

Model Identification . . . . . . . . 88

Data Analysis and Preliminary Findings . . . . 92

LEP Students' Initial Achievement . . . 92

Results of the $t$ Test for

1983 Achievement ........ 93

Regression Results for

Achievement Gains . . . . . . 97

The Choice of Instrumental Variables . . . . . 102

Specification of the Model . . . . . . . 107

IV Empirical Results . . . . . . . . . . 113

Descriptive Statistics . . . . . . . . 113

Summary Findings of the Breakdown

Analysis of LEP Students'

Initial Achievement . . . . . . . 116

Summary Findings of $t$ Tests Comparing

Means for Reading, Mathematics and

Language Usage Gains . . . . . . 116

Summary of Regression Results . . . . . . . 118

Introduction . . . . . . . . . 118

Obtaining Instrumental Variables . . . 122

Regression Results for Reading

Achievement . . . . . . . . . 124

Regression Results for Mathematics

Achievement . . . . . . . . 127

Regression Results for Language

Usage Achievement . . . . . . . 131 
Regression Results of Some Other Variables Which

May Influence LEP Students' Achievement . . . 131

Age . . . . . . . . . . . 131

Time in Portland Public Schools

(TIPPS) . . . . . . . . . . . 135

Percent Neighborhood High School

Graduates (PHSG) . . . . . . . 136

Students' Grade Level . . . . . . 137

SUMMARY AND CONCLUSIONS . . . . . . . . . 138

Summary . . . . . . . . . . . . . 138

General Issues on LEP Education . . . 139

Hypotheses . . . . . . . . 140

Summary Findings for Achievement Gains in Reading,

Mathematics, and Language Usage . . . . . 142

Reading Achievement ......... 142

Mathematics Achievement . . . . . . 142

Language Usage Achievement . . . . . 144

Other Variables Included to Assess Their

Influence on LEP Students' Achievement . . . . 144

Conclusions . . . . . . . . . . . 145

Limitations of the Study . . . . . . . . 147

Implications for Policy and Practice . . . . . 149

Recommendations for Future Research . . . . . 151

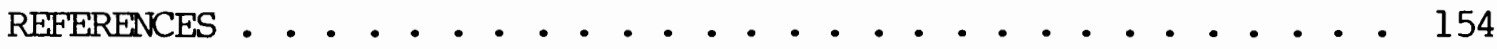

APPENDICES

A PRIMARY LANGUAGES OF ESL/BILINGUAL STUDENTS, PORTIJAND PUBLIC SCHOOLS, 1990-1991 . . . . . . . 166

B PRIMARY LANGUAGE OF ESL/BILINGUAL STUDENIS, PORTLAND PUBLIC SCHOOLS, 1982-1983 . . . . . . . 168

C 1983 PERCENT OF SOUTHEAST ASIAN ENROLTMENT PER TOTAL SCHOOL POPULATION . . . . . . . . . . 170 
D 1982-1983 LANGUAGE, READING, AND MATHEMATICS GOALS FOR PORTLAND ACHIEVEMENT LEVELS TESTS • • • • • • • 174

E FLOW CHART OF IDENIIFICATION, ENROLIMENT AND ASSESSMENT OF ALL CHILDREN WITH HOME LANGUAGE OTHER THAN ENGLISH . • • • . • • • • . 176

F PERCENT TOTAL HIGH SCHOO SOUTHEAST ASIAN STUDENTS BY CITY LOCATION DURING 1982-1983 SCHOOL YEAR . . . . . . 178

G AGE DISTRIBUTION OF STUDENTS IN THE STUDY . . . . • 180

H PERCENT DISTRIBUTION OF STUDY POPUIATION BY GRADE LEVELS . . . . . . . . . . . . . 182

I DISTRIBUTION OF STUDENTS BY THEIR LEVEL OF ENGLISH PROFICIENCY . . . . . . . . . . . 184

J NUMBER OF YEARS STUDENTS HAVE BEEN IN PORTLAND PUBLIC SCHOOL SYSTEM . . . . . . . . . 186

K SUPPLEMENTARY REGRESSION RESULTS FOR READING ACHIEVEMENT WITH DIFFERENT SUBSETS OF VARIABLES . . . . . . . . . . . 188

L SUPPLEMENTARY REGRESSION RESULTS FOR MATHEMATICS ACHIEVEMENT USING DIFFERENT SUBSETS OF VARIABLES . • . . 191

M SUPPLEMENTARY REGRESSION RESULTS FOR LANGUAGE ACHIEVEMENT USING DIFFERENT SUBSETS OF VARIABLES . . . . . . . . . . . . 194 


\section{LIST OF TABLES}

TABLE

PAGE

I Ethnic Composition of ESL/bilingual Students 1982-83 • • 26

II Reported LEP Students' Enrollment by State and

by Year, 1986-1990 • • • • • • • • • •

III Mean of Initial LEP Students' Achievement Broken

Down by Subpopulation Groups . . • • . • • •

IV Means of Achievements in Reading, Mathematics, and

Language Usage Broken Down by Subpopulation

Groups and by Year . . . . . . . . . . .

V Means and Standard Deviations of 1983 Achievement

for Reading by Subpopulation Groups . . . . . . .

VI Means and Standard Deviations of Achievement Gains

for Mathematics by Subpopulation Groups . . . . .

VII Means and Standard Deviations of Achievement Gains

for Language Usage by Subpopulation Groups • • 97

VIII Regression Results for Reading Achievement Gains . . . . 98

IX Regression Results for Mathematics Achievement Gains . • 99

X Regression Results for Language Usage Achievement

Gains . . . . . . . . . . . . . . . 
XI Percent Distribution of Students into Their Language Groups . . . . . . . . . . . 114

XII Average Weekly ESL and Bilingual Hours Received by Each Student . . . . . . . . . . 115

XIII Means and Standard Deviations of the Variables in the Regression Equation ........... 120

XIV Comparison of the Regression and the Predicted Signs of the Variables in the Regression Equation . . . 121

XV Regression Results to Obtain Estimated Values of ESL Hours . . . . . . . . . . . . 123

XVI Regression Results to Obtain Estimated

Values of Bilingual Hours . . . . . . . . . 123

XVII Regression Results for Percent Reading Gains

with All Variables in the Equation . . . . . . 125

XVIII Regression Results for Percent Reading Gains with

Variables for Personal, School, Neighborhood, and Program Characteristics . . . . . . . 126

XIX Regression Results for Percent Mathematics Gains with All Variables . . . . . . . . . . 128

XX Regression Results for Percent Mathematics Gains with Different Sets of Variables . . . . . .

XXI Regression Results for percent mathematics Achievement with Variables for Personal, School, Neighborhood, and Program Characteristics . . . . . . . 130 XXII Regression Results with All Variables for Percent Language Usage Gains . . . . . . . 
XXIII Regression Results for Percent Language Achievement with Different Sets of Characteristics . . . . 133

XXIV Regression Results for Percent Language Achievement Using Selected Personal, School, Neighborhood, and Program Characteristics . . . . . . . . 


\section{LIST OF FIGURES}

\section{FIGURE}

PAGE

1. LEP Students' ESL/bilingual Education Total Enrollment

$$
\text { 1986-1992 ................. . . }
$$

2. LEP Students' Major Language Groups Enrollment

Report 1986-1992 ...............

3. LEP Students' ESL/bilingual Enrollment Trend

$$
1976-1992 \text {. . . . . . . . . . . } 13
$$

4. Causal Model .................. 109 
CHAPTER I

INTRODUCTION

BACKGROUND

Providing equal educational opportunity for students who speak a language other than English has been a policy problem in the United States for some time now. Educators, researchers, politicians and other policy makers continue to grapple with the issue of educating language minority children. Millions of students attending the public school systems in the United States speak little or no English, making it difficult for them to perform academically at their grade level (Chamot, 1988; Cumins, 1986; Gersten \& Woodward, 1985; McKay \& Freed$\operatorname{man}, 1990)$.

As a result of federal and state legislation, court orders, or school district policy, many educational programs have been designed to help limited English proficient (LEP) students succeed in school. An example of a program which was designed to help LEP students improve their academic achievement is the Portland Public School district's English-as-a-Second-Language (ESL)/bilingual education program.

One of the major goals of the present study was to assess the impact of the Portland Public School (PPS) district's ESL/bilingual education program. The present study sought to evaluate the ESL/bilingual education, assessing its impact on reading, mathematics, and 
English language achievement of LEP students. The other major issue is an attempt to correct a statistical bias which may cause underestimation of the effectiveness of the ESL/bilingual program. Other issues to be discussed which have generated considerable interest among educators and politicians concerning educating minority students include: (a) the use of the student's first language as a foundation for learning English and other academic skills (Cummins, 1986; Cummins \& Skutnabb-Kangas, 1988; Gonzales, 1990), and (b) the notion that all citizens of the United States should speak English (Harlan, 1991; Madrid, 1990).

Aspects of bilingualism and bilingual education have consistently been part of the American experience. This unique experience has resulted in an ongoing language controversy since large numbers of German, Irish, Polish, and other European immigrants settled in this country during the late 1800s and early 1900s (Harlan, 1991; Molesky, 1988; Roman, 1986/1987).

In recent years a large number of children whose first language is not English have entered and settled in the U.S. This influx of students under 20 years of age has caused great concern for teachers and anxiety for the students, who face totally new schools and new lifestyles (Chung, 1988; Kleimann, 1982). According to Vomin (1981, pp. 1-5) some students and their parents have little or no previous education or work experience relevant to an industrialized economy, or have little or no exposure to urban life or Western technology and values. Most settle in cities where they can get support from their earlier immigrant relatives. In addition to the enormous economic and 
cultural adjustments facing immigrants with such a background, special problems in learning English seem to arise for these people and their school-aged children.

Many LEP students encounter language problems which may cause them to have low academic achievement and, possibly, drop out of school. When LEP students speak English in class, their classmates and peers tend to make fun of them because of their heavy accents. For example, the LEP students may be told that they talk "funny" and cannot be understood. This is difficult for students who are just beginning to adjust to the "new language." It makes it even more difficult for the students to have academic success if the ESL/bilingual education teacher does not show any sensitivity to this situation (Kleven, 1988).

LEP students may also have some social adjustment difficulties which hinder academic progress or competence in an employment interview. For instance, some LEP students may be portrayed as not being assertive enough when talking to a teacher or during an interview with a possible employer because they have been taught at home to look down or look away when talking to elderly people or anyone of higher social economic status. To them, it is disrespectful not to do so. Vamin (1981) further explains that

a child who has been taught since childhood to respect and obey elders and persons in authority is often confused and bewildered by the direct and spontaneous behaviors of his American peers toward adults. (p. 2)

These behaviors may seem odd to the LEP student's American peers, who might think these actions are overly polite and formal. And if these behaviors are misinterpreted by the teacher, the LEP student may 
be placed in a situation that could affect the student's academic progress.

Many urban school districts across the country have experienced large increases in the number of language minority students. Thus it has become necessary for school districts to provide language assistance programs for their LEP students (Hakuta, 1986; Harlan, 1991; McKay \& Freedman, 1990; Ruiz, 1988). These programs have been established as intervention strategies to give equal access to educational opportunity and to improve the educational achievement and economic position of LEP children. According to McKay (1988) and Teitelbaum and Hiller (1977) the programs are the result of several federal actions, Supreme Court decisions, and the efforts of the office of Civil Rights $(O C R)$.

The problem of educating LEP students has intensified in the last decade in many school districts. The number of eligible students and LEP enrol lments have increased while the financial resources for alleviating the problem have become increasingly scarce.

The ensuing section of this chapter outlines the statement of the problem of this dissertation. It is followed by a discussion of the objectives and the importance of the study. Next, the definitions of relevant terms and some goals of ESL/bilingual education are discussed. Other topics discussed include funding and federal support, population characteristics, data sources and the limitations of the study. The final part of this chapter describes the organization of the remaining chapters. 
STATEMENT OF THE PROBLEM

For decades researchers, educators and politicians have been trying to find the best method to educate immigrant students whose native language is not English. The major question is whether or not bilingual education and its many alternative approaches are effective in teaching English and other academic skills to LEP students (Baker \& de Kanter, 1981; Curmins, 1986; Cummins \& Skutnabb-Kangas, 1988; Gersten \& Woodward, 1985; Gonzales, 1990; Harlan, 1991; Long, 1983; Ruiz, 1988; Willig, 1985, 1987).

Presently many states have mandates to provide bilingual education to LEP students, while other states have employed ESL or other alternative approaches placing the LEP students in the all-English instructed curriculum (Bennett, 1986a). There have been continued efforts by many researchers to evaluate the effectiveness of different approaches.

Specifically, this dissertation attempts to answer these and other related questions:

1. Is the Portland (Oregon) Public School district's ESL/bilingual approach an effective method for teaching the English language and other academic subjects to LEP students?

2. Does the amount of ESL/bilingual instruction influence LEP students' performance in English, mathematics, and reading?

3. Do the personal characteristics of LEP students (age, gender, home language, and race) influence their academic performance in English, mathematics, and reading?

4. Do neighborhood factors affect LEP students' gains in English, mathematics, and reading performance? 
Most previous studies have not addressed these issues appropriately and as a result have come up with contradictory reports and inconclusive findings.

Many studies and evaluations have reported for and against bilingual education and/or ESL instruction (Willig, 1985). For example, Baker and de Kanter (1981) examined the results of 28 studies on the effectiveness of bilingual education and concluded that the case for bilingual education was very weak. Baker (1987), in commenting on Willig's (1985) earlier research, stated that existing research failed to provide significant support for mandating bilingual education. He felt a bilingual education approach had no academic effect or "had a negative effect" (p. 356). Ravitch (1986) observed that the research available is too weak, too inconclusive and too politicized to serve as a basis for national policy. Other research efforts on the effectiveness of bilingual education have been favorable (Burnham \& Pena, 1986; Crawford, 1987; Cummins, 1986; Hakuta, 1986; Krashen \& Biber, 1988; Long, 1983; Willig, 1985, 1987). These studies have demonstrated that bilingual education seems to be effective in increasing gains in English language and other academic subjects.

But there continue to be discussions about the effectiveness or lack of effectiveness of ESL/bilingual education. According to Hakuta (1986) and Willig (1985, 1987) the majority of studies on bilingual education effectiveness have serious methodological shortcomings. In another statement on the quality of bilingual education research Rossell (1988) states that the quality is deplorable and consists of local evaluations with inadequate research designs and analyses. 
Some of the major methodological weaknesses of bilingual education research and evaluation have been discussed by many researchers (Chamot, 1988, p. 24; McLaughlin, 1985, p. 233; Rossell, 1988, p. 26; Willig, 1985, p. 270). Most of the criticisms can be summarized in the following way:

1. Most studies lack a control or comparison group similar to the treatment groups.

2. Most studies lack random assignment of subjects to treatment and control groups.

3. Most studies lack a statistical control for differences that existed prior to the time one group received ESL/bilingual education, i.e., social economic status and other variables.

4. Most studies lack a definition and description of bilingual education.

Willig's (1985) meta-analysis of Baker and de Kanter (1981) attempted to correct most of these flaws. Other recent studies have also had better methodological designs and descriptions of ESL/bilingual education and somewhat better control groups (Gonzales, 1990; Karm, 1987/1988; Krashen \& Biber, 1988).

The efforts of these researchers and others have not solved the major research problem, the "selection bias" of students to programs. This problem must be corrected statistically. Willig (1985) alludes to this problem when she states:

Groups slated to participate in bilingual programs in the United States usually are from a population whose distribution of language scores falls at the lower end of a scale (at least in English). On the other hand, the comparison groups, who for some reason have not been provided with a bilingual 
program, usually represent a population whose distribution of scores would fall in a higher range than the population of the experimental group. (p. 300)

Willig $(1985,1987)$ therefore calls for improved statistical techniques to deal with this problem in order to truly determine the effectiveness of ESL/bilingual education.

\section{OBJECTIVES OF THE STUDY}

The first objective of this dissertation was to assess the impact of an ESL/bilingual education program. The program aspects under scrutiny involve LEP students who receive an ESL/bilingual treatment and those who receive no treatment. The Portland Public School program is basically an ESL program with a bilingual education support.

The program is used in teaching English and other subjects to LEP students in Portland's public schools. What needs to be determined is whether or not the students who were exposed to the ESL/bilingual program had differential academic achievement results from other students with similar backgrounds who had less or no exposure to the ESL program. Same earlier researchers concluded that programs such as ESL/bilingual do not help and have little effect on certain aspects of language learning (Dulay \& Burt, 1973; Fathman, 1975). Others found the ESL instruction to be beneficial, especially during the first 2 or 3 years (Chamot, 1988; Kanm, 1987/1988; Long, 1983, p. 359).

The second objective of this research was to determine the extent to which selected personal characteristics of LEP students relate to their gains in English language and other subjects. The limited English speaking students in the PPS system are a diverse group. They 
come from divergent cultural and geographic backgrounds. Differences exist in the language spoken at hame and length of time in the school district. It is assumed that these differences have differential impacts on their gains in English language and other subjects.

Finally, the last objective of this study was to determine whether or not neighborhood characteristics--e.g., percent of students with little or no English, percent high school graduates, etc.--relate to gains in English and other academic subjects. These and other neighborhood factors are said to be considerably more important in determining children's language achievement than is the particular instructional approach used (Molesky, 1988; C. B. Paulston, 1978). The present study attempts to adequately deal with the issue of the effectiveness of the ESL/bilingual program using a more refined and more sophisticated statistical method than previous studies.

To summarize the foregoing statement of the problem and the objectives in somewhat different words, there were three purposes for this research. The first was to provide information that could be useful in the evaluation and planning of language minority students' education by the program administrators. The information contained in this study was also intended to be beneficial to the officials of the PPS district in its district-wide planning for LEP students' education. The second purpose was to increase understanding of some empirical phenomena, such as effect of ESL hours and environmental factors on English language acquisition. The final purpose was to supply public policy suggestions based on the empirical results as well as provide suggestions for further research. 
THE IMPORTANCE OF THE STUDY

Presently ESL/bilingual education practitioners are questioning the effectiveness of various approaches to second language learning. The conclusions of many studies in the field both support and refute the effectiveness of bilingual education and ESL instruction. Orfield suggests that the continuing criticism of bilingual education programs is due to the lack of consistent and significant outcomes of many research efforts (Orfield, 1986). Applying a more refined and improved quality of research as suggested by Willig (1985, 1987), Medrano (1988) and others, the analysis of the PPS district's ESL/bilingual program and the conclusions to be drawn from this investigation should help the policy makers and the practitioners make important decisions about educating LEP students.

Detemining the effectiveness of the PPS district's ESL/bilingual program is necessary for program administrators and classroam teachers who need to plan and implement programs for the academic success of LEP students. The knowledge gained from the impact of the ESL/bilingual program is essential for future planning, especially, as the population of school-aged LEP students continues to grow. For various reasons (e.g., legal immigration, refugee settlement, and undocumented workers) the number of LEP students in the PPS district has increased dramatically since 1987. From 1987 to 1992 the total LEP enrollment has grown by more than $43 \%$ (see Figure 1).

The enrollment growth is not consistent among language groups, as Figure 2 indicates. While the number of students in some language groups has grown substantially (e.g., Romanian, Spanish, and Russian), 
others have decreased. The Russian language group, with only one LEP student between 1986 and 1988, has become the second largest group, with an enrollment of 699 students. The Vietnamese group has always been the largest group of LEP students in the PPS district. Campared to the previous data, the 1992 ESL/bilingual education enrollment is at an all-time high (see Figure 3 ).

The present study is both important and timely because of the current budgetary constraints. The PPS district and others involved in making policy need all the relevant information they can get to make sound, pedagogical decisions for future refinement of the district's

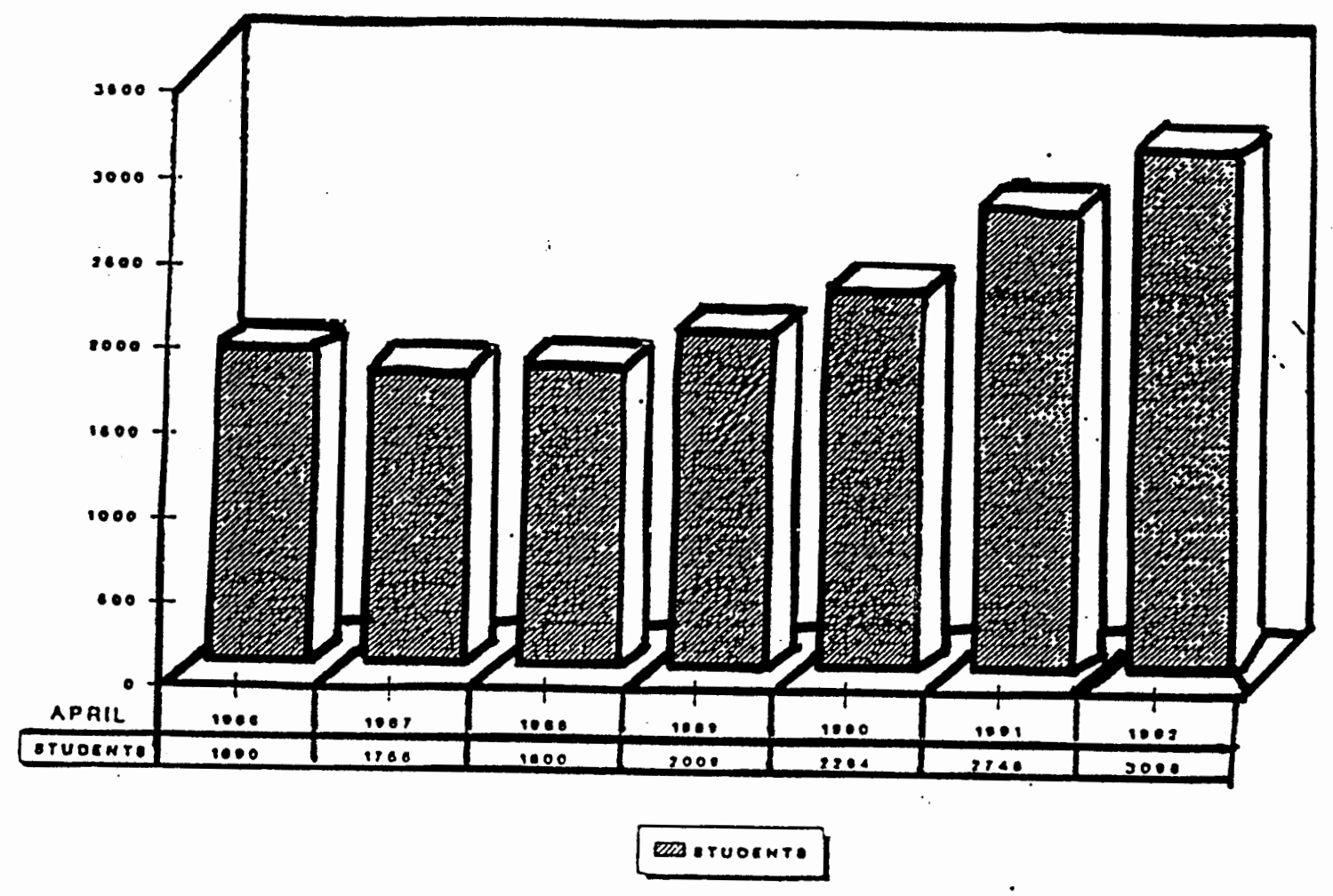

Figure 1. LEP students' ESL/bilingual education total enrollment 1986-1992. 


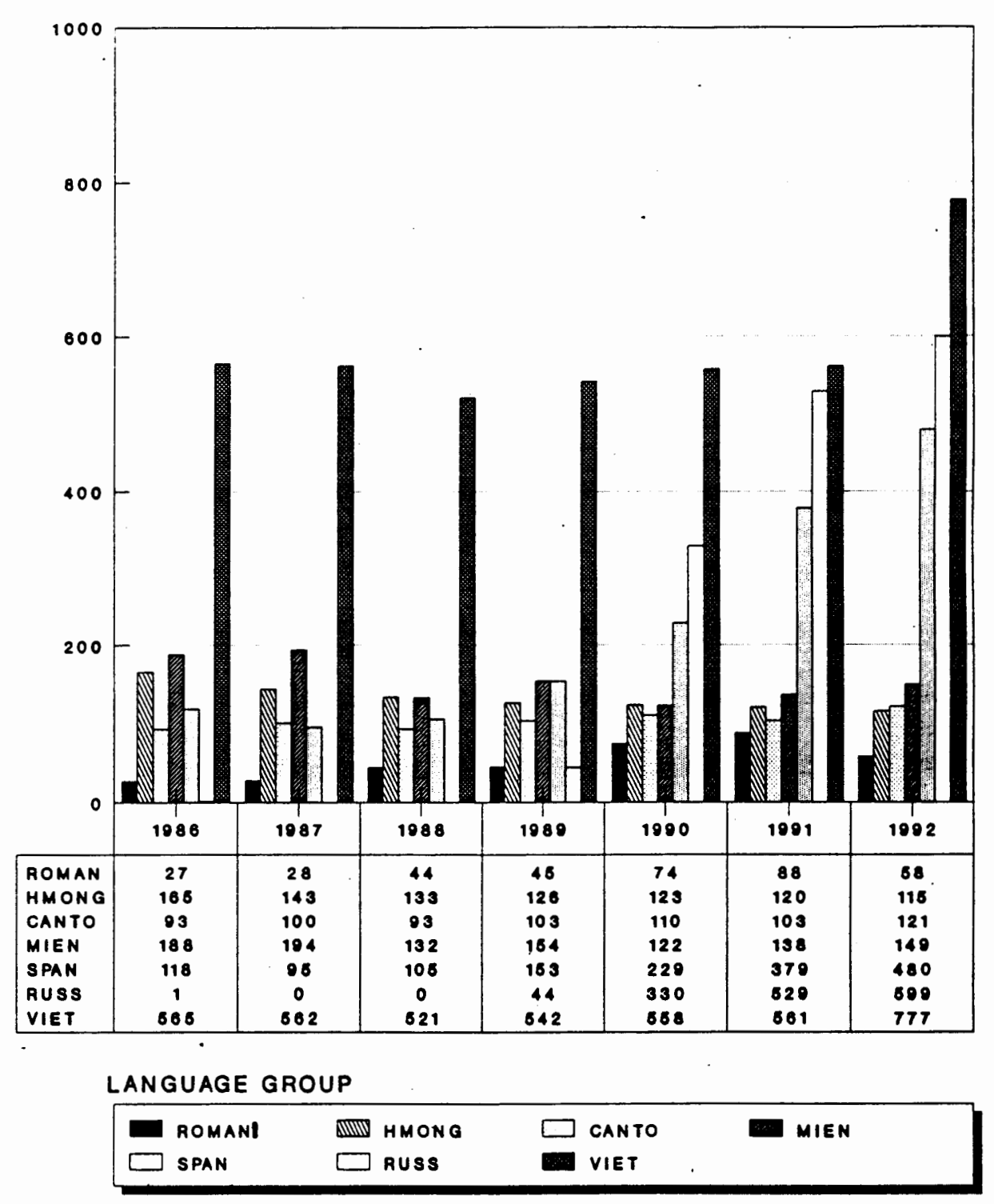

FIGURE 2

Figure 2. LEP students' major language groups enrollment report 1986-1992. 


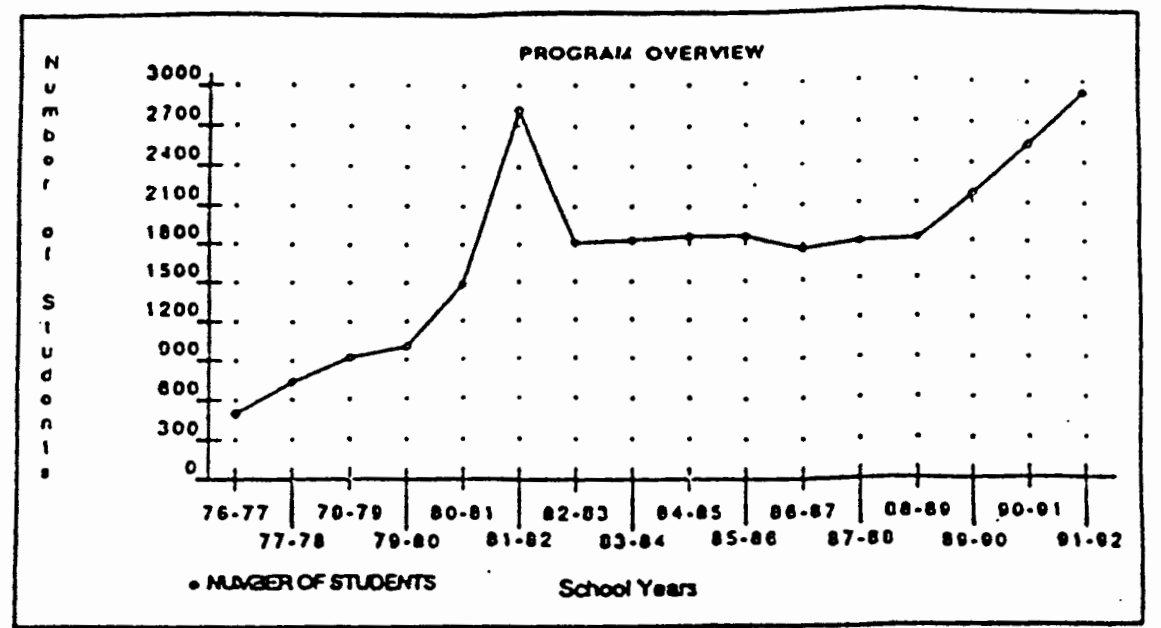

Figure 3. LEP students' ESL/bilingual enrollment trend 1976-1992. From ESL/bilingual enrol lment report, ESL/bilingual Education Department, 1992, Portland Public Schools, Portland, OR, p. 1 .

ESL/bilingual programs. The district is currently "down-sizing" or eliminating programs because of the impact of the passage of the recent Ballot Measure $5^{l}$ that altered the way school districts are financed.

Overall, the determination of the effectiveness of ESL/bilingual education programs is important at this time. It is important to know whether ESL/bilingual hours had any impact in increasing the academic

${ }^{1}$ Ballot Measure 5 is an initiative passed by Oregon voters in November 1990. It amends the Oregon Constitution by setting a limit on property tax rates for schools and other local government operations. over a 5-year period, the measure phases in property tax rate limits to a maximum of $\$ 15$ per $\$ 1,000$ real market value. The limit is $\$ 10$ in Fiscal Year 1991-92 for non-school local government operations and phased-in reduction for schools to $\$ 5$ in Fiscal Year 1995-96 (Multnomah County Auditor, 1991, p. 2). 
gains of LEP students in English and other subjects. It is also important to know whether environmental or personal factors contribute to LEP students' academic gains.

It is hoped that the results of this dissertation will contribute to the field of educating LEP students and increase program administrators and policy makers' understanding of ESL/bilingual education programs.

\section{BRIEF DEFINITIONS AND DISCUSSION}

OF REIEVANT TERMS

Some definition of terms and concepts will be helpful at this point. These definitions are based on federal guidelines (U.S. General Accounting Office [GAO], 1987) and will be referred to throughout this study.

\section{Limited English Proficiency}

LEP describes students whose native language is a language other than English or who come from environments where a language other than English is dominant. LEP students matching this description have difficulty speaking, reading, writing, or understanding the English language sufficient to be denied the opportunity to succeed academically.

Home Language or First

Language (L1)

This is any language other than English that is frequently used and spoken in the home environment. The home language is also known as 
the native language or the primary language. The LEP students' target or second language (L2) is the language which is being acquired. In the United States this would mean English.

\section{Bilingual Education}

Bilingual education is a general approach used by a variety of instructional programs in schools in which students are taught in two languages, English and the native language of the LEP students. English is taught as a second language.

\section{Transitional Bilingual Education}

Transitional Bilingual Education (TBE) emphasizes the development of English-language skills in order to enable LEP students to shift to an all-English program of instruction. Some programs include English as an L2.

\section{Bilingualism}

Bilingualism is the ability to use two languages for communication. A balanced bilingual person can use both languages equally well but usually prefers one language or the other.

\section{Additive Bilingualism}

This refers to a situation in which instruction in the second language is given in addition to the LEP students' first language. Additive bilingualism encourages LEP students to maintain their first language in addition to learning the second language. 
Subtractive Bilingualism

In subtractive bilingualism the focus is on replacing or eliminating the effect of the students' Ll and culture during the process of assimilating them into the dominant language and culture.

Elementary and secondary Education

Act Title VII

Title $\mathrm{VII}^{2}$ is the Bilingual Education Act, which is part of the Elementary and Secondary Education Act (ESEA) of 1968. The Act passed in 1968 and was reauthorized in 1974, 1978, 1984, and 1988. The law mandates the provision of bilingual education to LEP students when there are enough students of the same language group attending the same school.

\section{Iau Category}

$\mathrm{Lau}^{3}$ categories were established to designate a student's degree of bilingualism in English and a native language.

2 The Title VII legislation, or the Bilingual Education Act, was first enacted by Congress in 1968. It was one of several major pieces of educational legislation passed by Congress during the 1960s designed to serve students with special educational needs--students who are lowachieving, have physical or mental handicaps, come from low-income families, or have limited English proficiency.

${ }^{3}$ Iau v. Nichols is a class action suit. It was brought by nonEnglish speaking Chinese students against officials of the San Francisco Unified School District. This school system failed to provide adequate language assistance to 1,800 students of Chinese ancestry who do not speak English. The Supreme Court ruled that languageminority children receive some type of special assistance to enable them to participate in the regular school program (for details, see Lau v. Nichols, 414 U.S. 563, 1974). 


\section{English-as-a-Second-Language}

ESL is English taught in an English-speaking country to nonEnglish speakers who need to study or work in English. The instruction is based on a special curriculum that typically involves little or no use of the student's native language. The instruction takes place only during a specific school period.

\section{Pull-out ESL Approach}

In a pull-out method LEP students attend separate classes in English language development part of the day. The students leave (are pulled out of) their class daily for a specific school period. They attend regular English-only classes for the remainder of the school day. The time that LEP students spend per week in pull-out ESL class may vary greatly.

\section{Immersion Programs}

Immersion refers to the teaching approaches for language minority students not involving children's native language. Two specific types of immersion are structured immersion and submersion.

Structured Immersion. In structured immersion, instruction is in English. The teacher usually understands the students' native language, and students may speak it to the teacher, although the teacher generally answers only in English. Students' knowledge of English is not assumed; therefore, the curriculum is simplified so that the content will be understood.

Submersion ("Sink or Swim"). In submersion programs LEP students are placed in ordinary classrooms in which English is the language of 
instruction. The students receive no special program to help them overcome their language problems, and their native language is not used in the classroom. Submersion was found unconstitutional in the Supreme Court decision, Lau V. Nichols (1974) (Ruiz, 1988; Wong, 1988).

THE GOALS OF ESL/BILINGUAL EDUCATION

One of the goals of ESL/bilingual education and other alternative programs is to teach LEP students to read, write, and speak English. Another important goal is to give students full access to the educational programs of the schools (Vargas, 1986).

According to Ruiz (1988) most U.S. bilingual education programs are of the transitional type. The goal is to keep the students in the ESL/bilingual program only as long as it takes to learn English well enough so that they may then be enrolled in the regular Englishspeaking classroom.

Arriving at a consensus on specific goals and policies conceming the education of LEP students is difficult. Educators, politicians, and researchers all have different opinions on this issue. 'Arguments surrounding this issue often end up in ideological and political controversy (Cummins, 1987; Harlan, 1991; Judd, 1987; Lanmouth, 1987; Marshall, 1986; Skutnabb-Kangas, 1988; Stalker, 1988).

The viewpoints of two distinct groups seem to shape the discussions in the literature on this issue. These are the proponents and the opponents of bilingual education. The proponents argue that the goal of bilingual education should include (a) helping LEP students learn English, (b) improving self-estem and self-concept of LEP 
students through the use of the students' native languages, and (c) raising the academic achievement level of LEP students, thus (d) creating a more productive citizenry and (e) pramoting languages other than English as a national resourœe (Vargas, 1986).

The opponents argue that bilingual education and pull-out ESL will (a) decelerate the entrance of non-English speakers into the American mainstream, (b) segregate LEP students from their regular class, (c) slow down the rate of English acquisition for LEP students, and (d) cause political and social conflict and national disunity (Gonzalez, Schott, \& Vasquez, 1988).

Same opponents of bilingual education sought to amend the U.S. Constitution to make English the "official" language of the United States. The opponents have not succeeded in making any constitutional changes at the federal level. However, as Harlan (1991) points out, the Official English advocates have won several victories in the U.S. political arena in the 1980s, convincing voters and legislators to pass English-language laws and constitutional amendments at the state level. (p. 59)

Gonzalez et al. (1988) examine the ideas of U.S. English, an organization that these researchers believe represents the English Language Amendment movement. These investigators disagree with three of the organization's primary contentions, terming them "myths." They argue that: (a) it is a myth that "linguistic diversity inevitably causes political conflict"; (b) it is a myth that "an official language is the primary determinant of national unity"; and (c) it is a myth that "bilingual education decelerates the entrance of non-English speakers into the American mainstream" (Gonzalez et al., 1988, pp. 24-29). 
Roman (1986/1987) asserts that many politicians and some educators in the 1980s continue to regard bilingual education as a threat to American unity. She explains that the perceived threat is due to the rapid growth of the minority population in the United States and the extent to which it is holding on to the minority language and culture through the bilingual education programs.

An example of the perceived threat of the goal of bilingual education programs is expressed by Westell (1981). Westell argues that

the romantic view of the United States has always been that it is a gigantic melting pot in which immigrants from all over the world rapidly learn English, acquire American values, and become proud Yankees. But instead the immigrants are transforming the United States urban landscape into something that it has not been for decades: a mosaic of exotic languages, faces, costumes, customs, restaurants, and religions. And in the alarmed view of same Americans, the trend is likely to accelerate because instead of being forced into the melting pot, newcomers are holding onto language and culture, becoming "hyphenated Americans" rather than fully committed Americans. (p. 54)

Similar views were expressed earlier by Glazer (1974). He

believes that

immigrants who came to this country willingly to work and to become citizens of the new land were not deprived when they gave up an old language for English, old culture for a new emerging cuiture, old al legiance for new allegiance. (p. 59)

The notion that the English language is the social glue that holds this multi-cultural country together and makes all of us, regardless of national origin, Americans is well disputed by Harlan (1991). According to Harlan the bilingual supporters agree that English is important in order to function well in this society and that it is part of the American culture. However, they argue that the English language is not 
the best nor the only social glue that Americans have. For example, bilingual supporters assert that

more important than language in uniting Americans is the American sense of shared destiny. The freedoms and opportunities that attract people from all over the world to the United States unite us all. (p. 54)

Continuing with the same line of thought, Harlan explains that "Americans are more than just a group of people who live near each other and speak the same language" (p. 54). She argues that the adopted culture for many immigrants is an elastic culture that allows for much individual expression. According to her, the best social glue in the United States is shared opportunities.

The discussions in this section have focused on some goals of ESL/bilingual education programs. There was also a discussion of how a specific goal and policy of including the students' native language in classroam instruction may end up in ideological and political controversies. The remaining part of this section looks at the summary of other goals of ESL/bilingual education.

Bilingual education means many things to a lot of people. Its goals and purposes are many (C. B. Paulston, 1980). Paulston 1ists 10 major goals:

1. To assimilate individuals or groups into the mainstream of society.

2. To unify a multilingual community.

3. To enable people to communicate with the outside world.

4. To gain an economic advantage for individuals or groups.

5. To preserve ethnic or religious ties. 
6. To reconcile different political or socially separate cammunities. Understanding each other's languages can enhance relations.

7. To spread and maintain the use of a colonial language. This goal is to socialize an entire population to a colonial language.

8. To strengthen the education of elites.

9. To give equal status to languages of unequal prominence in the society.

10. To deepen understanding of language and culture. For detailed explanations of these goals, the reader is referred to Paulston (1980, pp. 1-2). A comparison of the goals of bilingualism and the degree of success in educating LEP students in different countries is given by Skutnabb-Kangas (1988, pp. 22-27).

\section{FUNDING AND FEDERAL SUPPORT}

Issues surrounding ESL/bilingual education are many but politics and finance are among the top of the Iist. As Harlan (1991) has observed, politicians, not educators, control the government's budget. To some extent they also control what kinds of programs schools will offer to children with limited English skills, and they control the financing of these programs.

The United States Congress passed the Elementary and Secondary Education Act in 1965 (P.L. 89-10). The amendment of this Act in 1968 added Title VII, which is known as the Bilingual Education Act. Funds 
were appropriated at this time to support a few programs designed to serve the needs of children of limited English-speaking ability. Al though Title VII did not specifically require local school districts to establish bilingual programs, it did encourage their development. This amendment provided federal appropriations in the form of discretionary grants to school districts interested in planning and developing programs to meet the special educational needs of LEP students. The federal funds explicitly identified for support of bilingual programs are provided under Title VII, Title 1--Migrant, Title VIII-C (Indochinese) and Emergency School Aid Act (ESAA) (Rotberg, 1982).

From 1969 through 1973 most of the funds appropriated under Title VII went for the support of bilingual programs in the elementary schools. Federal financial support continued under the 1974 Bilingual Education Act through the end of 1978. The level of federal financial support increased progressively beginning with the Johnson presidency and on through the Nixon, Ford, and Carter administrations. The financial support grew over the years from $\$ 7.5 \mathrm{million}$ in fiscal year (FY) 1969 to about $\$ 160$ million in FY 1981 (Huffman, 1980, p. 30; Rotberg, 1982, p. 154). These funds provide support for additional teachers, para-professionals, staff development activities, development and purchase of materials, parental involvement, administration, evaluation and other support functions (Huffman \& Samulon, 1981, p. 33 ).

This level of federal financial support diminished considerably after President Reagan took office. For example, the level of support in 1981 was $\$ 161$ million; in 1982 it diminished to $\$ 138$ million and 
remained the same in 1983. In 1985 and 1986 the level of support was \$145 million.

Spending for Bilingual Education Act (BEA) programs was cut during the 8 years of the Reagan presidency. Additionally, his administration focused its energies on trying to get rid of one of the BEA's requirements that stipulates that programs must use students' native languages in the teaching process (Harlan, 1991, p. 103). As Harlan reports, the Reagan administration wanted Congress to remove the $4 \%$ limit of funding for English-Only programs. Finally, in 1988 Congress passed an amendment to the BEA. Instead of lifting the $4 \%$ limit, Congress changed it to $25 \%$. Thus bilingual education programs that use students' native languages would continue to get at least $75 \%$ of the BEA budget, and English-Only programs would get up to 25\% (Harlan, 1991, p. 105).

It is important to state here that federal funding for the ESL/bilingual education program is a small fraction of the program. For example, the federal contribution to ESL/bilingual education for LEP students is less than $10 \%$ in the PPS district, and across the nation most school districts provide most of their support to LEP students through their district's general fund. 4 According to Durgan (1991) the PPS's ESL program budget has increased from \$3.7 million in FY 1987-88 to $\$ 5.6$ million in FY 1990-91.

Although federal financial support for the PPS district's ESL/bilingual program is insignificant, there are many reasons for investigating the program's effectiveness. First, there is a pragmatic

${ }^{4}$ A camment made by Darlene Durgan, Director ESL/bilingual Program, Portland Public Schools, October 6, 1991. 
interest in evaluating the effectiveness of an educational service program since educational phenomena have implications for the social, political, economic and cultural growth of the target group. Second, there is a theoretical interest in identifying possible major factors influencing academic gains in English, mathematics, and reading for IEP students. Finally, education is one of the largest items of public expenditure and among the most important ways in which cities can influence their economic future.

\section{POPUIATION CHARACTERISTICS}

AND DATA SOURCES

\section{Population Characteristics}

Federal and state legislation includes non-English speaking students in the target population for bilingual education programs. There is no uniformity in the criteria for admitting students into programs. For example, the process for inclusion of students who speak some English has ranged from selecting those who are culturally different to selecting only those who perform below a certain percentile on a standardized English language test. The Portland public schools have many ethnic group students who have difficulty speaking, reading, and writing English. In the 1982-83 school year most students in the ESI/bilingual program came from Southeast Asian countries, as shown in Table I. Five major language groups constituted most of the students in the program: Vietnamese, Hmong, Laos, Cantonese, and Khmer. In recent years there has been a dramatic increase in the number of 
TABLE I

ETHNIC COMPOSITION OF ESI/BIIINGUAL STUDENTS 1982-83

\begin{tabular}{lrc}
\hline \multicolumn{1}{c}{ Ethnic Group } & $\underline{\mathrm{n}}$ & Percent \\
\hline American Indian & 2 & 0.2 \\
Black & 80 & 6.5 \\
White & 25 & 2.0 \\
Southeast Asian & 1,031 & 84.3 \\
Hispanic & 81 & 6.6 \\
Other & 4 & .03 \\
\hline
\end{tabular}

students from Eastern Europe in the Portland public schools due to the political conditions in that part of the world (see Figure 2).

At the inception of the ESL/bilingual program there were 983 Himong-speaking students and 1,148 Vietnamese-speaking students in the Portland public schools. These students represent over 50\% of the major ethnic groups from Southeast Asia in the school district who were in the program. There is also a host of other nationalities (see Appendix A and Appendix B). All but five ethnic groups (Bengali, Burmese, Slovak, Slovian, and Yiddish) listed in the 1982-83 school year are also listed in the 1990-91 school year.

The subjects for this study were LEP students across several schools who met the criteria for inclusion. The criteria were that the student: 
(a) attended Portland public schools between fall 1982 and spring 1983;

(b) had test scores on Portland Achievement Level Test in reading, language and mathematics for fall and spring;

(c) had complete personal background records on file; and

(d) had a rating of $\mathrm{A}, \mathrm{B}$, or $\mathrm{C}$ in the English language screening proficiency test given by the student's parents and the ESL/bilingual program staff. A student with a rating of "A" spoke no English, "B" spoke the native language more than English, and " $\mathrm{C}$ " spoke English as well as the native language.

A total of 1,223 students were identified as meeting the criteria for inclusion in the study population for the 1982-83 school year. This number was later reduced by 87 cases. There were 72 students who changed schools during the year; 12 had test scores for fall and not spring, or vice versa; and there were three incidents of duplicate cases.

\section{Data Sources}

The principal sources of data for this study were the student's master files, the testing data base, and the census data records. From these sources personal, school, and neighborhood characteristics were extracted. The student's master file was kept for all LEP students in the special ESL/bilingual program. Information was available on all the pertinent variables for every student who had participated in the Portland public schools' Achievement Level Test. The master file contained the student's identification number, his or her ethnicity, 
age, gender, language spoken at home, and the number of years since the student had been enrolled in the PPS system. Other variables extracted from the master file included the weekly hours of ESL instruction, schools attended, and current grade level. The proportion of Southeast Asian LEP students per school was calculated from the 1983 Enrollment Report by PPS Management Information Services (see Appendix C).

Every fall and spring the Portland public school district's Evaluation Department administers the Achievement Level test to all students fram Grades 3 to 11. All LEP students participate in this testing program. From the testing data base, performance records on reading, math, and language usage were obtained for fall term 1982 and spring tem 1983. Only those students who had records for the two periods were included. Information obtained here enabled the calculation of the percentage gains. The 1982 data provide an observation point which can reveal the effectiveness of the ESL/bilingual program. Prior to 1982 only scattered and often non-comparable data were available for the ESL/bilingual programs in the PPS system. The data on the general neighborhood characteristics of the population where a particular student lives were taken from the 1980 census tract records. From this source the percentage of the population in the neighborhood who speak little or no English, percent high school graduates, and percent below poverty level were extracted. Finally, average family size of the neighborhood population was obtained. These variables were included for two main reasons. The first reason was to determine which neighborhood variables, if any, contribute to English language gains of LFP students. Second, it has been shown that several important 
societal factors, such as the language of the surrounding community, impacts the language performance of LEP students (Rotberg, 1984).

ORGANIZATION OF THE STUDY

The next chapter presents a review of the literature pertinent to the educational opportunities of LEP students. It discusses some relevant theories and socio-political issues as they pertain to education of IEP students. Other topics reviewed include: historical perspectives of EST/bilingual education, legislative and judicial influence, enrollment and number problem, and current research on the effectiveness of ESL/bilingual education.

The methodology used in the analysis of the data is described in Chapter III. Chapter IV presents the empirical results. In the final chapter a summary and statement of conclusions are given. The findings are compared to those of other studies and some implications for policy and future research are offered. 
REVIEW OF THE LITERATURE

To have a broader view and better understanding of ESL/bilingual education programs and their effect on academic achievement, several theories and issues pertinent to education of language minority students need to be addressed. This chapter reviews the Iiterature on aspects of ESL/bilingual education and its effectiveness. It provides further insight and information on the underlying theoretical perspectives and assumptions of ESL/bilingual education.

The major topics included in the literature review are: theories and issues relevant to ESL/bilingual education, a brief historical perspective on ESL/bilingual education, the impact of legislative and judicial actions on ESL/bilingual education, an estimate of the number of LEP school-aged children, underlying assumptions of ESL/bilingual education, and relevant research on effectiveness of ESL/bilingual education.

THEORIES AND ISSUES REUEVANT TO ESL/BILINGUAL EDUCATION

The Equilibrium Paradigm

As stated earlier in Chapter I, there is considerable controversy and no consensus when discussing IEP students' school performance, 
suggested treatments or solutions, and expected outcomes. One helpful way to understand this disagrement is to examine Kuhn's (1971) conceptual framework of paradigm shift. C. B. Paulston (1980) defines a paradigm as "the way a scientific/professional cormunity views a field of study, identifies appropriate problems for study, and specifies legitimate concepts and methods" (p. 15). She continues to explain that people whose research is based on shared paradigms are committed to the same rules and standards.

Kuhn's theories were further developed by R. G. Paulston (1976) in his monograph, Conflicting Theories of Social and Educational Change: A Typological Review. This monograph was reviewed extensively by C. B. Paulston (1980) in her attempt to outline same major theories of social and educational change and to identify and interpret some variables of ESL/bilingual education within the framework of each particular theory.

Two major paradigms were discussed: (a) the functional or "equilibrium" paradigm and (b) the conflict paradigm. Theories which fall under the equilibrium paradigm are (a) evolutionary and neo-evolutionary, (b) structural-functional, and (c) systems analysis. As C. B. Paulston (1980) states, all these theories are "concerned with maintaining society in an equilibrium through the harmonious relationship of the social components, and they emphasize smooth, cumulative change" (p. 16).

Theories which fall under the conflict paradigm are (a) group conflict theory, (b) cultural revitalization theory, and (c) an anarchistic utopian approach. The emphasis on the conflict paradigm is in the inherent instability of social systems and the conflicts over 
values, resources and power that follow as a natural consequence (R. G. Paulston, 1976, p. 7). Economic conflict, conflicting values and cultural systems, and conflict due to oppressive institutions and imperfect human nature are the major issues here. Although references will be made to a discussion of theories under the conflict paradigm, the major concern here is the theories which fall under the equilibrium paradigm. This is appropriate because the equilibrium paradigm approach tends to be the position of the ESL supporters in the ESL versus bilingual education controversy. The equilibrium paradigm assumes that IEP students have an unequal opportunity to succeed academically and that an effective ESI/bilingual program can provide that equality. This is the approach of the majority of ESI programs.

\section{The Evolutionary Theory}

Citing previous studies, R. G. Paulston (1976, p. 7) states that the evolutionary theories are strongly influenced by Darwin's work on biological evolution. He states that these theories are characterized by notions of progress--by stages of development from lower to higher order form. Education, he says, is an integrative structure which functions to maintain stability and changes from simple to more complex modern forms in response to changes in other structures.

As previously mentioned in this dissertation, many have questioned the lack of academic achievement by many IEP students. The evolutionary theorists tend to give a simple answer to this question, usually attributing academic failure of LEP students to hereditary inferior intelligence quotients (IQS) (Jensen, 1969). C. B. Paulston (1980, 
p. 17) points out that this idea has since been dismissed by many, but warns that some people still believe that the answer given by evolutionary theorists is correct, and she asserts that many of these people serve in our public schools.

\section{Structural-Functional Theory}

According to R. G. Paulston (1976) structural-functional (S/F) theory is a "discrete set of interrelated assumptions about values, norms, and appropriate questions and methods" (p. 13). Major differences exist between evolutionary theory and S/F theory. The evolutionists place primary emphasis on linked stages of economic and cultural development, while the S/F theorists focus on homeostatic or balancing mechanisms by which societies maintain a uniform state (C. B. Paulston, 1980 , p. 20). C. B. Paulston indicates that S/F theory has not only been important to social change in the United States but has also had a tremendous influence on the interpretation of educational systems and valid educational reforms. She goes on to say that most of the writings on aspects of ESL/bilingual education fall under S/F theory.

The equalizing approach of S/F theory is recognizable in the Bilingual Education Act. The United States Congress recognized the problems of 1 imited English speaking children from low-income families and proposed measures to solve these problems by stating:

The Congress declares it to be the policy of the United States, in order to establish equal educational opportunity for all children, to encourage the establishment and operation, where appropriate, of educational programs using bilingual educational practices, techniques and methods--to enable LEP students, while using their native language, to achieve competence in the English language. (Geffert, Harper, 
Sarmiento, \& Schember, 1975, p. 13; see also Gray, Convery, \& Fox, 1981, p. 7)

With this action Congress has moved to equalize the unequal educational opportunity for IEP students. The goal of these mandated programs is

to equalize educational opportunity for children from limited English speaking families by compensatory training in English where such training can be theoretically interpreted as a balancing mechanism to maintain the equilibrium of society. (C. B. Paulston, 1980, p. 21)

To summarize, two major assumptions underlie the S/F theory research in ESL/bilingual education. One is that LEP students are assumed to have had unequal educational opportunity because of their language situation. The other assumption is the importance of cultural contact and cultural diversity in schools. From this assumption many school districts, including the PPS district, have established the Newcomers Center for the promotion and interaction of different cultures.

Social and Cultural Factors Affecting Education of LEP Students

Research on ESL/bilingual education has shown that social and cultural factors may affect IEP students' language learning and academic success (Collier, 1987; Ogbu, 1982; Ogbu \& Matute-Bianchi, 1986; Pearson, 1988; Schumann, 1978). Critics have often cammented that many American schools fail to understand the cultural differences which LEP children bring to the classroom situations. It is argued that some teachers and educators may not quite understand the complex relationship between cultural beliefs and family values and expectations, and how these influence the way a child responds to the academic demands or expectations of the school (Sugai, 1988). 
While the experiences of learning the English language and succeeding academically in school may be inspiring to some students, the same experiences may be mystifying to most LEP students. Students from culturally and linguistically different backgrounds are more likely to experience significant adjustment problems and discontinuities between their home environment and that of the school (Ogbu, 1982). According to Padilla (1980) and Ogbu and Matute-Bianchi (1986) LEP students undergo a process of adaptation or acculturation when they enter school. The process of acculturation is defined here as the changes that occur when members of one culture come into direct and continuous contact with another culture.

When LEP students enter school, most usually encounter changes in language, customs, values, social interactions, learning environments, and educational materials. These changes have been shown to have negative effects on school success (Ogbu, 1982). But the impact of these changes is harder on some LEP students than on others. For example, the LEP students whose parents came to this country involuntarily may have many more problems in their adjustment than those whose parents migrated here of their own volition. Those who are here involuntarily might be refugees who had to depart their place of birth without planning or preparation. Refugees have no choice in the location of their new home. A host country is chosen for them according to the original 1951 laws of the United Nations High Commissioner for Refugees (Strouse, 1988, p. 115).

Initial adjustments to the new educational system may present problems to many IEP students. Some aspects of the system of education 
in the United States are by far different from what the LEP students experienced in their native country. In the American schools, the participatory open-discussion type of classroom is common. Many IEPP students who experienced the European type of educational system learn in a well structured classroom environment with a lot of direction and guidance. In the United States learning is more dynamic, with strong emphasis on searching, participation, testing, and questioning.

In their former educational experiences, LEP students do not question their teacher's knowledge. The teachers have the last word in classroom situations; they are generally highly respected and have complete authority over the students in class. Unlike in the United States, students stand up before every class as the teacher enters the room and remain standing until they are told to be seated. Once the lecture begins, there is no talking and no moving around to sharpen pencils or to get a drink of water. The students do not ask questions. They can only talk when they are called upon to do so.

Unlike in the United States, the former educational experience of same LEP students is highly campetitive. Preparing for and succeeding in college entrance examinations are of paramount importance for the students and their parents. The urge and pressure to study and succeed academically are extremely high because, when a student fails in school, the whole family fails.

Recognizing these adjustment problems and how they might affect academic success of LEP students, the Portland Public School district's ESL/bilingual program department established the Newcomers Center in 1985. According to Durgan (1992) the center was financed by Title VII 
money up until last year. This is the second year that the PPS district will fund the Newcomers program. The students in this program receive intensive instruction in English and in their native languages. They get help to adjust socially and academically. The Newcomers program is a self-contained program which lasts 6 months. Because the program seems to be successful, it has been recommended that more centers be established that could last 2 or 3 more years (Durgan, 1992). Presently there are two centers, one at Vestal Elementary School and the other at Hosford Middle School.

One significant aspect of this program is the involvement of the LEP students' parents who can now directly discuss the academic progress of their children in the language they fully understand. Another significant aspect of the program involves the students themselves. Where cultural diversity exists, as in the Portland Public School district, it is important that all students are aware of differences as well as similarities in the values and cultural traditions of those with wham they interact on a daily basis.

Finally, the Newcomers program is significant because it enables LEP students to develop to their full potential socially and academically. Research has shown that some aspects of bilingual education techniques that are being used for educating language minority children have negative effects on academic success and may be producing castelike minorities (Spener, 1988). Participation in the Newcomers program may prevent new LEP students from becoming members of these caste-like minorities who, according to Ogbu (1978), occupy the least desirable positions in society and face job ceilings which only a few 
may surmount. LEP students who are mainstreamed into English-only classrooms may be presented before their teachers and classmates not as equal-but-different representatives of another language and culture, but rather as imperfect or inferior members of the majority culture (Skutnabb-Kangas, 1981). Spener (1988) explains that education is an integral part of the socialization of LEP students and may also be used effectively to promote negative attitudes towards these students. Spener states that

educational policy can serve to reinforce caste distinctions in the society by providing IEP students with an inferior education. In doing so, the educational system plays a role in creating a pool of adults who are "qualified" to be economically exploited, unemployed, or underemployed. (1988, pp. 149-150)

Other researchers have contributed different factors to the discussion of social and cultural experiences of LEP students. For example, Northcutt and Watson (1986) added personality, age, education, and natural ability of the student within the construct of the affective filter. In addition the student's preferences for certain input models (e.g., peers over parents or teachers, teachers over parents, similar ethnic individuals, or same-gender teachers), amount of daily social community interaction with L2 speakers, and positive or negative emotions towards the majority culture were examined by Ovando \& Collier (1985).

The affective filter theory is important in explaining students' differences in language mastery when they have identical community, school, and language acquisition experiences. Oftentimes teachers report students who appear to be anxious about learning new information 
in L2 and others who seem not to want to learn (Curtain \& Pesola, 1988). It has been shown that these psychological factors influence the rate of language acquisition.

In commenting on these ideas, Schumann (1978, 1986) addresses the socio-cultural and psychological variables as they affect the learner and the target language group. Socio-cultural factors such as dominance, integration strategy, and enclosure are said to affect social distance between a learner and the target language group. This distance, in turn, determines the learner's success in acquiring L2 and other academic subjects (McGroarty, 1988, pp. 318-326).

\section{Cummins's Developmental} Interdependence Theory

Cummins's (1979b) early work stressed the interrelationships that may exist between the two languages of a bilingual child. Cummins asserts that, in order to understand how I2 acquisition occurs, one must first understand the connection between L1 and L2.

The developmental interdependence theory states that

the level of L2 competence which a bilingual child attains is partially a function of the type of competence the child has developed in Ll at the time when intensive exposure to L2. begins. (Cumins, 1979b, p. 233)

Cummins and Swain's (1986) study on contextual interaction theory is particularly relevant here. The theory describes how student input factors interact with instructional treatments to contribute to LEP students' academic achievement. For LEP students, proficiency in both LI and I2 is input which may be positively associated with academic achievement (California State Department of Education, 1982, p. 7). 
Additionally, Cummins has proposed a framework for language skill to elucidate types of language acquisition. one type is similar to communicative competence which other researchers have discussed. It is characterized by the surface level skills evident in everyday communicative exchanges. Cummins calls this basic interpersonal communication skills, or BICS. He describes the other type as language abilities which are needed to succeed academically and calls these cognitive academic language proficiency (CALP) (Cummins, 1979a).

Cummins's framework gives "a strong rationale for using a minority language student's home language as the language of initial school and literacy experience" (McGroarty, 1988, p. 306). Cumins's hypotheses also support his assertion and that of other researchers that the development of a strong Ll skill is necessary for the aoquisition of L2. He stresses that the stronger the LI skill, the easier and more efficient the transfer to I2. According to Cummins, the most effective way for LEP students to learn English is through additive bilingualism. Subtractive bilingualism, such as ESL and submersion programs, is not effective and may be harmful to the academic success of LEP students. This section has reviewed many theories and their possible relationships to LEP students' academic achievement. The importance of this connection is often omitted in studies about LEP students' education. Additionally, it is suggested by Cumins (1984) that educators and policy makers have failed to appreciate the role of theory in the formulation of policy. Unless the underlying theories and concepts about ESt/bilingual education are understood, providing a meaningful 
education that is effective and formulating appropriate policies may be difficult.

\section{BRIEF HISTORICAL PERSPECTIVES OF ESL/BILINGUAL EDUCATION}

Anyone reading the present national policy debate on ESL/bilingual education may think it is a new phenomenon. But ESL/bilingual education has been present in the United States since it became a nation (Anderson \& Boyer, 1978; Harlan, 1991; Ovando \& Collier, 1985).

According to Anderson and Boyer, education in another language was a common practice in colonial America, and Dutch bilingual public schools flourished in New York state after Independence. Congress upheld petitions requesting the use of French in the schools in the Northwest Territory in 1796. The first public school in Texas used German as a language of instruction, and German bilingual schools were established in Maryland in 1874 (Anderson \& Boyer, 1978).

What is evident at this time is that "millions of immigrants who arrived in the United States after 1820 needed to leam English in order to make economic and social adjustments to the way the majority of the population lived" (Karski, 1987, p. 10).

Entry into World War I by the United States seemed to end cultural tolerance. The entry also brought about a subsequent rise in the downgrading of foreign languages, especially German. At the same time the development of nationalism within the United States emerged. Some nationalists started to demand the assimilation of new arrivals into one cultural and linguistic group. The public schools were given the 
responsibility to "Americanize" the newest immigrants (Stacy \& Lutton, 1985).

In the 1950s and 1960s there was a growing public awareness of the basic rights of various groups, including those with Iimited English proficiency. The problem of achieving equal educational opportunity for all was addressed in the famous Supreme court case of Brown v. the Board of Education of Topeka in 1954. The Court ruled that

segregation of children in public schools solely on the basis of race, even though the physical facilities and other tangible factors may be equal, deprives the children of minority groups equal educational opportunity. (Hooker, 1978, p. 78) Although this case originally focused on the issue of black children, the ruling forever changed the ways in which educators viewed linguistically different children.

During the early 1960s there was a mass exodus of Spanish-speaking Cuban refugees from Cuba to Miami, Florida (Mackey \& Beebe, 1977). Responding to the needs of many non-English speaking refugee students, Dade County started to experiment with ways to improve the education of these students. According to Mackey and Beebe, a formal ESL/bilingual education program was initiated for 350 LEP children in the first three grades at the Coral Way Elementary School in Miami. This made these children "the first group in the United States to participate in an ESL/bilingual school program specifically designed for both Spanishspeaking and English-speaking students" (p. 47).

As other schools in Dade County noted the success of the Coral Way program, ESL/bilingual instructions were started for their LEP students. Several similar LEP programs were begun in various counties 
throughout Texas, New Mexico, Arizona, and California prior to the signing of the BEA of 1968 (Anderson \& Boyer, 1978; Harlan, 1991, p. 93).

THE IMPACT OF LEGISLATTVE AND JUDICIAL ACIIONS ON ESL/BILINGUAL EDUCATION

Federal policy in bilingual education is based primarily on the Supreme Court Lau V. Nichols decision and on the 1978 amendments to Title VII of the ESEA of 1965 (Bilingual Education Act of 1978). The Supreme Court decision was based on Title VI of the Civil Rights Act of 1964 which states:

No person in the United States shall, on the ground of race, color, or national origin, be excluded from participation in, be denied the benefits of, or be subjected to discrimination under any program or activity receiving Federal financial assistance. (Economic Opportunity Act of 1964)

The OCR translated Title VI to include the denial of equal educational opportunity to language-minority children. A staff memorandum stated:

Where inability to speak and understand the English language excludes national origin minority group children from effective participation in the educational program of fered by a school district, the district must take affirmative steps to rectify the language deficiency in order to open its instructional program to these students. (Wong, 1988, p. 372)

The OCR memorandum was upheld in 1974 by the Supreme Court in Lau V. Nichols. The federal court had made many decisions that contributed to the growth of bilingual education, but it was not until 1974 that the Supreme Court, in its landmark decision Lau v. Nichols, ruled on what to do about children who arrive in the classroom knowing 
little or no English. The court found that Chinese-American, nonEnglish speaking students were denied equal educational opportunity under Title VI of the Civil Rights Act when instructed in English, a language they did not understand (Rotberg, 1982). This case stated:

There is no equality of treatment merely by providing students with the same facilities, textbooks, teachers, and curriculum, for students who do not understand English are effectively foreclosed from any meaningful education. (Lau V. Nichols, 1974; Ovando \& Collier, 1985, p. 34)

The Court ordered that schools must rectify the language deficiency, but how this should be done was not specified.

\section{Lau Remedies}

In 1975 a task force was set up by the OCR of the U. S. Department of Health, Education, and Welfare (HEW) to find ways to enforce the Supreme Court's decision. The task force issued some guidelines that are now known as the Lau Remedies. These Remedies are not laws but serve only as guidelines to be used in determining whether or not a school district is complying with the Supreme Court's decision (HEW, 1975). The Lau Remedies outline procedures to be used in identifying linguistically different students. The Remedies support a program that considers the learning of English the primary goal and the use of nonEnglish language only as a dispensable vehicle. The Remedies do not accept ESL as a method of instruction in bilingual education (HEW, 1975). 
Oregon Laws Relevant to

ESL/bilingual Education

The Equal Education Opportunities Act of 1974, Section 1703(f) states:

No state shall deny equal opportunity to an individual on account of his or her race, color, sex, or national origin by - (f) the failure by an educational agency to take appropriate action to overcome language barriers that impede equal participation by its students in its instructional programs. (Wong, 1988, p. 372)

In response Oregon has enacted various laws in the form of the Oregon Revised Statutes (ORS 343) and Oregon Administrative Rules (OAR) which directly or indirectly address educating language-minority students (Gray et al., 1981, pp. 85-88; Smith \& Heflin, 1988). These statutes and rules are divided into sections. Each section addresses different aspects of ESL/bilingual education. Districts must develop and implement a plan for identifying LEP students and provide them with appropriate programs until they can benefit from participation in regular academic programs. Districts are required to develop "Equal opportunity Plans" which must include components of multicultural education. Districts must instruct IEEP students in English, but instruction may be conducted in more than one language so students can develop bilingual skills and benefit from increased educational opportunities. LEP students must receive specific instruction in speaking, reading, and writing the English language, beginning at the first-grade level. Parental consent is required in writing before any intelligence or personality tests can be given an LEP student. Such consent must be in the parents' primary language if a language other than English is spoken at home IJEP students must be assessed and instruction given 
according to the desired achievement, considering the needs and interests of each student, requirement to evaluate all instructional programs regularly, requirement for each district school board to adopt written policies and maintain plans and programs that assure equality of opportunity for all students, and requirement for continued state funding.

\section{ESTIMATING THE NUMBER OF IEP SCHOOL-AGED CHILDREN}

No one knows exactly how many school-aged LEP students requiring special assistance attend primary schools in the United States. Estimates of actual number have ranged from 1.2 million to 5.3 million (Chamot, 1988). Two studies first attempted to estimate the number of LEP school-aged children. The first study was done by the Children's English and Services Study in 1978. This study found that 2.4 million school-aged children were limited in English proficiency. A second IEP enrollment estimate was made by the English Language Proficiency Survey in 1982, arriving at a figure ranging from 1.2 to 1.7 million (Chamot, 1988, p. 16).

Other researchers have given diverse estimates. For example, Waggoner (1986) estimates 5.3 million, using the 1980 census data, and Oxford et al. (1981) project that the LEP population aged 5-14 years will increase from 2.5 million to 3.4 million by the year 2000 .

In a more recent study of LEP enroliments, the GAO reported 1.5 to 2.6 million students for school year 1985-86 (GAO, 1987). Figures similar to those of the GAO were also estimated by the office of 
Bilingual Education and Minority Languages Affairs (OBEMLA) for school year 1986-87 (English Language Consultants, 1988).

In a survey of LEP students' enrollments Olsen (1989, p. 470) gives three reasons for the nationwide diverse estimates. First, not all states report LEP students' enrollments. According to him, 7 of the 50 states were not required to report because they had not sought federal funds. Second, there are no uniform reporting practices from state to state. For example, some states only reported LEP students receiving services and not others who are identified as IEP students. Finally, Olsen reports that identification criteria vary widely. Not all states define IEEP students in the same way; thus variations are found in the criteria used for LEP identification.

Studies by Olsen (1991) and others project that enrollment of IEP minority students in United States elementary schools will continue to rise in the coming year.

As Table II shows, all Pacific Northwest states identified here have substantial increases in LEP school enrollments fram 1986 to 1990. This is typical in many other states as well, such as Tennessee, Indiana, Utah, and Arizona (Olsen, 1991, p. 6). The data presented here suggest two conclusions: (a) there is an increasing number of LEP students in the nation's schools (reported LEP student enrollment K-12 continued to increase from 1986-1990), and (b) more school systems reported LEP student information (only 30 states reported K-12 LEP enrol Iment data in 1989; all the states reported in 1990) (OIsen, 1991, p. 4). 
TABLE II

REPORTED LEP STUDEN'TS' ENROLIMENT BY STATE

AND BY YEAR, 1986-1990

\begin{tabular}{lrrrrr}
\hline State & 1986 & 1987 & 1988 & 1989 & 1990 \\
\hline & & & & & \\
Cal ifornia & 567,564 & 613,624 & 652,439 & 742,559 & 861,531 \\
Hawaii & 8,836 & 10,884 & 10,585 & 9,028 & 9,077 \\
Idaho & 1,990 & 2,399 & 2,884 & 2,503 & 3,440 \\
Oregon & 3,988 & 5,216 & 5,578 & 6,578 & 7,557 \\
Washington & 17,151 & 18,138 & 20,131 & 21,082 & 24,279 \\
\hline
\end{tabular}

NOTE: From reported K-12 LEP students enrollments in U.S. schools 1986 to 1990 by state, Olsen, 1991, San Francisco, CA, Table I, p. 6.

Why is accurate documentation of LEP school enrol lment important? As the funds become increasingly scarce for bilingual education programs, it is necessary for program and policy planners to have an accurate number of enrollments. It is important to know how many students are IEP so that adequate services can be provided for them.

\section{LANGUAGE PLANNING PERSPECTIVES}

The basic policy of ESL/bilingual education may be based on a philosophy of "language-as-right," "language-as-resource" or "languageas-problem," a classification which was proposed by Ruiz (1988) and used by Mckay in discussing orientations in language planning. A language-as-problem perspective states that IEP children are basically deficient in English and, thus, all they need is special attention to their language skills. The key to academic and vocational success is seen to rest in the acquisition of English (MCKay, 1988, p. 347). 
In discussing this issue, Ruiz (1988, p. 7) points out that the BEA of 1968 and the state statutes that follow started with the assumption that LEP students have a handicap to overcome. Acquiring English through transitional bilingual education and at the expense of Ll became the objective of school programs. The social assumption for pull-out ESL and the submersion programs is language-as-problem. These programs adhere to assimilationist theory which states:

Assimilationist policy seeks to merge the minority members into the wider society by abandoning their own cultural distinctiveness and adopting their superordinates' values and style of life. (C. B. Paulston, 1980, p. 46)

Language-as-right can be expressed in many ways, as shown by the following authors. Del Valle (1981) points out that the right to effective participation in governmental programs has several aspects: providing unemployment insurance benefit forms in Spanish for Spanish speakers; bilingual voting materials, such as ballots and instructional pamphlets; and interpreters. Hernandez-Chavez (1978), in looking at the legal system, adds the right to the use of ethnic language in legal proceedings and the right to bilingual education. Finally, Macia (1979) cites two types of language rights: (a) the right to freedom from discrimination on the basis of language, and (b) the right to use one's own language in the activities of communal life.

According to Mckay (1988, p. 352) bilingual education programs reflect a perspective of language-as-right in that they are the result of federal and local mandates. To emphasize this point, the U.S. Supreme Court decision in Iau V. Nichols decreed that LEP students 
have a legal right to bilingual instruction as part of equal educational opportunity.

In a language-as-resource orientation there is a demonstration of a cormitment to preserving and developing minority languages. As Ruiz (1988, p. 15) has indicated, development is an important aspect of any resource-oriented policy, and preservation is important as well. He goes on to say that there is no acknowledgement of the fact that existing language resources are being destroyed. As he puts it,

language planning efforts which begin with the assumption that language is a resource to be managed, developed and conserved would tend to regard language-minority communities as important sources of expertise. (Ruiz, 1988, p. 17)

Irmersion and two-way bilingual programs are examples of language-asresource. Here students can acquire the language by using it as the medium of instruction, and the skills learned in one language can transfer to another.

Cummins (1986) and others have shown that immersion, two-way bilingual, bilingual education, and ESL programs that incorporate the native language will have beneficial effects on both English speakers and LEP students. Other bilingual education advocates have commented that these programs give English-speaking students an excellent opportunity to develop an understanding of other cultures and languages. For example, Fishman (1976) expresses satisfaction with programs that value bilingual education as enrichment for one and all, rather than as merely compensation for down-and-out minorities. He continues, saying that "bilingual education is good for everybody and particularly for 
the relatively homogeneous and monolingual populations of the world" (p. viii).

The enrichment mentioned above is a sort of "elitist" bilingualism where an individual may consciously decide to acquire another language either formally in a classroom setting or informally. For instance, those who study foreign languages and seek out contacts with speakers of these languages are referred to as elitist bilinguals. Bilingualism in this case is a matter of choice and has never been an educational problem. Elitist bilingualism can be distinguished from folk or "natural" bilingualism, a situation in which ethnic groups become bilingual involuntarily when their Ll will not suffice to meet all of their cammication needs. To function fully in the society or simply to survive, many LEP students have to acquire an L2 (C. B. Paulston, 1980, pp. 2-3; Valdes, 1988, pp. 113-116).

As previously mentioned, the PPS district's ESL/bilingual program is really not a bilingual program since its emphasis is only on English language acquisition. This program is a type of pull-out ESL program. According to Ruiz (1988) and McKay (1988, p. 346) the pull-out ESL program, such as the PPS district's EST/bilingual program, "reflects a language-as-problem-perspective." It is the view of this program that IFP children may be deficient in English and, therefore, may need special attention to improve their language skills. It is assumed that LEP students' academic success, their quick initiation into the mainstream culture, and effective functioning in the U.S. seem to depend on their acquisition of English. 
The PPS district's ESL program is transitional in nature. One of the major objectives of programs such as ESL has been to raise the English proficiency of non-English speaking children quickly so that they may be able to participate effectively in English-only classrooms (Ovando \& Collier, 1985). ESL can be differentiated from Transitional Bilingual Education. In a TBE program the students' native languages are necessary to introduce content materials. Native languages are also used to develop the literacy competencies that may help students learn to read and write English. The main focus of this type of program is on the development of students' oral cammand of the language as well as communicative competencies in English (Spener, 1988, p. 147). The TBE lasts from 2 to 3 years before students are mainstreamed into the regular English-only classrooms. By this time the use of the primary languages of the students for any type of instruction has been terminated. Some believe the students may become 1 imited in both languages. According to Spener (1988, p. 148) this limited bilingualism "has been associated with impeded cognitive development and lowered academic achievement" (California State Department of Education, 1982; Hakuta, 1986). It has also been shown by Cumins (1984, 1986) and Hakuta (1985, 1986) that I2 acquisition is most successful when there is a strong foundation in the mother tongue. These authors also state that conversational skills in an L2 are learned earlier than the ability to use the language for academic learning.

Research evidence indicates that early mainstreaming as is done in TBE programs is flawed as a compensatory education program for LEP students. LEP students who are mainstreamed out of TBE may not be 
ready to fully participate and compete in English-oniy classrooms in which English is the mother tongue of the majority of their peers (Spener, 1988, p. 149).

The role of ESL/bilingual education in educating LEP students is slowly changing. Presently there is an increasing number of ESL programs implementing a content-based syllabus through which teachers attempt to relate the curriculum of the ESL class to regular classroom content areas (Milk, 1985). The PPS system's ESL/bilingual program is also changing. According to Durgan (1991) the district's ESL program is moving away fram its English-only instruction and language-asproblem orientation towards the language-as-resource perspective.

\section{RELEVANT RESEARCH ON THE EFFECTIVENESS OF}

ESL/BILINGUAL EDUCATION

For more than two decades numerous attempts have been made to evaluate the effectiveness of ESL/bilingual education programs. The findings and conclusions from these studies have generally been mixed and inconclusive. A majority of these studies have been faulted for methodological weaknesses (McLaughlin, 1985; Willig, 1981-1982, 1985, 1987).

One of the major large scale research studies on the effectiveness of bilingual education in the 1970s was done by the American Institute for Research (Chamot, 1988; Danoff, Coles, McLaughlin, \& Reynolds, 1978). This study examined about 11,000 Spanish/English-speaking students from 38 school districts around the country. These Title VII LEP students were compared to students not in bilingual programs. The 
purpose of this study was to see if bilingual programs made any dramatic increases in LEP students' gains in English language and other academic skills. The study found no significant gains in either English or mathematics for LEP students in the program when a comparison was made with the control group.

During the 1970s much more research on the effectiveness of ESL and bilingual education was conducted (Fathman, 1976; Krashen, Long, \& Scarcella, 1979; Moore \& Parr, 1978). These studies did not receive as much attention as the study done by the American Institute for Research.

The study by Moore and Parr (1978) resembles the one that is being discussed here. The researchers attempted to measure and compare the effectiveness of four aspects of ESL/bilingual education programs. These programs are: (a) a maintenance bilingual program; (b) a transitional bilingual program; (c) a minimal bilingual program; and (d) a non-bilingual program in one school district.

The subjects were 130 children of limited English speaking ability and 77 English-dominant children from four elementary schools, Grades $\mathrm{k}-2$. Students were selected for the project on the basis of their ethnic background and their limited skills in speaking English.

Students in the maintenance group recived at least 50\% of their instruction in Spanish. In transitional classes, instruction was given in Spanish as needed. Twenty minutes per day of instruction was given in Spanish in the minimal classes, and in non-bilingual classes no instruction was given in Spanish.

Students' measures included a pretest in the fall and a posttest in the spring. Posttest scores were analyzed using analysis of 
covariance, with the pretest scores as covariates. Several social and non-experimental instructional variables were compared. These variables included sex, sociceconomic level, and language dominance. The result of the study showed that students not receiving bilingual support scored significantly higher than those receiving help in reading, mathematics, and language achievement. The comparisons of various levels of non-experimental variables showed that females scored significantly higher than males on reading and language measures.

Westlander and Stephany (1983) evaluated the ESL program in the Des Moines, Iowa public schools. The population included 577 Southeast Asian students in Grades 2-10 who were receiving ESL instruction. Background data such as age, place of birth, ethnic group, primary language, number of months in Des Moines schools, and amount of ESL instruction per week were collected. The student performance data included were: (a) Bilingual Syntax Measure; (b) grades in classes; and (c) a teacher rating. Correlation analyses and multiple regression were used to examine the relationships of background variables and the learning of English. The authors found that length of time in Des Moines schools was the single best predictor of how well students performed on the performance test scores. The researchers concluded that more instruction in English seemed to be beneficial during the first year of schooling, but had diminishing effects thereafter (Westlander \& Stephany, 1983, p. 473).

There are two major problems with this study. One is the order in which variables were included in the regression. The other is the lack of any kind of comparison group. 
A multiple regression program requires that the order of predictor variables be fixed by the researcher prior to run time. This is in contrast to programs which use the so-called stepwise procedures, allowing the data to dictate the order of the predictor variables. Stepwise procedures seek a subset of predictors that al low for maximal prediction using a minimum number of antecedents. The procedures assume that the researcher is ignorant about the processes that give rise to the outcome measures. Any study using this method must be regarded as exploratory and requires confirmation with a second data set.

In the 1980 s one of the most widely reviewed and often cited studies on the effectiveness of bilingual education is the research synthesis by Baker and de Kanter (1981). These researchers examined more than 300 evaluation studies and selected 28 which met their established criteria. From the analysis of these studies the authors intended to determine whether or not LEP students achieve English language skills better than students in non-traditional bilingual education programs. These authors concluded that "the case for the effectiveness of transitional bilingual education is so weak that exclusive reliance on this instructional method is clearly not justified" (Baker \& de Kanter, 1981, p. 1).

Many have strongly criticized Baker and de Kanter's report, not only for its methodological inadequacies, but also because their "conclusions have been disseminated widely and have misled policy makers and researchers who are concerned about issues in bilingual education" (Willig, 1987, p. 363). Additionally, the report has been quite 
influential in guiding the policy of the Department of Education for the education of IEP students (Chamot, 1988, p. 25).

A re-analysis of the Baker and de Kanter report by Willig (1985), as briefly discussed in chapter I of the present study, is another study of the effectiveness of ESL and bilingual education which has received much attention in the 1980s. Willig (1985) used a metaanalysis method to review the same 28 evaluations used by Baker and de Kanter (1981) in their analyses. By using a meta-analysis method, Willig (1985, 1987) intended to avoid the major pitfalls of the narrative review method that Baker and de Kanter used. Willig identified two major pitfalls:

1. Failure in the narrative review to keep track of all factors that might have an impact on study findings.

2. The tendency in some narrative reviews to aggregate information in ways that masked important characteristics of the studies or their outcomes (Willig, 1987, p. 365).

After eliminating these pitfalls and other study design problems, Willig found that "there were overall significant, positive effects for bilingual education programs, both for tests administered in English and tests administered in Spanish" (Willig, 1985, p. 277). Other findings included the impact of the research design problem. Willig found that the quality of the research design had significant effects on the outcomes.

Willig (1985), for example, cited studies that included comparison group students who had completed bilingual programs and were functioning successfully in the regular English-only classrooms. She also 
cited other cases in which the student attrition rate between pretest and posttest lowered posttest scores because better students were exited into the mainstream and replaced by others who were less proficient in the English language. According to Willig's research, studies that employ better quality research methodology demonstrate the most positive effects of bilingual education. She strongly criticized the inadequacy of the research methodology on the effectiveness of bilingual education. Willig encouraged more studies that compare program types, since true random assignment of students to programs is not legally possible (Chamot, 1988, p. 26).

Another important study conducted in the latter part of 1980 is the one by the GAO. Prior to this study there were constant criticisms of the effectiveness of bilingual education. Additionally, the federal effort to deregulate bilingual education policy under the Reagan administration was being carried out. Financial support for bilingual education at this time was greatly reduced. To this end, the Department of Education proposed to not adopt regulations for the BEA that would require school districts to provide native language instruction (GAO, 1987).

To strengthen their position, many officials of the Department of Education, including the Secretary of Education, made statements supporting alternative approaches to bilingual education. These officials often cite research, such as the Baker and de Kanter report (1981), claiming that the research on bilingual education's effectiveness is inconclusive. According to these officials the bilingual education 
method should not be the major approach to educating LEP students. Instead they favor English-only instruction.

Many, including members of the United States Congress, saw this as indicating a policy shift on the part of the administration. The Chairman of the Congressional Cormittee on Education and Labor therefore requested that the GAO investigate and determine the validity of the statements and claims of the officials of the Department of Education.

According to the GAO report 10 nationally recognized experts in bilingual education, general education, and educational research were selected to examine these official statements and judge their validity (GAO, 1987, p. 37). These experts were to review 10 syntheses of the effectiveness of different approaches to language minority students' education, including the Baker and de Kanter report (1981) and a review of this study by Yates and Ortiz (1983), two immersion studies by Gersten and woodward (1985) and Hernandez-Chavez (1984), Willig's metaanalysis (1985), and five other reviews.

The 10 experts were asked to address the following issues:

1. The native language instruction requirement and the learning of English.

2. The native language instruction requirement and the learning of other subjects.

3. The merits of alternative language instruction approaches.

4. Long-term educational outcomes of students receiving bilingual education.

5. Targeted versus generalized conclusions about LEP students' education. (GAO, 1987, p. 6)

The GAO report indicated that most of the experts give no credenœ to the Department of Education's claim that (a) there is insufficient evidence to support the law's present requirement, (b) evidence 
supports the promise of teaching methods that do not use native languages, and (c) there was inadequate evidence to permit them to reach a conclusion about the research basis for the legal requirement (GAO, 1987). When the views and judgments of the expert reviewers were recorded,

1. Only two of the ten experts agree with the department that there is insufficient evidence to support the law's requirement of the use of the native language.

2. Seven of the ten believe that the department is incorrect in characterizing the evidence as showing the promise of teaching methods that do not use native languages. . . . Few agree with the department's general interpretation that evidence in this field is too ambiguous to permit conclusions. (GAO, 1987, p. 3).

Although the experts acknowledge the overall weaknesses in research and evaluation in bilingual education, most of them indicate that there is adequate research evidence to support the legal requirement of native language instruction in LEP students' classroams. A number of other private and goverment-sponsored studies were conducted examining the issue of $\mathrm{Ll}$ instruction. These studies suggested that initial learning in the native language might be desirable, both acadenically and psychologically (Cumins, 1986; Kleven, 1988). These researchers believe that initial learning in the native language may be necessary for LEP students who speak little or no English, come from low-income families, live in communities where the home language has low status, and where teachers may not be members of the same ethnic group as students (Curmins, 1986; Kleven, 1988). LEP students who experience these conditions may have low academic performance. 
Early Exit in ESL/bilingual

Programs

Another issue that relates to native language instruction and academic achievement is early-exit in ESL/bilingual programs (Ramirez, 1986). In early-exit programs LEP students are exited fram the ESL/bilingual program within 2 or 3 years. ESL has often been used in early-exit programs to supplement the time necessary to master English.

Many attempts were made in the last decade to determine the relative impact of early-exit programs. For example, Ovando and collier (1985) indicated that early-exit ESL/bilingual programs have been shown to be minimally effective. These authors found that the students in these types of programs scored below a comparable group of students in English-only programs. The researchers note that the academic performance of LEP students starts to accelerate during the third or fourth year in the program. More methodologically sound research is needed to study this assertion. As Rossell (1988) indicates:

All children will show progress in academic performance in English language knowledge over time. IEP children will know more English the longer they are in this country, regardless of the effectiveness of the program in which they are enrolled. (p. 26)

The debate over early versus late exit fram the ESL/bilingual program and the use of native language instruction continues to dominate the research discussion in this area. The educational impact of this type of program has been particularly debated widely.

Ramirez (1986) examines the relative effectiveness of both earlyand late-exit ESL/bilingual programs. The author reports that teachers in early-exit programs use native language more frequently to issue 
commands or to question students. In contrast, teachers in the lateexit programs use native language more frequently to explain academic content. As expected, the early-exit ESL/bilingual programs have been found to be minimally effective. Students in these programs are often mainstreamed before they are academically and linguistically ready to succeed in the English-only classroom (Baker, 1987; Ramirez, 1986).

In another study, Burnham and Pena (1986) report the academic performance of language-divergent students who have been studied from Grades 1-5. The authors indicate that LEP students in the fifth grade surpassed national noms on all academic evaluations. They also found that the fourth-graders performed above national norms in mathematics and reading. From this and other studies one can state that LEP students who are allowed to stay in the ESL/bilingual program for more than 3 years seem to achieve better academic performance. The study by Krashen and Biber (1988) supports this view. This study reports that by the fifth grade LEP students in the late-exit ESL/bilingual programs are at or above the national and district norms in mathematics, reading, and language.

A study by Milk (1985) examined the changing role of ESL in bilingual education. Milk observed that the traditional way of conceptualizing ESL as an isolated element within bilingual programs is declining. His review of recent literature finds support for an integrative approach to second language development. In this approach classroam situations focus on grouping strategies that allow students to receive appropriate input in the second language (Milk, 1985, p. 657). 
Referring to previous research, Milk defines an integrative language development approach as

a method that involves developing English-language aoquisition during on-going instruction in the regular classroam. . - Students learn the language of instruction when engaged in classroom instructional tasks using that language. Thus, if one intended outcame of bilingual instruction is to develop LEP students' English proficiency . . . then such proficiency is best developed in relation to learning the language of instruction while learning to participate competently in instructional activity. (1985, p. 660)

One important element that must be present before this approach can work well is that the classrom must be organized to enable students to obtain the kind of linguistic input that will stimulate second language acquisition (Johnson, 1983; Milk, 1982). A growing number of ESL teachers are now implementing a "content-based syl labus" approach where the ESL curriculum is related to the regular classroom content areas (Long \& Crookes, 1992; MCKay, 1988; Milk, 1985).

Other studies, sponsored by the Office of Bilingual Education and Minority Language Affairs, have examined various aspects of ESL/bilingual education, including: (a) description of student characteristics; (b) bilingual teacher training programs; and (c) comparison of effectiveness of current instructional programs for LEP students (Chamot, 1988, p. 29).

In one OBEMLA-supported study, Baker and Ramirez (1987) compared the relative effectiveness of three instructional methods over a 4-year period. The approaches these investigators studied were immersion strategy plus early exit and late-exit ESL/bilingual programs. The authors report that students in the late-exit program made more 
progress in both Spanish and English and other academic subjects compared to students in the other two programs.

The debate on the effectiveness of FSL/bilingual education and the controversy over the use of the students' native languages continues to attract interest among researchers in the 1990s. For example, Gonzales (1990) examined three types of ESL/bilingual education programs and how each program impacts LEP students' academic performance. The ESL/bilingual programs analyzed were: (a) the in-class instruction in which the classroom teacher gives the LEP students a comprehensive lesson in their classroom; (b) the team-taught approach in which the certified bilingual teacher and the English teacher provide the instruction; and (c) the pull-out approach in which students attend separate English classes in English language development for part of the day (p. 63).

The focus of Gonzales' research was the comparison of different instructional approaches used to educate LEP students. The researcher sought to discover whether the level of use of LEP students' native language influences the students' mastery of English proficiency, mathematics achievement, and reading skills, and whether different types of ESL instructions influence LEP students' academic achievement (Gonzales, 1990, p. iii).

Using descriptive and inferential statistics, Gonzales analyzed the standardized achievement data that were collected using McGraw-Hill and Data Collection Survey instruments. The author found that, while bilingual education programs were effective in producing higher academic performance for LEP students, ESL instruction insignificantly 
improved their academic performance. According to Gonzales a bilingual program in self-contained classrooms or through team-teaching showed a much higher academic performance for LEP students than an English-only program (1990, pp. iii-iv).

Gonzales' research is similar to the present dissertation in several aspects: (a) both studies attempt to compare the effectiveness of variants of special education (ESL/bilingual) programs for LEP students in a school district; (b) both studies analyze standardized achievement scores in reading, mathematics, and language arts; and (c) both studies use data from a relatively medium-sized school district. In spite of these similarities major differences exist between Gonzales' study and the present dissertation. One major issue amitted in Gonzales' study is a possible bias in the selection process of LEP students into the ESL/bilingual programs. This is a problem that is overlooked by most studies, yet it is serious enough that it may becloud any research findings if it is not addressed. Another methodological problem overlooked by Gonzales' study is the initial differences in the knowledge of various groups that she compared. Because there can be no true randam assigrment of students into programs, if this problem is not statistically corrected for, the research results may be misleading. Finally, Gonzales' study does not include some important variables that may influence academic learning (e.g., home language; proxies of neighborhood factors, such as percentage of high school graduates; and percentage of little or no English spoken).

Gonzales has attempted to correct the methodological weaknesses by using what was thought to be a large sample (132 cases) and utilizing 
null hypothesis testing. However, the population sample of 132 subjects is too small to minimize the systematic errors in the sample, and without a truly random assignment of subjects to programs her analysis is inadequate.

The present dissertation on the effectiveness of ESL/bilingual education recognizes the problem of selection bias as students are assigned to programs. Therefore, it has employed a more powerful statistical technique that is appropriate to deal with this type of problem. The use of a more sophisticated statistical analysis is needed to show how variables in the study relate to each other. Additionally, important information that could influence academic learning might be omitted if proxies of some important neighborhood variables are excluded from the study.

Recently a study conducted by Ramirez, Yuen, and Ramey (1991) was released by the U.S. Department of Education. The study examines 2,000 Spanish-speaking elementary school children in California, Texas, Florida, New York, and New Jersey. The subjects in this study participated in three main bilingual programs in which different amounts of English and Spanish are used in the classroam. The three aspects of the program examined were: (a) immersion--programs in which LEP students received instruction in English, with Spanish used only for clarification. The goal was to move students into al1-English classes within a 2-year period; (b) early-exit--programs in which LEP students received initial instruction in Spanish and slowly moved into Englishonly instruction by the second grade; (c) late-exit--programs in which LEP students use Spanish about $40 \%$ of the time. IEP students often 
stayed in this program through sixth grade (Ramirez et al., 1991). The major findings of this study were that LEP students who received bilingual instruction advanced at the same rate as other students and were not hindered in obtaining academic achievement.

\section{SUMMARY}

This chapter reviewed relevant studies pertinent to some aspects of ESL/bilingual education. The review started with theories and issues relating to ESL/bilingual education. It discussed several theories on L2 learning, a brief historical perspective of ESL/bilingual education, and the influence of the judicial system in educating LEP students. The last section dealt with the relevant research on the effectiveness of ESL/bilingual education.

The Contextual Interaction Theory (Cummins \& Swain, 1986) seems to be useful in making policy decisions concerning programs for educating LEP students. According to these authors, this theory accounts for the interaction of several variables with instructional treatments and their effects on students' outcames. The variables accounted for in this theory may relate to proxies of neighborhood factors, student input factors, and instructional factors (California State Department of Education, 1982).

Two important educational policy implications can be identified in reviewing this theory. First, instruction of LEP students in two languages does not necessarily confuse them nor harm them cognitively. Research has shown that it may, in fact, increase academic achievement among LEP students. Second, the principles behind Cumins's (1981) 
BICS and CAIP may be applied to educational policies that determine the length of time students remain in ESL/bilingual programs and the process for exiting IEP students into the regular English-only classroams (Smith \& Heflin, 1988, p. 8).

The literature review has shown that empirical studies on the effectiveness of ESL/bilingual programs are profuse but that methodologically sound studies are scarce. A methodologically sound study is described by Rossell (1988, p. 26) as a study that has a treatment group and a control group similar to the treatment group. Rossell explains that in the absence of perfect randomization there must be statistical control for pre-existing differences between groups of LEP students. Statistical control is necessary because students with higher achievement before ESL/bilingual education often have higher achievement after participation in the program (Rossell, 1988, p. 27).

Another problem that has been ignored by most studies in this area is the selection issue. Two types of selection issues are discussed here. First, there is a self-selection bias. The sample of subjects suffers from self-selection bias if selection is based only on those subjects who agree to be studied. One recent example is Walsh and Carballo's (1986) evaluation of the effectiveness of ESL/bilingual education programs in five Massachusetts communities. The authors studied only those school districts that agreed to participate in the study. But Rossell (1988) explains that choosing only school districts willing to be studied is unacceptable by social science research standards. The school districts that refuse to participate are likely to be those with unsuccessful programs. Second, there is a selection bias 
due to some predetermined conditions. For example, IEP students are selected into programs because they have low achievement and language problems. This type of selection bias is the concern of this study. The problem of selection bias is rarely discussed in most studies dealing with the effectiveness of ESL/bilingual education. The present dissertation on the effectiveness of the PPS district's ESL/bilingual education recognizes the problem of selection bias and has used an appropriate statistical technique to address it in the next chapter. 
CHAPIER III

\section{MEIHODOLOGY}

\section{INTRODUCTION}

The review of the literature on the effectiveness of ESL/bilingual education has shown that there are few conclusive and consistent findings to indicate that the ESL/bilingual education approach is effective. Most of the studies conducted thus far have had numerous methodological weaknesses and conflicting results (McLaughl in, 1985; Rossell, 1988; Willig, 1985, 1987).

\section{STATISTICAL PROBLEM}

One of the major methodological problems to which previous researchers have paid little or no attention is the issue of selection bias. Selection bias occurs when students, through a selection process, are identified as having substantial problems in learning because of language difficulty and are subsequently placed in an ESL/bilingual education program. If the achievement gains of these students are compared with other comparable LEP students who are not in the ESL/bilingual program, it may appear as if the students in the program were performing badly.

The major statistical problem in this study is that, if the number of hours in the ESL/bilingual education program is used as the 
regression variable and a straight simple regression is run, it will appear as if ESL/bilingual programs have a very negative effect on students' achievement gains. Specifically, the problem is that the independent variable (ESLHRS) is highly correlated with the error term.

The major focus of the present dissertation is to correct for this statistical problem caused by the selection bias. To accamplish this and find out what the real impact of an ESL/bilingual education program is, the researcher employed the statistical technique of instrumental variable analysis.

\section{Error Structure}

The problems of errors in variable and error structure in single equations as presented here and how to treat them have been discussed by many researchers (Heckman, 1990; Johnston, 1984; Kennedy, 1984; Lansing \& Morgan, 1977; Wonnacott \& Wonnacott, 1984). Errors in variables occur when either the dependent or the independent variables or both are measured with errors. Errors in variables involve incorrect measurements of same of the variables in survey or any other method of data collection. When an independent variable has a measurement error and is used in a regression, its reported regression coefficient (or related statistics) is biased.

To illustrate, references were made to the works of Lansing and Morgan (1977, pp. 309-335) and Johnston (1984, pp. 12-47). Imagine a situation in which two observed variables, $\mathrm{X}$ (ESL/bilingual hours) and G (achievement gains) were measured with errors. If $\mathrm{x}$ and $\mathrm{g}$ are the true variables, $\mathrm{X}$ and $\mathrm{G}$ are equal to the true variables plus errors: 


$$
\begin{aligned}
& x=x+u \\
& G=g+v
\end{aligned}
$$

A simple linear relationship between the true variables can now be postulated:

$$
g=a+b x
$$

With this, one may then find the correlation between the observed variables by substitution:

$$
\begin{aligned}
& G-v=g \\
& X-u=x \\
& G-v=a+B(X-u) \\
& G=a+B X-B u+v
\end{aligned}
$$

Therefore, $G=a+B X+w$, where $w=v-B u$. However, $w$ is not independent of $\mathrm{x}$. It includes the term $\mathrm{Bu}$, and $\mathrm{u}$ is a component of the observed value, X. Accordingly, ordinary least squares procedures will yield biased estimates of $a$ and $B$ even if the sample is infinite and even if the mean values of the error terms are zero.

The specific statistical problem in the present dissertation involves selection of LEP students into the ESL/bilingual program due to their low achievement and language problems.

If we begin with a single equation with two variables, the model can be assumed to postulate:

$$
G=f(X)
$$


Where $\mathrm{G}$ (achievement gains) indicates the dependent variable and $\mathrm{X}$ (number of actual ESL/bilingual hours) the independent variable.

A linear specification means that $G$, or some transformation of $G$, can be expressed as a linear function of $\mathrm{X}$, or some transformation of $\mathrm{X}$. Therefore, it can be assumed that $\mathrm{G}$ and $\mathrm{X}$ denote appropriately transformed data. Thus one can postulate the linear relationship:

$$
G=a+B X
$$

Where a indicates the intercept made by the line of the vertical, G, axis and $\underline{\mathbf{B}}$ indicates the slope of the line. If this stated simple regression model were really true, one would have no problem. However, the exact functional relationships as shown here are inadequate descriptions of econometric analysis. The specification of the linear relationship is expanded to:

$$
\mathrm{G}_{\mathrm{i}}=\mathrm{a}+\mathrm{B} \mathrm{X}_{\mathrm{i}}+\mathrm{z}_{\mathrm{i}} \quad \mathrm{i}=1,2, \cdots, \mathrm{n}
$$

Where $\mathrm{Z}$ denotes the disturbance term in the equation. The purpose of the $\mathrm{z}$ term is to characterize the discrepancies that emerge between the actual, observed values of $G$ and the values that would be given by an exact functional relationship (Johnston, 1984, p. 14).

In the present study, $\mathrm{z}$ is defined as some unobservable characteristics. For example, if

$$
G=f(x+z)
$$

but

$$
\mathrm{X}=\mathrm{f}(\mathrm{z})
$$


Where $z$ denotes some unobserved characteristics that influence G. Both $\mathrm{G}$ and $\mathrm{X}$ are as previously defined. If $\mathrm{G}$, the dependent variable, is just regressed on $\mathrm{x}$, the independent variable, without removing the influence of $\mathrm{z}$ from $\mathrm{X}$, the independent variable would show biased effects on G. This is what happened in the regression results when the actual number of ESL/bilingual hours was used to assess the students' achievement gains.

By assumption $\underline{z}$ in equations (3-8) and (3-9) is determined outside the system of equations; therefore, it is called predetermined (or exogenous variable). The main point is that its values are determined elsewhere and are not influenced by G or X. Therefore, since $\mathrm{z}$ is predetermined, $\mathrm{z}$ and $\underline{e}$ (error terms) are statistically independent. Unlike $\mathrm{Z}, \mathrm{X}$ and $\mathrm{G}$ are determined within the system and thus are influenced by $\underline{z}$ and $\underline{e}$. The variables $X$ and $G$ are often called mutually dependent (or endogenous).

The problem involved here is that of simultaneous relationships. The single equation technique commonly used by many researchers in dealing with this problem is not adequate. Ordinary least square (OLS) is inconsistent and biased at best when estimating an equation that involves a system of simultaneous equations. The assumption that the error term is independent of $\mathrm{x}$, which held so well for the single equation model, cannot be sustained for the simultaneous equation model. Thus in a simultaneous equation system, regressors that are not predetermined are not independent of the error term e. For the simultaneous equation system a mutually dependent variable gives an 
inconsistent and biased estimate. A predetermined variable gives a consistent estimate.

Johnston (1984) has proposed three general approaches to the problem of how to conduct statistical analysis of data subject to errors of measurement. The first is the classical approach which involves making stringent assumptions about the error terms. This procedure depends on what is known about the errors. The second approach involves grouping the data and making less stringent assumptions about the error terms. The third approach, which is used in the present dissertation, is the method of instrumental variables (IVs). The IV technique is chosen because of its appropriateness in dealing with most situations in which a regressor (an independent variable) is contemporaneously correlated with the disturbance. In such a case, a new independent variable must be found which will be correlated with the original variable and be contemporaneously uncorrelated with the disturbance. If an appropriate instrumental variable can be found for each endogenous variable that appears as a regressor in the simultaneous equation, the IV estimator can then be calculated using a formula involving both the original and the new IVs (Kennedy, 1984, pp. 96-115; Wonnacott \& Wonnacott, 1984).

One can obtain the instrumental variable estimator ${ }^{I V}$ by regressing the dependent variable on the estimated values of the independent variables obtained fram regressions of the independent variables on the instrumental variables (see Goldberger, 1964; Kennedy, 1984, p. 104). 
RESEARCH DESIGN

In using statistical tests to analyze any data, the researcher needs to consider many things. For example, consideration should be given to the manner in which the sample was drawn, the nature of the population from which the sample was drawn, and the levels of measurement of the variables to be used. The following statistical approaches were used to analyze the data in this study.

\section{Frequency Distribution}

Preceding all the other statistical techniques, an initial examination of the test score distributions in reading, mathematics, and language usage was made. The absolute and relative frequencies, averages, etc. provide a simple description of the main characteristics of the sample data. Additionally, other summary statistics of the central tendency and dispersion give clues to the use of more sophisticated statistical techniques.

\section{Breakdown Analysis}

Breakdown provides a simple technique for examining the means and variances of a criterion or dependent variable among various subgroups in a sample or total population. Like frequencies, the breakdown method gives clues to the use of more powerful statistical techniques.

\section{Regression Assumptions}

Regression analysis involves statistical assumptions which require some comment. Research has shown that the OLS estimator is the optimal estimator where none of the assumptions of the classical linear 
regression model are violated. The assumptions of the classical linear regression model state: (a) that the dependent variable is a linear function of a specific set of independent variables plus a disturbance term; and (b) that the expected value of the disturbance term is zero, that is,

$$
E(U)=0
$$

(c) that the disturbance terms all have the same variance and are not correlated with one another,

$$
\mathrm{U} \sim \mathrm{NID}\left(0, \sigma_{\mathrm{u}}^{2}\right)
$$

where the symbol means "is distributed," and NID stands for "nomally and independently distributed" (Johnston, 1984, p. 15); (d) that the observations on the independent variable are fixed in repeated samples; and (e) that the number of observations are greater than the number of independent variables, and the variables are linearly independent of each other. For further descriptions of these assumptions, see Kennedy (1984, pp. 36-37). Violation of any of these assumptions would create a methodological problem requiring a different kind of estimator.

\section{IDENIIF ICATION OF VARIABLES}

Through a review of the relevant literature the key variables are hereby identified. Nearly all the variables examined here have been identified previously by other researchers as variables that could affect ESL/bilingual program effectiveness (Anderson, 1990; Chamot, 
1988; Gonzales, 1990; Krashen et al., 1979, p. 573; Long, 1983; Moore \& Parr, 1978, p. 94; Westlander \& Stephany, 1983).

The Dependent Variables

The ESL/bilingual program evaluation involves the measuring of relationships between program goals, the dependent variable, and a chosen group of independent variables. The evaluation attempts to determine which independent variables are important and the nature of the relationship. It is assumed that the dependent variable is a function of more than one independent variable. The dependent variables for which an explanation is sought are indirect measures of program effectiveness. These measures show students' progress over time. Measures of effectiveness for an individual student include progress measures such as test gains in reading, mathematics, and language usage. For this study, fall 1982 to spring 1983 achievement gains for students in reading, mathematics, and language usage were selected as potential variables describing effectiveness aspects of the ESL/bilingual program.

Students in Grades 3 through 11 were tested in reading, mathematics, and language usage each fall and spring. The percentage gains in each subject area were calculated for each student by subtracting the fall term 1982 test score from the spring term 1983 score and dividing by the fall score. The result was then multiplied by 100 to obtain the percentage gain in reading (PRG), mathematics (PMG), and language usage (PLG). 
The present study has chosen percentage gain rather than level or absolute change for students' achievement measure. The percentage gain is used in an attempt to control for the students' level of achievement. Obviously, students in the ESI/bilingual program start at a lower level of achievement than students who are not in the ESL/bilingual program. Percentage gain may be more important and desirable than either the level or the absolute gain.

\section{The Independent Variables}

A variety of characteristics have been identified as influencing school performance. They fall into four main categories: (a) variables pertaining to program variants such as weekly ESL and bilingual hours; (b) personal background characteristics such as age and gender; (c) school characteristics such as time in PPS system, grade level, and percent Southeast Asian per school; and (d) neighborhood characteristics such as percent high school graduate and family size in the student's cammunity. Several selected independent variables were identified for this study. The non-program characteristics are included to control for other factors which may influence performance and also be correlated with the program variables.

There was a certain arbitrariness in putting these variables into one category or another. The definitions of the variables and their expected relationships to gains in reading, English language usage, and mathematics (positive and negative) were as follows:

Home Language. This is a binary variable that has the value of 1 if the usual language of the student's home is any language other than 
English; otherwise it was 0 . It was hypothesized that LEP students living in households in which the usual language spoken at home is one other than English would show less gains in reading and English language usage than those living in homes where the usual language is English. It was also anticipated that the students whose home language is one other than English would do less well in mathematics, since the mathematical concepts and operations which they have to learn are written in English. The signs on the home variable were expected to be negative for all the dependent variables.

Age. The student's age is measured in years. It was expected that older IEP students would have more acadenic achievement gains in reading, mathematics, and English language usage. Collier (1987) and Ovando and collier (1985) made some important observations regarding age of LEP students and learning of academic skills: Younger LEP students acquire and learn communicative language faster than older IEP students, and older LEP students who are proficient and literate in Ll acquire cognitively demanding aspects of L2 faster than younger LEP students. A somewhat different opinion is presented by Collier (1987) and Krashen et al. (1979, pp. 573-579). These authors argue that age of arrival in the country where the language is spoken is the best predictor of IEP students' eventual achievement gains; however, these researchers also found that older children are faster learners of academic skills.

MALE. This variable was included to differentiate between male and female achievement gains. It is a binary variable, having a value of 1 if the student was male and 0 if female. A positive sign was 
expected for mathematics, and negative coefficients were expected for reading and language usage. Traditionally gender is one of the major determinants of formal education in most Southeast Asian countries. Differences exist in male and female's social roles in their traditional culture. Males usually have more opportunities for engaging in outside contacts and for going to school.

VIET. This is the selected language group to which a particular student belonged. It is a binary variable, having a value of 1 if a student was Vietnamese and 0 if otherwise. The Vietnamese language group has the largest number of students. This group accounts for more than $50 \%$ of all Southeast Asian LEP students. Of all the Southeast Asian language groups coming into this country, the Vietnamese may be the group with the best formal education. Most Vietnamese are literate in their own native language; the Mien and Laos groups had little or no formal education before coming to the United States. However, being literate in one's native language alone may not be enough to do well in school. One cannot say definitely whether this variable will have a. negative or positive sign.

ASIAN. This is a dumy variable having a value of 1 if a student is an Asian and 0 otherwise. There were five major ethnic groups enrolled in the ESL/bilingual education program in the PPS system. These were American Indian, Hispanic American, Asian American, African American, and European American. In 1982-83 more than $84 \%$ of the total enrollment in the ESL/bilingual program was Asian American (Table I). Because of the large number in this group, the researcher wanted to know if the group was significantly different from all other groups. 
DL1. This is a rating of English proficiency. It is a dummy variable having a value of 1 if the student speaks Iittle or no English and 0 otherwise. A negative regression sign was expected for this variable in all subject areas.

DL2. This is a rating of English proficiency. It is a dummy having a value of 1 if a student speaks his/her native language better than English and 0 otherwise. Since the students are not proficient in English, a negative sign was expected for all subject areas.

Time in PPS (TIPPS). The unit of measurement for TIPPS is the number of years. It was designed to measure the effect of the length of time a student had been in the PPS system. One would expect that time spent in school in the United States would have a positive association with oral English acquisition and that the longer an LEP . student had been in school the higher his/her achievement gains in English knowledge. However, Collier (1987) and Long (1983) found time to be one of the determining factors of achievement gains in the first and second years only. After this period the time factor becomes negative. Since the mean time in the PPS system is about 3.5 years, it was expected that TIPPS would have negative signs for reading, mathematics, and language usage. This is another selection variable. Those who learn quickly are out of program while those who do not are still in.

Instructional Intensity (ESLHRS). This refers to the number of ESI instructional hours per week. It shows the relationship between the amount of instruction and achievement gains. It is anticipated that LEP students who were enrolled in an ESI program and received 
weekly ESL instructional hours would have a higher achievement gain in reading, mathematics, and English language usage. The sign on this variable was expected to be positive for all subject areas. However, if ESL hours alone is used in the regression model, it is likely to lead to biased estimates because of the selection issue. If students are placed in an ESL/bilingual program on the basis of their low achievement and serious language problems, and if the number of weekly hours these students receive is used to explain their achievement gains, the result will be negative. One will have to generate predicted values of ESL hours (EHAT) and use this new variable to estimate the true impact of ESL hours on achievement gains.

\section{Percent Asian Per School (PAPSCH). Limited English speaking}

students with a lower concentration of students from the same ethnic and cultural group in their school have higher gains in English knowledge. It is believed that a higher proportion of a particular ethnic group in a school exacerbates that group's English speaking problems. Students who speak the same language tend to congregate outside the classroom or in the cafeteria and hold discussions in their native language. A negative sign was hypothesized for this variable in readreading and language usage. Because mathematics involves less verbal communication and students can get help from their peers, a positive sign was predicted for this subject.

Grade. The student's grade level was expected to have a positive sign. With increased years of schooling and higher education, gains in English language are increased. When older children in higher grades are compared with younger children, it has been found that older 
children consistently learn English faster than their younger counterparts. This is especially true when the duration of the exposure is identical.

Percent Iittle or No English (PLONE). The proportion of people in the student's neighborhood who speak little or no English was included to test the neighborhood effect. The LEP students who live in communities where little or no English is spoken may not have adequate exposure to English for developing good communication skills. The language skills which LEP students learn at school need to be reinforced at home and in their community during play and other neighborhood activities. This opportunity may be limited if a large proportion of the community speaks little or no English. The coefficient of this variable was expected to be negative.

Percent High School Graduate (PHSG). The percent of neighborhood population 25 years and over completing a high school education was expected to influence gains in all subject areas. Research has shown that interaction between a student and his/her environment does affect academic achievement. It was expected that LEP students who live and interact with adults and children from an environment with a higher PHSG would have better achievement gains in reading, English language, and mathematics tests. Thus a positive sign was anticipated on this variable.

Percent Below Poverty Level (PPIEVL). This variable is the percentage of local neighborhood families below the poverty level in the census tract in which the student lives. Since poverty is associated with less opportunity to succeed, it is conceivable that IEP students 
living in a low-incame environment would have low achievement gains. A study by Perl (1973, pp. 156-180) found an inverse relationship between an incame measure and a measure of students' ability. Thus it was hypothesized that the PPLEVI variable would have a negative association with English reading, mathematics, and English language usage gains.

Family Size (FSIZE). It has been shown that verbal and reading achievement is inversely related to family size (Michelson, 1970). Children from large families learn verbal skills less well because their principal models are peers rather than adults. A negative sign was expected for this variable in all subject areas.

Many proposed variables were dropped, such as measure of the student's prior education before coming to the U.S., the teacher's number of years teaching LEP students, and socio-economic status. Data on the student's prior education and the teacher's teaching experience were not available. The study population was found to be homogeneous on the socio-econamic status variable. Nearly all students came from the low-incame group.

Description of ESL/bilingual Instructional Variants

ESL Only Hours. There are variations in the instructional models of bilingual education. However, it is difficult to predict whether ESL hours have more impact on language usage and bilingual hours on reading and mathematics. As previously explained, ESL is instruction about English for limited and non-English speakers. It focuses on oral language development, introduction to reading, writing and reading 
improvement, and English vocabulary. Courses are usually taught by monolingual English speakers. All ESL students in the Portland case receive direct ESL instruction from a certified ESL teacher each day. They are pulled out of the regular classroom for this class. The students in this group take only ESL classes. They do not have any bilingual instruction.

Bilingual only Hours. Instruction is provided by the bilingual aides or teachers under the direction of a classroom teacher. These people use the students' native language to help them with concepts presented in English. They confer with the classroam teacher to determine the student's greatest need. In certain cases a bilingual aide or the classroam teacher provides bilingual support within the classroam. After ideas are presented in English, the teacher or the aide explains the ideas to groups of non- or limited-English speakers in the students' native language.

The Comparison Group Characteristics. The camparison group students are those students who have gone through the same processes as those in the program. They must have been rated as follows: speak no English (A), speak native language more than English (B), or speak native language as well as English (C). They must have been enrolled in Grades 3 through 11 in the PPS system.

This group of students did not participate in the program for one or a combination of the following reasons: (a) there was no program in the neighborhood school; (b) the students were unwilling to move to another geographic location; (c) the students' parents denied 
permission to enroll their children in the program; and (d) there were not enough students in a particular building to warrant hiring an ESL teacher.

MEASURES OF PROGRESS IN THE PPS SYSTEM

The PPS district's ESL/bilingual program, with the cooperation of the district's Evaluation Department and Management Information, maintain a special testing record. This record contains information on measures of progress for all ESL/bilingual education program students.

The PPS system uses two types of measures of progress. The first is called the Rasch Unit (RIT) achievement score, which is analyzed in the present study. The RIT scores range from about 140 to 280 , with the average score increasing from grade to grade. A student's real achievement level may be slightly higher or lower than the reported RIT score. The RIT scores represent the midpoint of a range of error band of plus or minus 3 to 5 points.

The tests are designed to measure specific goals (see Appendix D) in subject areas. All of the reading and most of the mathematics goals are tested at every grade. Other goals for mathematics are tested only in the lower and upper grades to show how LEP students develop with regard to the district's curriculum. The students receive a letter grade for each goal on which they were tested. A letter $\mathrm{H}$ (High) is given if the student answered more items correctly than approximately 80 응 of students at the same grade level. An A (Average) is given if a student performed within the average range for students at the same grade level. An $\mathrm{L}$ (Low) is given if a student requires additional help 
to meet the basic skills graduation standard by the end of eighth grade.

All students in the PPS system are expected to achieve the basicskills standards for high school graduation. These standards are RIT scores of 212 for reading and 222 for mathematics. The gains on the score have some meaning as long as the longer term pattern is one of gains. The tests given each year are in effect over the same knowledge, thus one would expect continuing progress.

The second progress measure is the Portland score (P-score), which is a standard score. The average score is 50 , and scores range from below 30 to above 80 . A P-score shows how a student is performing in relation to all PPS students at the same grade level. A student's P-score that remains about the same over the years indicates steady progress.

MODEU IDENTIFICATION

This study was an attempt to assess the effectiveness of a special ESL/bilingual education program and how time in the program affects the students' outcome measures. It also attempted to determine the extent to which selected characteristics influenœ the students' achievement.

In the most general terms, an individual student's gains in reading, English language, and mathematics (over a period of time) were viewed here as the result of variations in personal characteristics (P), school characteristics (S), and neighborhood characteristics (N). Thus percentage gains can be seen as the "output" of a production 
process that assumes that an IEP student's percentage gain is determined by personal, school, and neighborhood characteristics.

In the input-output approach, the school in which the students are enrol led affects their achievement only to the extent that it serves as the channel through which inputs flow to them. This approach does not examine the school's organization, structure, and what takes place in the classroam (Averch, Carroll, Donaldson, Kiesling, \& Pincus, 1974, p. 39).

The production function is camonly expressed in an equation by most researchers. It states that the performance on a given task is a function of several factors. The mathematical relation used by Averch et al. (1974, pp. 40-41) is followed here. The percentage gains in students' achievement can be expressed as:

$$
G=\mathrm{E}\left(\mathrm{P}_{1}, \cdots, \mathrm{P}_{\mathrm{n}}, \mathrm{S}_{1}, \cdots, \mathrm{S}_{\mathrm{m}}, \mathrm{N}_{1}, \cdots, \mathrm{N}_{\mathrm{k}}\right)
$$

where it is assumed that there are $\mathrm{n}$ relevant personal characteristics, $\mathrm{m}$ relevant school-related characteristics, and $\mathrm{k}$ relevant neighborhood characteristics that influence learning gains.

$$
\begin{aligned}
\mathrm{G}_{1}{ }^{\prime--\mathrm{I}_{\mathrm{C}}=} & \text { a student's output--for instance, the student's } \\
& \text { achievement in test scores measured on reading, } \\
& \text { mathematics, and language usage; } \\
\mathrm{P}_{1},---, \mathrm{P}_{\mathrm{n}}= & \text { the amounts of personal characteristics } 1 \text { through } \\
& \mathrm{n}, \text { that are attributable to the student--for } \\
& \text { example, } \mathrm{P}_{1} \text { might be the student's age, } \mathrm{P}_{2} \text { might } \\
& \text { be home language, and so on; }
\end{aligned}
$$




$$
\begin{aligned}
& \mathrm{S}_{1}, \cdots-\mathrm{S}_{\mathrm{m}}= \text { the amounts of school-related characteristics } 1 \\
& \text { through } \mathrm{m} \text {, that the student has been exposed to-- } \\
& \text { for example, } \mathrm{s}_{1} \text { might represent the amount of ESL } \\
& \text { hours, } \mathrm{S}_{2} \text { might be the students' length of time in } \\
& \text { PPS system, and so on; } \\
& \mathrm{N}_{1},-\mathrm{N}_{\mathrm{k}}= \text { the amounts of neighborhood characteristics } 1 \\
& \text { through } \mathrm{k} \text {, that are exposed to the student--for } \\
& \text { example, } \mathrm{N}_{1} \text { might stand for the proportion of the } \\
& \text { student's neighborhood that are high school gradu- } \\
& \text { ates, } \mathrm{N}_{2} \text { might denote the mean family size in the } \\
& \text { student's neighborhood, and so on. }
\end{aligned}
$$

The above equation is a general representation of an educational production function. To make a quantitative estimation of the impact of any particular input upon the output, a precise relationship must be stated. The relationship may or may not be a linear functional form since determinants of functional relationships can also be important. The linear production function assumes that each unit of a particular input contributes a constant amount to student gains and that the amount of any one characteristic does not influence the contribution of any other. This linear relationship can be expressed as:

$$
\begin{aligned}
\mathrm{G}= & a+a_{1} \mathrm{P}_{1}+\cdots+a_{n} \mathrm{P}_{\mathrm{n}}+\mathrm{b}_{1} \mathrm{~S}_{1}+\cdots+ \\
& \mathrm{b}_{\mathrm{m}} \mathrm{S}_{\mathrm{m}}+\mathrm{c}_{1} \mathrm{~N}_{1}+\cdots+\mathrm{c}_{\mathrm{k}} \mathrm{N}_{\mathrm{k}}
\end{aligned}
$$

As previously defined, G represents the student's gains in English language and mathematics, $\mathrm{P}_{i}$ denotes the amount of the ith personal 
factor received by the student $(i=1, \ldots, n), s_{j}$ is the amount of the $j$ th school input $(j=1,---, m)$, and $N_{k}$ denotes the amount of the kth neighborhood influence $(h=1,-\cdots, k)$. Also, $a_{i}$ is the unit contribution of the $i$ th personal characteristics, $b_{j}$ the unit contribution of the jth personal characteristics, and $c_{h}$ the unit contribution of the hth neighborhood input.

Possible interpretation of this equation is presented here. If, for example, a student receives $P_{1}$ units of the first personal factor, and if each of these units contribute $a_{1}$ to his/her gains independently of the quantities of any other inputs, the total contribution of the first personal factor to his/her gains is a times $P_{1}$. This argument is true for the total contribution to achievement gains of any other personal factors in the study; it is $a_{i}$ times $P_{i}$. The same is true for the rest of the inputs. It is assumed that the contributions are independent of one another and that every input that influences a student's gains is included in the relationship.

The major research question in this study addressed the effectiveness of ESL and bilingual programs. Others included the controls for biases of likely correlations and possibility of specification bias. The objective here was to estimate the numerical values of parameters in the equation. Knowing these values enabled the researcher to predict what would happen if students were given more or less of any particular input. From this knowledge one could detemine whether increasing or decreasing the amount of one particular input would influence students' achievement gains more or less than increasing or decreasing the amount of any other input. The multiple regression 
analysis is commonly used to estimate the values of the parameters a, b, and c mentioned above.

\section{DATA ANALYSIS AND PRELIMINARY FINDINGS}

\section{LEP Students' Initial Achievement}

A breakdown analysis was conducted to examine the initial LEP students' achievements in reading, mathematics, and language usage. The result (Table III) indicates that the LEP students who were selected to receive ESL/bilingual hours and those receiving

TABLE III

MEAN OF INITIAL LEP STUDENIS' ACHIEVEMENT BROKEN DOWN BY SUBPOPULATION GROUPS

\begin{tabular}{llll}
\hline Mean & Std. Dev. \\
\hline
\end{tabular}

Reading

Students with no ESL hours Students with ESI, hours

School with no ESL program School with ESL program

Mathematics

Students with no ESL hours Students with ESL hours

School with no ESL program

School with ESL program

Language Usage

Students with no ESL hours Students with ESL hours

School with no ESL program School with ESL program
196.57

181.50

17.38

15.33

641

194.23

190.08

17.09

18.53

321

649

205.63

192.50

19.26

18.51

618

203.36

19.39

20.16

325

198.98

707
201.29

183.64

199.46

194.15
14.68

13.34

610

258

310

15.09

16.82 
ESL/bilingual hours in schools with ESL/bilingual programs consistently had lower achievement means in all subject areas than their counterparts not receiving ESL/bilingual education hours. The statistical problem which this initial selection bias may cause and an attempt to correct it so that the true effect of an ESL/bilingual program can be determined are the major focus of this dissertation. Further analysis, as shown in Table IV, attests to the fact that students receiving ESL/bilingual education hours and those not receiving any ESL/bilingual hours have substantial differences in initial achievement and achievement gains.

Results of the $t$ Test for 1983 Achievement

The results of the $t$ tests for achievement gains in all academic subjects show that LEP students who received no ESL/bilingual hours in reading, mathematics, and language usage outperformed LEP students who received ESL/bilingual hours. Tables V, VI, and VII show a systematic statistically significant difference $(\mathrm{p}<.01)$ between the means of the achievement gains of the two groups. Additionally, the $\underline{t}$ test results indicate that the LEP students who attended schools with no ESL/bilingual programs had better performances on achievement gains in reading, mathematics, and language usage than students who attended schools with ESL/bilingual programs.

One must be careful in interpreting these results to show that ESL/bilingual education programs were not effective. The differences in the performances of the two groups may reflect the bias in the selection of students into the different programs at the outset. 
TABLE IV

MEANS OF ACHIEVEMENTS IN READING, MATHEMATICS, AND IANGUAGE USAGE BROKEN DOWN BY SUBPOPULATIION GROUPS AND BY YEAR

\begin{tabular}{|c|c|c|c|}
\hline & $\begin{array}{l}1982 \\
\text { Means }\end{array}$ & $\begin{array}{l}1983 \\
\text { Means }\end{array}$ & Gains \\
\hline \multicolumn{4}{|l|}{ Reading } \\
\hline $\begin{array}{l}\text { Students with no ESL hours } \\
\text { Students with ESL hours }\end{array}$ & $\begin{array}{l}196.57 \\
181.50 \\
(15.07)^{a}\end{array}$ & $\begin{array}{l}203.10 \\
186.97 \\
(16.13)\end{array}$ & $\begin{array}{l}6.53 \\
5.47\end{array}$ \\
\hline $\begin{array}{l}\text { School with no ESL program } \\
\text { School with ESL program }\end{array}$ & $\begin{array}{c}194.23 \\
190.08 \\
(4.15)\end{array}$ & $\begin{array}{c}201.15 \\
195.89 \\
(5.26)\end{array}$ & $\begin{array}{l}6.92 \\
5.81\end{array}$ \\
\hline \multicolumn{4}{|l|}{ Mathematics } \\
\hline $\begin{array}{l}\text { Students with no ESL hours } \\
\text { Students with ESL hours }\end{array}$ & $\begin{array}{l}205.63 \\
192.50 \\
(13.13)\end{array}$ & $\begin{array}{l}213.38 \\
199.90 \\
(13.48)\end{array}$ & $\begin{array}{l}7.75 \\
7.40\end{array}$ \\
\hline $\begin{array}{l}\text { School with no ESL program } \\
\text { School with ESL program }\end{array}$ & $\begin{array}{r}203.36 \\
198.98 \\
(4.38)\end{array}$ & $\begin{array}{c}210.86 \\
206.65 \\
(4.21)\end{array}$ & $\begin{array}{l}7.50 \\
7.67\end{array}$ \\
\hline \multicolumn{4}{|l|}{ Language Usage } \\
\hline $\begin{array}{l}\text { Students with no ESL hours } \\
\text { Students with ESL hours }\end{array}$ & $\begin{array}{l}201.29 \\
183.64 \\
(17.65)\end{array}$ & $\begin{array}{l}206.63 \\
189.44 \\
(17.19)\end{array}$ & $\begin{array}{l}5.34 \\
4.80\end{array}$ \\
\hline $\begin{array}{l}\text { School with no ESL program } \\
\text { School with ESL program }\end{array}$ & $\begin{array}{l}199.46 \\
194.15 \\
(5.31)\end{array}$ & $\begin{array}{c}204.91 \\
199.64 \\
(5.27)\end{array}$ & $\begin{array}{l}5.45 \\
5.49\end{array}$ \\
\hline
\end{tabular}

a Numbers in parentheses indicate mean differences between the two groups. 
TABLE V

MEANS AND STANDARD DEVIATIONS OF 1983 ACHIEVEMENT FOR READING BY SUBPOPULATION GROUPS

\begin{tabular}{|c|c|c|c|c|c|}
\hline & $\underline{\mathrm{n}}$ & Mean & $\begin{array}{l}\text { Std. } \\
\text { Dev. }\end{array}$ & value & $\begin{array}{l}\text { 2-Tail } \\
\text { Prob. }\end{array}$ \\
\hline $\begin{array}{l}\text { Students with no ESL hours } \\
\text { Students with ESL hours }\end{array}$ & $\begin{array}{l}641 \\
329\end{array}$ & $\begin{array}{l}203.10 \\
186.97\end{array}$ & $\begin{array}{l}15.93 \\
14.48\end{array}$ & 15.38 & $.00 *$ \\
\hline $\begin{array}{l}\text { School with no ESL program } \\
\text { School with ESL program }\end{array}$ & $\begin{array}{l}321 \\
649\end{array}$ & $\begin{array}{l}201.15 \\
195.89\end{array}$ & $\begin{array}{l}16.30 \\
17.42\end{array}$ & 4.52 & $.00 *$ \\
\hline $\begin{array}{l}\text { Students with no bil. hours } \\
\text { Students with bil. hours }\end{array}$ & $\begin{array}{r}882 \\
88\end{array}$ & $\begin{array}{l}198.82 \\
185.64\end{array}$ & $\begin{array}{l}17.12 \\
13.39\end{array}$ & 7.01 & $.00^{\star}$ \\
\hline $\begin{array}{l}\text { Home language is English } \\
\text { Home language is not English }\end{array}$ & $\begin{array}{l}461 \\
509\end{array}$ & $\begin{array}{l}199.96 \\
195.51\end{array}$ & $\begin{array}{l}17.10 \\
17.09\end{array}$ & 4.04 & $.00 *$ \\
\hline $\begin{array}{l}\text { Female students } \\
\text { Male students }\end{array}$ & $\begin{array}{l}480 \\
490\end{array}$ & $\begin{array}{l}198.19 \\
197.08\end{array}$ & $\begin{array}{l}17.57 \\
16.89\end{array}$ & 1.00 & $\mathrm{NSD}^{\mathrm{a}}$ \\
\hline
\end{tabular}

aNSD stands for No Significant Difference between the two groups of means.

*Significant at the .01 level or better. 
TABLE VI

MEANS AND STANDARD DEVIATIONS OF ACHIEVEMENT GAINS FOR MATHEMATICS BY SUBPOPULATION GROUPS

\begin{tabular}{|c|c|c|c|c|c|}
\hline & $\underline{\mathrm{n}}$ & Mean & $\begin{array}{l}\text { Std. } \\
\text { Dev. }\end{array}$ & value & $\begin{array}{l}\text { 2-Tail } \\
\text { Prob. }\end{array}$ \\
\hline $\begin{array}{l}\text { Students with no ESL hours } \\
\text { Students with ESL hours }\end{array}$ & $\begin{array}{l}618 \\
414\end{array}$ & $\begin{array}{l}213.38 \\
199.90\end{array}$ & $\begin{array}{l}19.18 \\
18.30\end{array}$ & 11.22 & $.00 *$ \\
\hline $\begin{array}{l}\text { School with no ESL program } \\
\text { School with ESL program }\end{array}$ & $\begin{array}{l}325 \\
707\end{array}$ & $\begin{array}{l}210.86 \\
206.65\end{array}$ & $\begin{array}{l}19.18 \\
20.29\end{array}$ & 3.15 & $.00 *$ \\
\hline $\begin{array}{l}\text { Students with no bil. hours } \\
\text { Students with bil. hours }\end{array}$ & $\begin{array}{l}920 \\
112\end{array}$ & $\begin{array}{l}208.86 \\
200.69\end{array}$ & $\begin{array}{l}20.29 \\
16.06\end{array}$ & 4.10 & $.00 *$ \\
\hline $\begin{array}{l}\text { Home language is English } \\
\text { Home language is not English }\end{array}$ & $\begin{array}{l}467 \\
565\end{array}$ & $\begin{array}{l}210.91 \\
205.55\end{array}$ & $\begin{array}{l}19.90 \\
19.84\end{array}$ & 4.31 & $.00 *$ \\
\hline $\begin{array}{l}\text { Female students } \\
\text { Male students }\end{array}$ & $\begin{array}{l}497 \\
535\end{array}$ & $\begin{array}{l}207.53 \\
208.39\end{array}$ & $\begin{array}{l}19.56 \\
20.47\end{array}$ & 0.69 & $\mathrm{NSD}^{\mathrm{a}}$ \\
\hline
\end{tabular}

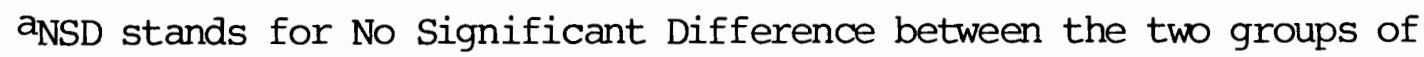
means.

*Significant at the .01 level or better. 
TABLE VII

MEANS AND STANDARD DEVIATIONS OF ACHIEVEMENT GAINS FOR IANGUAGE USAGE BY SUBPOPULATION GROUPS

\begin{tabular}{|c|c|c|c|c|c|}
\hline & $\underline{\mathrm{n}}$ & Mean & $\begin{array}{l}\text { Std. } \\
\text { Dev. }\end{array}$ & value & $\begin{array}{l}\text { 2-Tail } \\
\text { Prob. }\end{array}$ \\
\hline $\begin{array}{l}\text { Students with no ESL hours } \\
\text { Students with ESL hours }\end{array}$ & $\begin{array}{l}610 \\
258\end{array}$ & $\begin{array}{l}206.63 \\
189.44\end{array}$ & $\begin{array}{l}15.83 \\
15.23\end{array}$ & 14.79 & $.00 *$ \\
\hline $\begin{array}{l}\text { School with no ESL program } \\
\text { School with ESL program }\end{array}$ & $\begin{array}{l}310 \\
558\end{array}$ & $\begin{array}{l}204.91 \\
199.64\end{array}$ & $\begin{array}{l}16.61 \\
17.73\end{array}$ & 4.29 & $.00 *$ \\
\hline $\begin{array}{l}\text { Students with no bil. hours } \\
\text { Students with bil. hours }\end{array}$ & $\begin{array}{r}792 \\
76\end{array}$ & $\begin{array}{l}202.59 \\
190.43\end{array}$ & $\begin{array}{l}17.48 \\
13.61\end{array}$ & 5.89 & $.00^{*}$ \\
\hline $\begin{array}{l}\text { Home language is English } \\
\text { Home language is not English }\end{array}$ & $\begin{array}{l}414 \\
454\end{array}$ & $\begin{array}{l}204.67 \\
198.65\end{array}$ & $\begin{array}{l}16.99 \\
17.50\end{array}$ & 5.13 & $.00 *$ \\
\hline $\begin{array}{l}\text { Female students } \\
\text { Male students }\end{array}$ & $\begin{array}{l}434 \\
434\end{array}$ & $\begin{array}{l}202.89 \\
200.15\end{array}$ & $\begin{array}{l}17.89 \\
17.03\end{array}$ & 2.31 & $.02^{\star \star}$ \\
\hline
\end{tabular}

* Significant at the .01 level or better. **Significant at the .05 level or better.

Regression Results for Achievement Gains

Several regression runs were done on LEP students' achievement gains in reading, mathematics, and language usage. The objective was to determine the relationship between achievement gains (the dependent variables) and the actual number of ESL/bilingual hours (the independent variables).

The results of the regression analyses are presented in Tables VIII-X. In the first set of regression analysis (Table VIII), reading achievement was regressed on the number of actual ESL/bilingual hours and the other independent variables. As the results have 
TABLE VIII

REGRESSION RESUITS FOR READING ACHIEVEMENT GAINS

\begin{tabular}{|c|c|c|c|}
\hline Independent Variables & $b^{1}$ & $s^{2}$ & $\underline{F}^{3}$ \\
\hline $\begin{array}{l}\text { Actual ESL hours } \\
\text { Actual bilingual hours } \\
\text { Male durmy variable } \\
\text { Age of student } \\
\text { Student's race }\end{array}$ & $\begin{array}{r}-3.32 \\
-0.01 \\
-2.07 \\
-0.27 \\
1.46\end{array}$ & $\begin{array}{l}0.43 \\
0.05 \\
1.69 \\
1.21 \\
1.36\end{array}$ & $\begin{array}{c}57.40^{\star} \\
0.04 \\
1.50 \\
0.05 \\
1.14\end{array}$ \\
\hline $\begin{array}{l}\text { Vietnamese dummy variable } \\
\text { Home language } \\
\text { Student's grade level } \\
\text { Time in Portland Public Schools } \\
\text { Percent Asian per school }\end{array}$ & $\begin{array}{r}-0.66 \\
6.84 \\
5.30 \\
4.67 \\
-3.08\end{array}$ & $\begin{array}{r}0.45 \\
1.80 \\
1.33 \\
0.67 \\
-8.79\end{array}$ & $\begin{array}{l}2.14 \\
14.41^{*} \\
15.88^{*} \\
47.49^{*} \\
0.12\end{array}$ \\
\hline $\begin{array}{l}\text { Percent neighbor. high school graduate } \\
\text { Percent neighbor. little or no English } \\
\text { Percent neighbor. poverty level } \\
\text { Neighborhood family size }\end{array}$ & $\begin{array}{l}-2.38 \\
-4.59 \\
-9.67 \\
-0.14\end{array}$ & $\begin{array}{r}10.97 \\
7.40 \\
17.39 \\
3.03\end{array}$ & $\begin{array}{l}0.04 \\
0.38 \\
0.30 \\
0.00\end{array}$ \\
\hline $\begin{array}{lr}\text { Constant } & 54.88 \\
\mathrm{R}^{2} & 0.24\end{array}$ & & & \\
\hline
\end{tabular}

IThe parameter estimate.

2Standard error of the estimate.

3The $\mathrm{F}$ ratio.

*Significant at the .01 level or better. 
TABLE IX

REGRESSION RESULTS FOR MATHEMATICS ACHIEVEMENI GAINS

\begin{tabular}{|c|c|c|c|}
\hline Independent Variables & $b^{1}$ & $s^{2}$ & $\underline{\mathrm{F}}^{3}$ \\
\hline Actual ESL hours & -2.32 & 0.67 & 11.74 * \\
\hline Actual bilingual hours & -0.12 & 0.08 & 2.19 \\
\hline Male dummy variable & 1.13 & 2.62 & 0.18 \\
\hline Age of student & -1.18 & 1.87 & 0.40 \\
\hline Student's race & -0.25 & 2.11 & 0.01 \\
\hline Vietnamese dummy variable & -0.48 & 0.70 & 0.48 \\
\hline Home language & 5.17 & 2.79 & 3.43 \\
\hline Student's grade level & 3.14 & 2.06 & 2.32 \\
\hline Time in Portland Public Schools & 4.15 & 1.05 & $15.65 *$ \\
\hline Percent Asian per school & 13.26 & 13.62 & 0.94 \\
\hline Percent neighbor. high school graduate & -30.00 & 17.00 & 3.11 \\
\hline Percent neighbor. little or no English & 13.63 & 11.47 & 1.41 \\
\hline Percent neighbor. poverty level & -42.48 & 26.96 & 2.48 \\
\hline Neighborhood family size & 6.44 & 4.70 & 1.88 \\
\hline $\begin{array}{lr}\text { Constant } & 90.54 \\
\mathrm{R}^{2} & 0.07\end{array}$ & & & \\
\hline
\end{tabular}

$I_{\text {The parameter estimate. }}$

2Standard error of the estimate.

3The $\underline{F}$ ratio.

*Significant at the .01 level or better. 
TABLE X

REGRESSION RESULTS FOR IAANGUAGE USAGE ACHIEVEMENT GAINS

Independent Variables

Actual ESL hours

Actual bilingual hours

Male dummy variable

Age of student

Student's race

Vietnamese dummy variable

Home language

Student's grade level

Time in Portland Public Schools

Percent Asian per school

Percent neighbor. high school graduate

Percent neighbor. little or no English

percent neighbor. poverty level

Neighborhood family size $\mathrm{b}^{1}$

$s^{2}$

$F^{3}$

$\begin{array}{rll}-3.97 & 0.63 & 39.37 * \\ 0.23 & 0.08 & 8.86 * \\ -2.70 & 2.45 & 1.21 \\ -3.38 & 1.75 & 3.75 \\ -4.41 & 1.97 & 4.99 * *\end{array}$

$\begin{array}{ll}-0.98 & 0.65\end{array}$

2.27

7.96

2.60

5.12

1.92

5.52

0.98

11.94

12.71

9.33*

$7.09 *$

$31.70 *$

0.88

$-11.71 \quad 15.87$

0.54

$-3.55$

10.70

0.11

$-25.72$

2.39

25.16

1.04

0.29

IThe parameter estimate.

2 Standard error of the estimate.

3 The $\mathrm{F}$ ratio.

*Significant at the .01 level or better.

**Significant at the .05 level. 
shown, the actual ESL/bilingual hours had a negative correlation with reading achievement gains.

The major variable, ESL hours, has a negative correlation with reading achievement. Its coefficient is statistically significant ( $p<$ $.01)$, indicating that the program has a negative effect on reading achievement. An identical negative and statistically significant result was found on mathematics achievement gains (Table IX). For language achievement gains, ESL hours also had a negative and statistically significant effect. In all these analyses the actual number of ESL/bil ingual hours appears to have a negative effect on the achievement gains in reading, mathematics, and language usage.

The reason for these negative results is the issue of selection bias, which was mentioned previously. Given that the students who were in the ESL/bilingual education program were students who were expected to have learning difficulties because of their language problem, the number of instructional ESL/bilingual hours which these students received would then be correlated with the low achievement gains associated with their language problem. The relationship between the actual number of ESL/bilingual hours and the achievement gains as shown by the simple regression analysis tells the reader little about the effectiveness of ESL/bilingual education programs.

To determine the true effect of an ESL/bilingual education program and what impact the number of ESL/bilingual hours has on achievement gains, one has to use a more powerful statistical technique. The problem here is that of simultaneous relationships due to the selection issue. The single equation technique cormonly used by many researchers 
in dealing with this problem appears not to be adequate. An econometric method known as instrumental variable analysis was chosen to deal with the issue of selection bias.

\section{THE CHOICE OF INSTRUMENTAL VARIABLES}

How does a researcher decide which variables may be identified as IVs? The researcher who specifies the model makes this decision choosing from the list of the predetermined variables. Thus all exogenous variables are potential candidates for being chosen as the IV. There are two variables which could not be selected as instrumental variables in the present study. These are ESLHRS $\left(\mathrm{X}_{16}\right)$ and BHRS $\left(\mathrm{x}_{17}\right)$. These variables are mutually dependent and thus are correlated with the error e. They are detemined by some of the other predetermined $\mathrm{X}$ variables and the errors. These two variables violate the requirement of noncorrelation with the error $e$.

The author has to do two things. First he has to purge $\mathrm{x}_{16}$ and $x_{17}$ of their dependence on $e$. To do this $x_{16}$ is regressed on its chosen correlates to generate predicted values $\left(\tilde{x}_{16}\right)$. Similarly, $x_{17}$ is regressed on the exogenous $\mathrm{x}$ variables, resulting in the predicted values $\tilde{\mathrm{X}}_{17}$. In the second step the researcher applies these two new variables along with the other predetermined variables for the estimation. The Two Stage Least Squares (2SLS) comprises these two steps. There are three dependent variables in this study which require explanations. These are $\left(G_{1}\right)$ percent reading gains, $\left(G_{2}\right)$ percent mathematics gains, and $\left(G_{3}\right)$ percent language use gains. There must be 
as many equations as there are dependent variables for the system to be complete. Thus we have:

$$
\begin{aligned}
& G_{1}=A_{1} X_{1}+A_{2} X_{2}+A_{5} X_{5}+A_{6} X_{6}+A_{8} X_{8}+A_{9} X_{9}+ \\
& A_{10} X_{10}+A_{11} X_{11}+A_{12} X_{12}+A_{13} X_{13}+A_{14} X_{14}+ \\
& A_{16} \tilde{X}_{16} \quad A_{17} \widetilde{X}_{17}+e \\
& \mathrm{G}_{2}=\mathrm{B}_{1} \mathrm{X}_{1}+\mathrm{B}_{2} \mathrm{X}_{2}+\mathrm{B}_{5} \mathrm{X}_{5}+\mathrm{B}_{6} \mathrm{X}_{6}+\mathrm{B}_{8} \mathrm{X}_{8}+\mathrm{B}_{9} \mathrm{X}_{9}+ \\
& \mathrm{B}_{10} \mathrm{X}_{10}+\mathrm{B}_{11} \mathrm{X}_{11}+\mathrm{B}_{12} \mathrm{X}_{12}+\mathrm{B}_{13} \mathrm{X}_{13}+\mathrm{B}_{14} \mathrm{X}_{14}+ \\
& \mathrm{B}_{16} \widetilde{\mathrm{X}}_{16} \quad \mathrm{~B}_{17} \widetilde{\mathrm{X}}_{17}+\mathrm{e} \\
& G_{3}=c_{1} x_{1}+c_{2} x_{2}+c_{5} x_{5}+c_{6} x_{6}+c_{8} x_{8}+c_{9} x_{9}+ \\
& c_{10} x_{10}+c_{11} x_{11}+c_{12} x_{12}+c_{13} x_{13}+c_{14} x_{14}+ \\
& c_{16} \widetilde{x}_{16} \quad c_{17} \widetilde{x}_{17}+e
\end{aligned}
$$

Where:

$$
\begin{aligned}
& \mathrm{G}_{1} \quad=\text { (PRG) percent reading gains } \\
& \mathrm{G}_{2} \quad=\text { (PMG) percent mathematics gains } \\
& \mathrm{G}_{3} \quad=(P L G) \text { percent language gains } \\
& \mathrm{X}_{1}=(\mathrm{AGE}) \text { student's age in years } \\
& \mathrm{x}_{2}=(\mathrm{HMLANG}) \text { home language; } 1 \text { if home language is } \\
& \text { not English, } 0 \text { otherwise } \\
& \mathrm{X}_{5}=(\mathrm{PLONE}) \text { percentage neighborhood in census tract with } \\
& \text { little or no English } \\
& \mathrm{X}_{6} \quad=\text { (TIPPS) time (years) in Portland public schools } \\
& \mathrm{x}_{8}=(\mathrm{GRADE}) \text { student's grade level }
\end{aligned}
$$




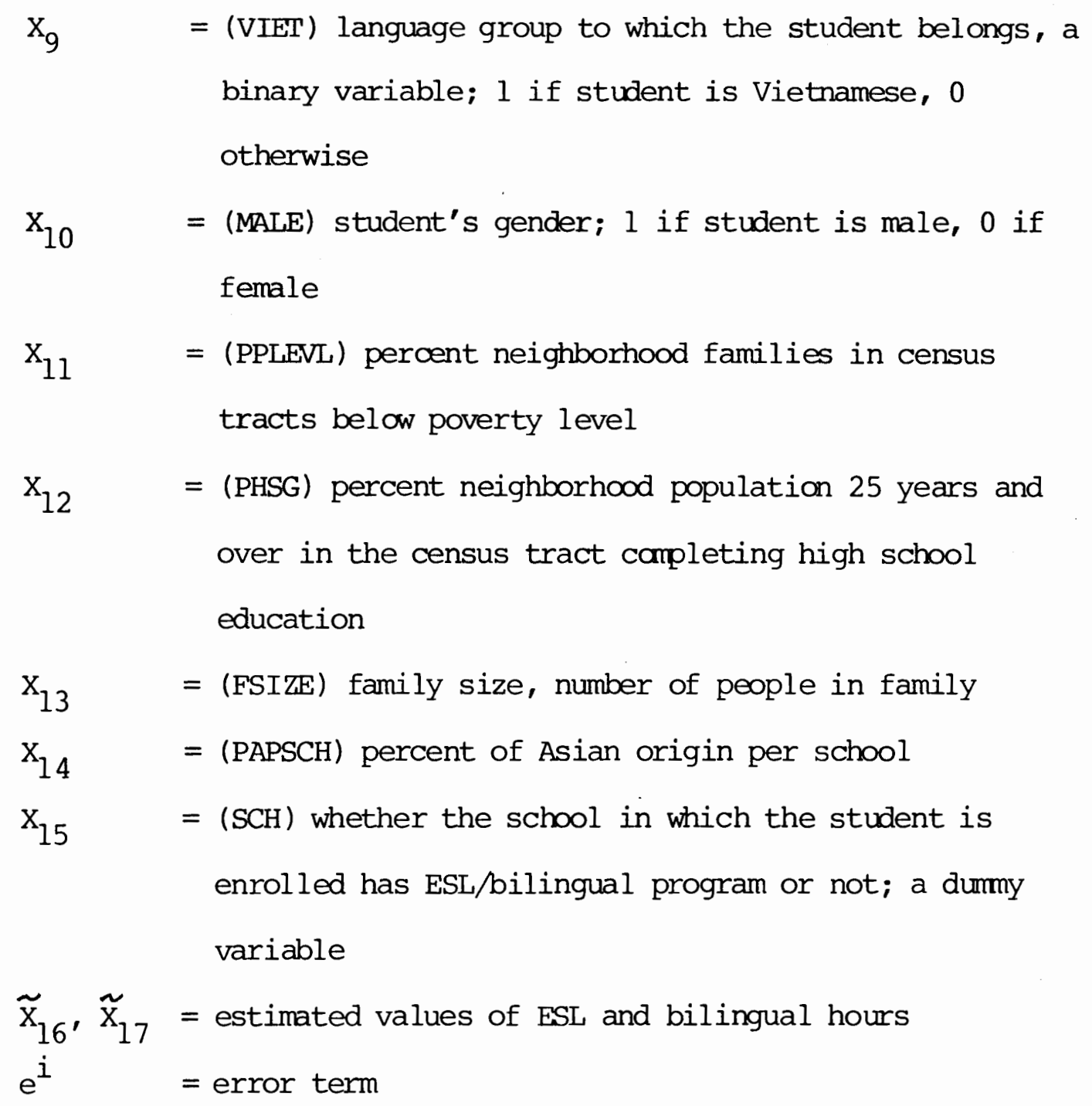

One problem with IV analysis is the arbitrary nature of choosing an IV. There is no way of knowing whether the most efficient of the IVs available has been chosen.

As stated previously, the major purpose of this study was to determine the effectiveness of ESL/bilingual program components. The first task was finding variables that could be used as instruments for ESLHRS $\left(\mathrm{x}_{16}\right)$ and BHRS $\left(\mathrm{x}_{17}\right)$. Second, $\mathrm{x}_{16}$ and $\mathrm{x}_{17}$ were regressed 
respectively on their instruments. Their respective estimates were then included in the regression analysis.

To find IVs for $\mathrm{X}_{16}$, one needed to ask why subjects receive ESL instructional hours. Two helpful tools were useful here. One was econometric theory; the other, and perhaps the most important in this case, was the knowledge of how the data are generated.

LEP students receive ESL hours for the following reasons: they speak no English $\left(\mathrm{X}_{3}\right)$; they speak much less English than they speak their native language $\left(\mathrm{x}_{4}\right)$; they attend a school with a reasonable percentage of Asians $\left(\mathrm{x}_{14}\right)$; and they are much older than their grade level $\left(\mathrm{x}_{1}\right)$.

The first part of the 2SIS was to purge $\mathrm{x}_{16}$ of its dependence on e. To accomplish this, the researcher regressed $x_{16}$ on the identified relevant variables. When Theil (1957) introduced 2SLS, he specified the whole system of equations. It is, however, acceptable to just use whatever exogenous variables are reasonably relevant and available in the data bank.

To obtain predicted values for $\mathrm{x}_{16}$ through an OLS regression, the researcher specified this model:

$$
\tilde{x}_{16}=b_{0}+b_{1} x_{1}+b_{3} x_{3}+b_{4} x_{4}+b_{14} x_{14}+e
$$

Where:

$$
\begin{array}{ll}
\widetilde{\mathrm{x}}_{16} & =\text { predicted values of } \mathrm{x}_{16} \text { (ESL hours) } \\
\mathrm{b}_{0} & =\text { constant } \\
\mathrm{b}_{1}--\mathrm{b}_{\mathrm{n}} & =\text { the coefficients of the regression equation }
\end{array}
$$




$$
\begin{array}{ll}
\mathrm{x}_{1}---\mathrm{x}_{\mathrm{n}} & =\text { the relevant variables } \\
\mathrm{e} & =\text { the error term }
\end{array}
$$

The exogenous $\mathrm{X}$ variables in this equation are independent of the error term e. Thus the linear combination $\widetilde{\mathrm{x}}_{16}$ will also be independent of $e$ and can be used as an IV for consistent estimation.

The procedure just described in obtaining the predicted values for ESL hours is similarly followed for bilingual ${ }^{5}$ hours. Two major factors determine whether or not LEP students recive bilingual instructional hours: (a) if their school has an ESL program, it tends to also have bilingual assistance $\left(\mathrm{x}_{15}\right)$, and $(\mathrm{b})$ if the student speaks a language other than English at home $\left(\mathrm{X}_{2}\right)$.

To purge BHRS $\left(\mathrm{x}_{17}\right)$ of its dependence on $e$, the researcher regressed $x_{17}$ on all the relevant exogenous $x$ variables. The regression equation required to estimate the predicted value for this variable is as follows:

$$
\tilde{x}_{17}=b_{0}+b_{2} x_{2}+b_{15} x_{15}+e
$$

All the variables and the coefficients are as previously defined. As with equation (3-15), the exogenous variables here are independent of the error term e, and likewise their linear combination $\widetilde{\mathrm{x}}_{17}$ is uncorrelated with the error term.

${ }^{5}$ Bilingual instruction is not a separate instructional service model. However, few enough cases are found in the data bank that make it necessary to treat it as separate and examine its effect on achievement gains of LEP students. 
In the final stage of the analysis $\left(\widetilde{\mathrm{X}}_{16}\right)$, the predicted values of ESL hours named EHAT, and $\left(\tilde{\mathrm{x}}_{17}\right)$, the predicted values of bilingual hours named BHAT, were applied with the other exogenous variables to the system of equations (3-12 to $3-14)$.

\section{SPECIFICATION OF THE MODEL}

As a first approximation, the model is specified as a system of simple, linear additive equations. The system provides a statistical analysis which includes all the variable meanings and measurements. The equations are expressed as:

$$
\underset{i}{G}=c^{i}+\sum_{j=1}^{17} b_{j}^{i} x+e^{i}
$$

Where:

$$
\begin{aligned}
G_{1}= & \text { (PRG) percent reading gains } \\
G_{2}= & \text { (PMG) percent mathematics gains } \\
G_{3}= & \text { (PLG) percent language usage gains } \\
x_{1}= & \text { (AGE) student's age in years } \\
x_{2}= & \text { (HMLANG) home language; } 1 \text { if home language is not } \\
& \text { English, } 0 \text { otherwise } \\
X_{3}= & \text { (DL1) English proficiency rating; } 1 \text { if student speaks no } \\
& \text { English, } 0 \text { otherwise } \\
x_{4}= & \text { (DL2) a dumy variable; } 1 \text { if student speaks native } \\
& \text { language better than English, } 0 \text { otherwise } \\
X_{5}= & \text { (PLONE) percentage neighborhood in census tract with } \\
& \text { little or no English }
\end{aligned}
$$




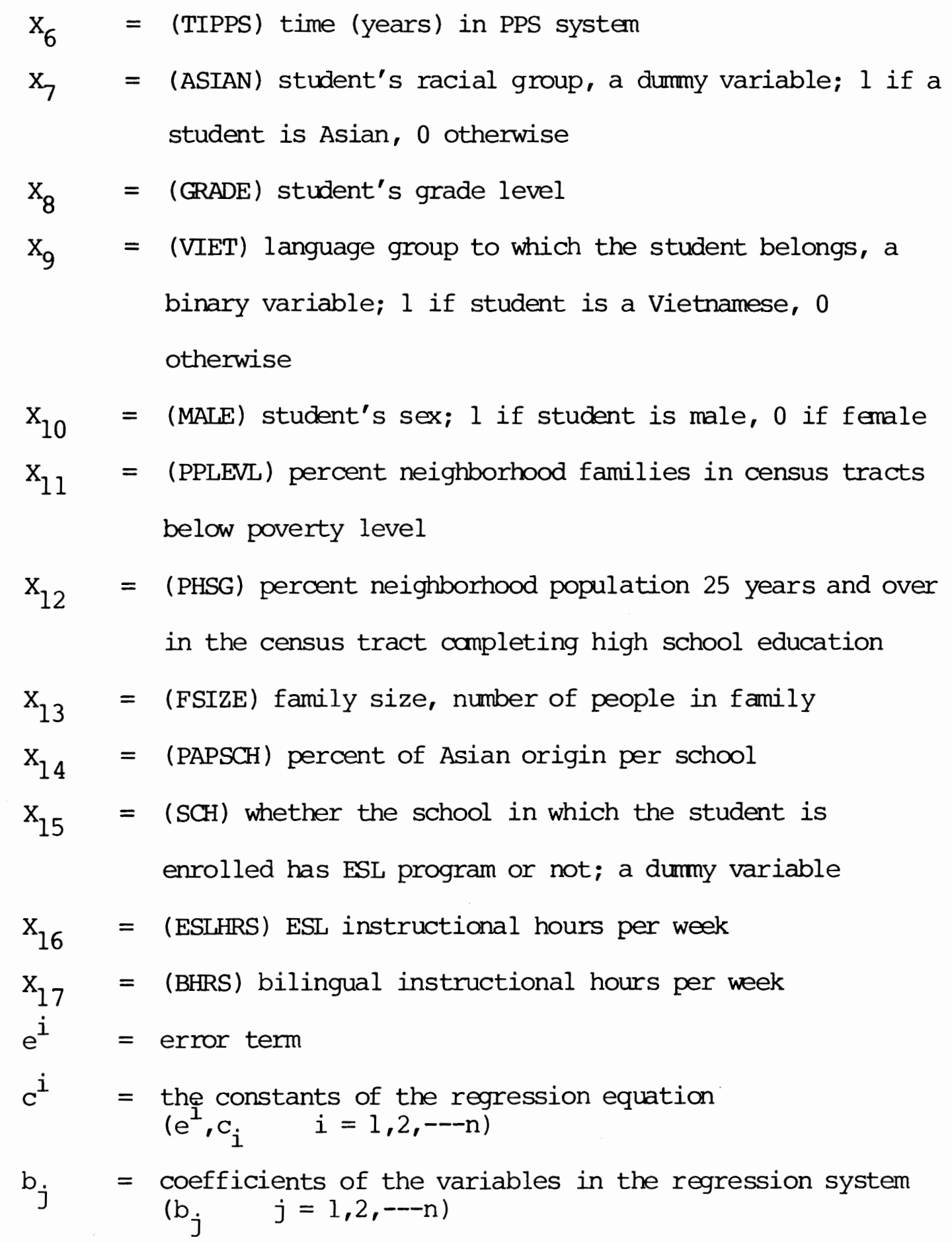

One serious problem with these variables for a researcher is isolating the effect of a variable such as ESL/bilingual hours from the influences of personal, neighborhood, and other school factors in 
producing students' achievement. Another problem is the selection issue in placing LEP students with substantial language difficulties into ESL/bilingual programs. Because of this selection bias, one gets a negative correlation between students' achievement and the ESI/bilingual hours. Additionally, there is the issue of multicollinearity in which the independent variables are highly correlated with each other. The present study uses variables that relate to personal, school, and neighborhood characteristics. Figure 4 clearly depicts this serious methodological problem.

The selection of LEP students into ESL/bilingual education programs involves two major processes. The first is the initial identification and assessment for students transferring within the district and those new to the school district. Both new and transferring students

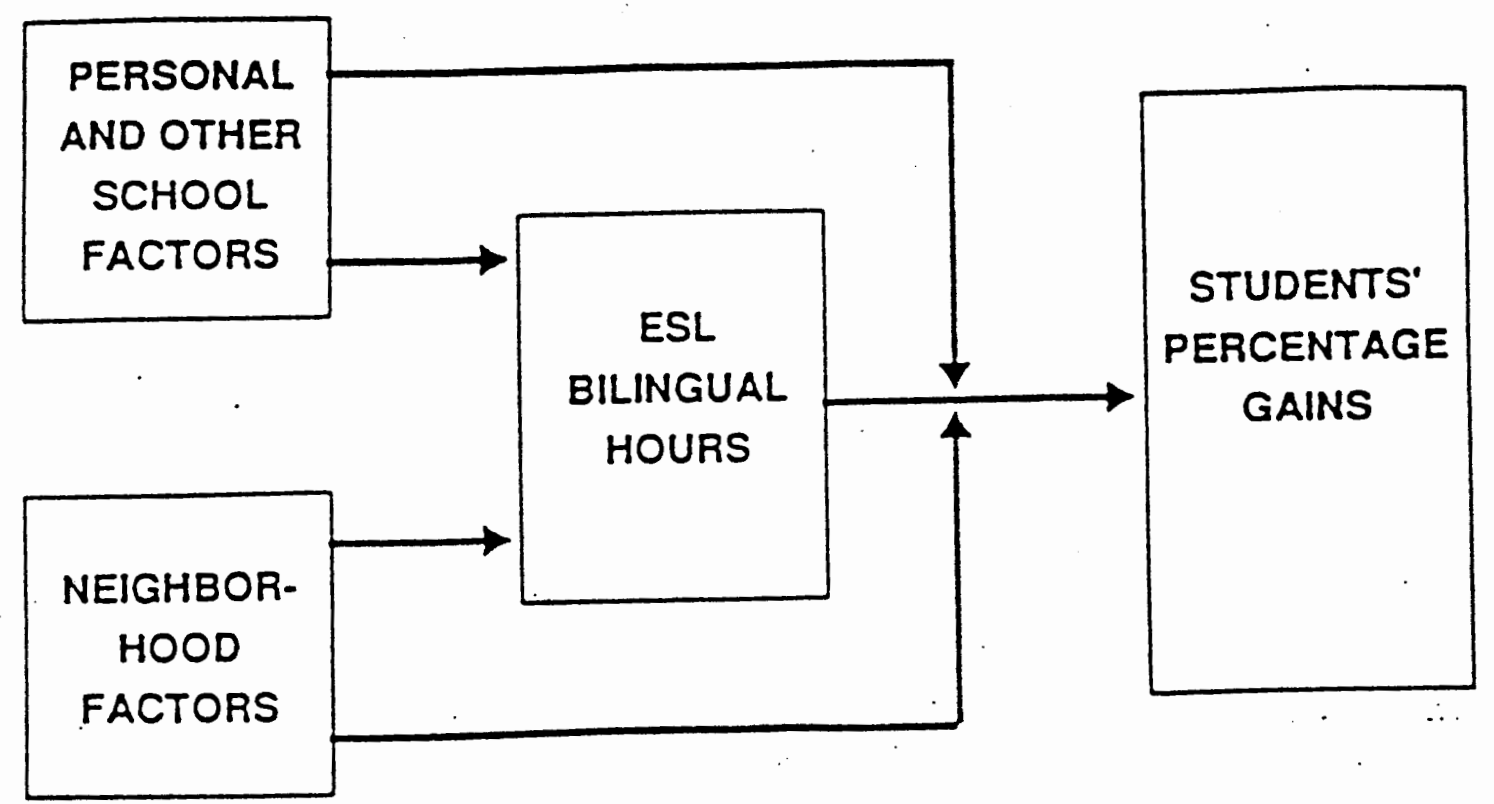

Fiqure 4. Causal model. 
should have a Home Language Other Than English (HLOTE). The identification and assessment procedures involve completing a Home Language Identification (HLID) form (see Appendix E). The information obtained here detemines whether a student needs language assistance services or can function in a monolingual English classroom. Students who have low achievement and serious language difficulties are placed in ESL/bilingual education programs. Parents or guardians of students new to the district and living in a home where a language other than English is spoken camplete the HLID form. Both transferring and new students follow assessment procedures established for all schools. This assessment typically includes the following steps:

1. A home language screening questionnaire is provided.

2. Parents complete the questionnaire.

3. School staff review the answer to the question about the level of the student's English proficiency. If the answer states that the student speaks the English language more than his/her native language, the student is enrolled into the regular classes. If the answer is that the student speaks no English (A), or that the student speaks the native language more than English (B), or that the student speaks the native language as well as English (C), the student is referred to the Assessment Center for further evaluation.

4. An English proficiency test is given and evaluated.

The second process is the enrollment of students who speak or understand little or no English into ESL/bilingual education programs. The ESL/bilingual student profile is completed for each student who is 
assessed at the ESL/bilingual Newcomer Assessment Center. The profile contains student personal data, such as family, educational level, and registration information. Using the profile, the school building representative determines proper placement of the students into the building's ESL/bilingual program. This is done in consultation with classroom teachers, counselors, and ESL/bilingual program staff.

Also related to the selection process are the "Lau" ratings or categories mentioned earlier. Full descriptions of each category as listed in the PPS ESL/bilingual Staff Handbook (Portland Public Schools ESL/bilingual Education Department, 1983) are as follows:

When speaking or reading about the District's limitedEnglish proficient (LEP) students, reference is often made to the "Lau Categories." These five categories, A through $E$, were developed by the U.S. Of fice of Education in order to help identify the degree of oral English proficiency of children in relation to their first language or the language spoken in their home. Placement in a category helps a school district detemine whether or not a child is in need of additional English language instruction. Portland Public Schools offers this English instruction to all students who are categorized by their parents as Lau $\underline{A}$ and $\underline{B}$ and some Lau $\underline{C}$ students.

Lau Category $\bar{A}$ includes students who speak little or no English. They are proficient in one and possibly more other languages, but English is new to them. Since Lau categories refer only to oral proficiency, they cannot be used to judge literacy. Other measures are employed when developing an appropriate instructional program for these students.

Lau Category B includes students who speak some English, but who still must primarily communicate in another language. This is a large category into which Lau $\mathrm{A}^{\prime} \mathrm{s}$ rapidly move but from which movement is dependent on a number of factors including individual aptitude in language learning, age and the amount and quality of language training provided. A child's stay in Lau B can last anywhere from a few months to several years. An important factor in determining the duration of this stay is the degree of first language literacy possessed at the time of entry. 
Lau Category C includes students who speak their first language and English equally well. For some students this means they no longer need additional assistance in learning English and are ready for full mainstreaming. But, since the Lau categories do not measure actual proficiency or literacy, some Lau $\underline{C}$ students may still not have a high degree of competence in either English or their first language. Additionally English language instruction may therefore still be required before full mainstreaming can take place.

Lau Category D includes students who speak primarily English, but have some degree of proficiency in another language. These may be students who have picked up this second language from a parent or relative or who may have lived abroad for a year or more. These may also be students who have forgotten much of their first language and/or whose families are keeping it alive at home.

Lau Category E includes students who speak only English. In most all cases these are students whose first language was English, but whose parents or relatives speak another language, also. (p. 4) 
CHAPTER IV

EMPIRICAL RESULTS

DESCRIPTIVE STATISTICS

The findings of the empirical work are presented in two main sections. The first contains the descriptive statistics encompassing frequency counts, percentages, means, and standard deviations of selected variables. The second section presents the results of various regression analyses and their possible interpretations.

During the 1982-83 school year more than 2,900 LEP students attended elementary and secondary schools in Portland. The majority of these students (84\%) were from Southeast Asia (see Table I). Appendix F shows the Asian student distribution among the district's high schools.

The students' age distribution (Appendix G) ranged fram 8 years to 21 years. The majority of the students, $81.9 \%$, were between the ages of 9 and 14 years. The 8- and 21-year-olds were represented by just $.1 \%$ and $.3 \%$, respectively.

As Appendix $\mathrm{H}$ shows, there was no significant difference in the distribution of students between Grades 3 and 8 . The students were also evenly divided among the high school grade levels that were included in the study. As previously mentioned, students from Grades 1,2 and 12 were not included. Data on them were not complete, and 
their number was so small that including them in the study yielded no additional information.

Of the 1,136 students in the study, $52.6 \%$ were male and $47.4 \%$ were female; $54.6 \%$ of the students had a home language which was other than English, as against 45.48 who used English as their medium of commnication at home.

Students were categorized into three levels of English proficiency (Appendix I). The smallest group, 4.2\%, was not proficient in English. Those whose proficiency in English was less than their native language was $40 \%$. The largest category, $55.8 \%$, were as proficient in the English language as they were in their native language.

Table XI shows the distribution of students in their major language groups. Only five major language areas were identified, with the rest of the groups forming the other language group. Same of the major language groups were a combination of one or two smaller groups. For example, the Cantonese (China) language group cambined with Cantonese, Vietnamese, and Chau chu to constitute the Cantonese language group.

TABLE XI

PERCENT DISTRIBUTION OF STUDENTS INTO THEIR LANGUAGE GROUPS

\begin{tabular}{lrr}
\hline Language Groups & Percent & $\underline{\mathrm{n}}$ \\
\hline & & \\
Vietnamese & 38.2 & 434 \\
Hmong & 7.5 & 85 \\
Lao & 17.1 & 194 \\
Cantonese-China & 9.7 & 110 \\
Khmer & 5.7 & 65 \\
Other & 21.8 & 248 \\
\multicolumn{1}{r}{ TOTAL } & 100.0 & $1, \frac{2436}{136}$ \\
\hline
\end{tabular}


All five of the major language groups were from Southeast Asia. The Thai, Korean, and Japanese language groups were included in the "other" language group category. The Vietnamese language group was by far the largest group, $38.2 \%$, and was more than twice the size of the Laotian language group (17.1\%). The other languages were camposed of groups from Europe, Africa, Middle East, Pacific Islands, and other Asian countries. Altogether they were $21.8 \%$.

Most of the ESL students in this study, 67\%, had been in the PPS system from 2 to 4 years (Appendix J).

Table XII shows the average weekly ESL and bilingual hours each student received. The ESL students received an average of over 5 hours of ESL instruction, and those in the bilingual program recived over 6 hours of bilingual instruction.

Only 125 students showed up in the data as taking bilingual instruction, while more than 3 times that number (479 students) had ESL instruction. There were 532 students with neither ESL nor bilingual hours.

TABLE XII

AVERAGE WEEKLY ESL AND BILINGUAL HOURS RECEIVED BY EACH STUDENT

\begin{tabular}{lccccc}
\hline & Mean & $\begin{array}{l}\text { Standard } \\
\text { Deviation }\end{array}$ & Minimum & Maximum & $\underline{\mathrm{n}}$ \\
\hline ESL hours & 5.51 & 3.12 & 1 & 20 & 479 \\
Bilingual hours & 6.57 & 2.12 & 2 & 9 & 125 \\
\hline
\end{tabular}


Summary Findings of the Breakdown

Analysis of LEP Students' Initial

Achievement

In the previous chapter, the preliminary results of the breakdown analysis were presented. The means of the LEP students' initial achievement in reading, mathematics, and language usage were compared between different subpopulation groups of students receiving ESL/bilingual hours and those who received no ESL/bilingual hours. The comparisons were also made between LEP students attending schools with ESL/bilingual programs and those attending schools with no ESL/bilingual hours. In all subject areas the non-ESL/bilingual students had higher initial achievements than those in the ESL/bilingual program. When 1982 initial achievement was compared with 1983 achievement (Table IV), the non-ESL/bilingual students continued to have higher scores than ESL/bilingual students.

The purpose of this section was to establish that the non-ESL/ bilingual program students started at a much higher achievement level than their counterparts in the ESL/bilingual program. The breakdown analysis did not indicate whether the observed differences in the initial achievement were statistically significant. Thus a stronger descriptive statistic ( $\underline{t}$ test) was used.

Summary Findings of $t$ Tests Camparing

Means for Reading, Mathematics

and Language Usage Gains

The summary of the $\underline{t}$ tests (reported in Chapter III) is presented for all subject areas. In reading, four of the five subpopulation groups had statistically significant results, $\mathrm{p}<.001$. When the means 
of students' achievement in reading were compared, the result showed that LEP students receiving no ESL instruction hours performed better than those students in the ESL program receiving ESL hours. Similar results were true for (a) students who attended schools with no ESL program and those who attended schools with an ESL program, (b) students receiving no bilingual hours and those with bilingual hours, and (c) students whose home language was English and those who spoke a language other than English at home.

The result of reading achievement gains, which is summarized here for LEP subpopulation groups, shows the same pattern as obtained for mathematics and language achievement gains. Statistically significant differences were found in favor of IEP student subgroups who had less difficulty with English language usage. Those LEP students with low initial achievement continued to have problems and thus scored less on achievement tests. This again refers to the issue of selection bias, which was mentioned previously.

The results of the $\underline{t}$ tests for reading and mathematics achievement gains showed no statistically significant differences between the female and the male students. The female LEP students slightly outperformed their male counterparts in language achievement gains.

It must be emphasized that on the basis of the breakdown analysis, the $\underline{t}$-test results, and comparison of the means of achievement gains, ESL did not have a significant positive effect on achievement. 
SUMMARY OF REGRESSION RESULTS

\section{Introduction}

As a first step in arriving at a priori notions concerning effectiveness of ESL/bilingual education programs, the methodological approach known as regression analysis was used. In particular, the instrumental variable technique in econometric theory was utilized. Several examples of work done in this area include Wonnacott and Wonnacott (1984), Bridge (1979), Cramer (1971), and Maddala (1977). This method involved using OLS estimators, where appropriate, to estimate parameter values. It gives alternative estimators to the OLS estimator for situations where the ors does not retain its desirable properties.

The results of the ouS suggests it may be a poor next step in the analysis to use a simple regression model. Because if actual number of hours in ESL is used as the independent variable in the simple regression model, the variable will be correlated negatively with the achievement gains in reading, mathematics, and language usage. The negative correlation is associated with the students' initial low achievement and language difficulty. The preliminary finding of the regression models for achievement gains is evidence of selectivity bias which was present while assigning students into the ESL/bilingual program.

The regression results as presented in the previous chapter indicate that the actual number of ESL and bilingual hours were correlated negatively with percent reading, mathematics, and language gains. These independent variables had negative correlation when they were introduced into the regression equation alone or with other variables 
proxying for various characteristics. With the simple regression analysis and using the actual number of ESL/bilingual hours as an independent variable, it is hard for the researcher to truly assess the impact of the ESL/bilingual program.

The result summarized here makes it appear as if the ESL/bilingual program has no positive effect on achievement gains. But the reason for the negative effect is due to the selectivity bias created initially through a selection process. To assess the true effect of ESL/ bilingual hours on various achievement gains, one must first remove or minimize the influence of the error created by the selection bias. According to Kennedy (1984) and other researchers the usual ouS estimate of the slope coefficient is biased and inconsistent in the simple regression model with errors in the independent variable. One must obtain additional information because such a model is underidentified, and thus consistent estimation is not possible. There are two ways for dealing with this problem. The first is weighted regression, which assumes that the error covariance matrix is known to the researcher. The second, preferred by the present researcher, is the IV estimation. It assumes the existence of a set of variables which is correlated with the true explanatory variables but uncorrelated with the error term.

The means and standard deviations of the variables in the regression equations are reported in Table XIII. The expected regression signs are presented in Table XIV. 
TABLE XIII

MEANS AND STANDARD DEVIATIONS OF THE VARIABLES IN THE REGRESSION EQUATION

\begin{tabular}{|c|c|c|c|}
\hline $\begin{array}{c}\text { Variable } \\
\text { Name }\end{array}$ & Mean & $\begin{array}{l}\text { Std. } \\
\text { Dev. }\end{array}$ & Variable Meaning \\
\hline EHAT & 1.422 & 2.094 & Predicted values of ESL hours \\
\hline PHSG & .730 & .070 & Percent neighborhood high school grad. \\
\hline GRADE & 5.578 & 1.900 & Student grade level \\
\hline RHMIANG & .536 & .499 & Home language \\
\hline PPLEVI & .095 & .058 & Percent neighborhood below poverty level \\
\hline DL2 & .289 & .454 & English profic. less than native lang. \\
\hline PAPSCH & .131 & .121 & Percent Asian per school \\
\hline RAGE & 11.955 & 2.077 & Age of student \\
\hline PLONE & .246 & .148 & Percent neighborhood little or no Eng. \\
\hline RMALE & .491 & .500 & Male dummy \\
\hline RACED & .853 & .354 & Student race dummy \\
\hline LGD & .419 & .494 & Language group dumy \\
\hline BHAT & .544 & .462 & Predicted values of bilingual hours \\
\hline FSIZE & 2.993 & .188 & Neighborhood family size \\
\hline RTIPPS & 3.520 & 1.382 & Time in Portland Public School \\
\hline PRG & 3.527 & 4.354 & Percent reading gain \\
\hline PMG & 3.873 & 3.705 & Percent mathematics gain \\
\hline PLG & 2.646 & 3.532 & Percent language usage gain \\
\hline
\end{tabular}


COMPARISON OF THE REGRESSION AND THE PREDICTED SIGNS OF THE VARIABLES IN THE REGRESSION EQUATION

\begin{tabular}{|c|c|c|c|}
\hline \multirow[b]{2}{*}{ Independent Variables } & \multicolumn{3}{|c|}{ Regression and Predicted Signs ${ }^{a}$} \\
\hline & $\begin{array}{l}\text { Reading } \\
\text { Gain }\end{array}$ & $\begin{array}{l}\text { Math } \\
\text { Gain }\end{array}$ & $\begin{array}{l}\text { Language } \\
\text { Gain }\end{array}$ \\
\hline Predicted values of ESL hours & $-(+)$ & $+(+)$ & $-(+)$ \\
\hline Time in Portland Public Schools & $-(-)$ & $-(-)$ & $-(-)$ \\
\hline $\begin{array}{l}\text { Neighborhood percent little or } \\
\text { no English }\end{array}$ & $+(-)$ & $+(-)$ & $-(-)$ \\
\hline $\begin{array}{l}\text { Neighborhood percent high } \\
\text { school graduate }\end{array}$ & $+(+)$ & $+(+)$ & $+(+)$ \\
\hline Male dummy & $-(-)$ & $+(+)$ & $-(-)$ \\
\hline Student race & $-(-)$ & $-(-)$ & $+(-)$ \\
\hline Student grade level & $+(+)$ & $+(+)$ & $+(+)$ \\
\hline Home language & $+(-)$ & $-(-)$ & $-(-)$ \\
\hline Neighborhood family size & $-(-)$ & $-(-)$ & $-(-)$ \\
\hline Student's language group & $-(-)$ & $+(+)$ & $+(+)$ \\
\hline $\begin{array}{l}\text { English proficiency less than } \\
\text { native language }\end{array}$ & $+(-)$ & $-(-)$ & $+(-)$ \\
\hline $\begin{array}{l}\text { Neighborhood percent below } \\
\text { poverty level }\end{array}$ & $+(-)$ & $-(-)$ & $+(-)$ \\
\hline Percent Asian per school & $+(-)$ & $-(+)$ & $+(-)$ \\
\hline Age of student & $-(-)$ & $-(-)$ & $-(-)$ \\
\hline $\begin{array}{l}\text { Predicted values of bilingual } \\
\text { hours }\end{array}$ & $-(-)$ & $+(+)$ & $-(-)$ \\
\hline
\end{tabular}

aThe predicted signs are in parentheses. 


\section{Obtaining Instrumental Variables}

The instrumental variable method and how to obtain an instrumental variable estimator were explained in the previous chapter. The technique involves regressing each endogenous variable being used as a regressor on the exogenous variables in the system. Then the estimated values of these endogenous variables from these regressions are used as required instrumental variables. The results of the regression equations 3-16 and 3-17 are presented in Tables XV and XVI.

As Table XV indicates, all the instrumental variables used to estimate the value of ESL instructional hours met the criteria previously specified in Chapter III for being chosen. These variables were highly correlated with the regressors for which they were acting as instruments.

The $\underline{t}$ ratios were all statistically significant beyond the .01 level. Similar results were obtained for estimating bilingual hours (Table XVI). Whether or not a school has an ESL program and home language were all highly correlated with bilingual hours.

As previously stated in Chapter III, one of the problems with the instrumental variable technique is the arbitrary nature of choosing an instrumental variable. Besides, finding a convenient set of variables is sometimes difficult. From the results of these two regressions, predicted values were generated. The estimated values of the weekly ESLHRS (named EHAT) and the weekly BHRS (named BHAT) will now be included in the structural equations. These new instrumental variables, together with the other predetermined variables, were used to evaluate the effectiveness of the ESL/bilingual program. The results 
TABLE XV

REGRESSION RESULTS TO OBTAIN ESTIMATED
VALUES OF ESL HOURS

\begin{tabular}{|c|c|c|c|}
\hline Independent Variables & $b^{1}$ & $s^{2}$ & $\underline{t}^{3}$ \\
\hline Percent Asian per school & 2.96 & 0.59 & $4.95 *$ \\
\hline Not proficient in English & 2.49 & 0.64 & $3.83 *$ \\
\hline Age of student & 0.25 & 0.03 & $7.04 *$ \\
\hline Eng. prof. less than native language & 3.95 & 0.16 & $23.57 *$ \\
\hline $\begin{array}{lr}\text { Constant } & -3.18 \\
\text { Sample size } & 1,136 \\
\mathrm{R}^{2} & .57\end{array}$ & & & \\
\hline
\end{tabular}

lThe parameter estimate.

2Standard error of the estimate.

${ }^{3}$ The $\underline{t}$ statistic.

*Significant at better than .01 level.

TABLE XVI

REGRESSION RESULTS TO OBTAIN ESTIMATED

VALUES OF BILINGUAL HOURS

\begin{tabular}{|c|c|c|c|}
\hline Independent Variable & $b^{1}$ & $s^{2}$ & $t^{3}$ \\
\hline Whether or not school has ESL prog. & 0.81 & 0.15 & $5.40 *$ \\
\hline Whether hame lang. is other than Eng. & 0.44 & 0.14 & $3.05^{\star}$ \\
\hline $\begin{array}{lr}\text { Constant } & 10.22 \\
\text { Sample size } & 1,136 \\
\mathrm{R}^{2} & .59\end{array}$ & & & \\
\hline
\end{tabular}

$l_{\text {The parameter estimate. }}$

2Standard error of the estimate.

${ }^{3}$ The $\underline{t}$ statistic.

*Significant at better than .01 level. 
of the regression analyses for the percentage gains are presented in the remainder of this chapter.

Regression Results for

Reading Achievement

Several regression equations were specified, first using all the variables in the system and then controlling for selected variables. The hypothesis that an ESL/bilingual program may or may not increase percentage gains in reading, mathematics, and English language usage was examined.

The result of the regression run for percent reading gain is shown in Table XVII, with all of the variables introduced into the equation. The predicted values of ESL hours (EHAT) and predicted values of bilingual hours had negative correlations with percent reading gains. In Table XVIII proxies for each of the school, program, neighborhood, and personal characteristics were chosen to explain the percentage gains in reading.

The predicted values of ESL hours seem to have minor positive impact (Table XVIII); its coefficient is not statistically significant. Additionally, the regression coefficients and signs for this variable vary from equation to equation; the overall $\mathrm{R}^{2}$ is only .077 , there is nothing consistent or persistent about the effect of ESL and bilingual hours on reading achievement. Based upon the data presented here, not much can be said about the effectiveness of the ESL and bilingual program on reading achievement gains.

The reason for this result may be due to: (a) the concentration of the program on language achievement and communication competence 
TABLE XVII

REGRESSION RESULTS FOR PERCENT READING GAINS WITH ALU VARIABLES IN THE EQUATION

\begin{tabular}{|c|c|c|c|}
\hline Independent Variables & $b^{1}$ & $s^{2}$ & $\underline{t}^{3}$ \\
\hline Time in Portland Public Schools & -0.19 & 0.14 & -1.33 \\
\hline Neighbor. percent little or no Eng. & 1.34 & 1.43 & 0.93 \\
\hline Neighbor. percent high school grad. & 1.72 & 2.82 & 0.61 \\
\hline Male dummy variable & -0.33 & 0.33 & -0.97 \\
\hline Students' race & -0.05 & 0.52 & -0.10 \\
\hline Students' grade level & 0.07 & 0.28 & 0.24 \\
\hline Home language & 0.68 & 0.42 & 1.60 \\
\hline Neighborhood family size & -0.36 & 1.00 & -0.36 \\
\hline Students' language group & -0.16 & 0.38 & -0.44 \\
\hline Eng. prof. less than native language & 1.39 & 2.41 & 0.57 \\
\hline Neighbor. percent below poverty level & 2.06 & 3.52 & 0.58 \\
\hline Percent Asian per school & 2.77 & 2.55 & 1.08 \\
\hline Predicted values of bilingual hours & -0.38 & 0.51 & -0.73 \\
\hline Age of student & -0.52 & 0.30 & $-1.73 * \star \star *$ \\
\hline Predicted values of ESL hours & -0.23 & 0.61 & -0.37 \\
\hline $\begin{array}{lr}\text { Constant } & 9.08 \\
\text { Sample size } & 640 \\
\mathrm{R}^{2} & 0.077\end{array}$ & & & \\
\hline
\end{tabular}

IThe parameter estimate.

2Standard error of the estimate.

${ }^{3}$ The $\underline{t}$ statistic.

***Significant at the .10 level. 
TABLE XVIII

REGRESSION RESULTS FOR PERCENT READING GAINS WITH VARIABLES

FOR PERSONAL, SCHOOL, NEIGHBORHOOD, AND

PROGRAM CHARACIERISTICS

\begin{tabular}{|c|c|c|c|}
\hline Independent Variables & $b^{l}$ & $s^{2}$ & $\underline{t}^{3}$ \\
\hline Time in Portland Public Schools & -0.11 & 0.13 & -0.84 \\
\hline Male dumy variable & -0.28 & 0.33 & -0.84 \\
\hline Neighbor. percent high school grad. & 1.04 & 2.38 & 0.44 \\
\hline Age of student & -0.60 & 0.09 & $-6.43 *$ \\
\hline Predicted values of ESL hours & 0.19 & 0.10 & $1.87 * \star \star$ \\
\hline $\begin{array}{lr}\text { Constant } & 4.90 \\
\text { Sample size } & 640 \\
\mathrm{R}^{2} & 0.06\end{array}$ & & & \\
\hline
\end{tabular}

$1_{\text {The parameter estimate. }}$

2Standard error of the estimate.

3 The $\underline{t}$ statistic.

*Significant at better than .01 level.

$\star * \star$ Significant at the .10 level.

which may divert attention from reading for some students; (b) LEP students' being pulled-out of the regular English classes. When they are pulled-out, they have less exposure to English, and this may eventually have negative impact on their reading performance; (c) the short evaluation period--one school year may not be enough for the students to show significant improvement in academic reading; and (d) reading materials and tests may be culturally biased. 
Regression Results for

Mathematics Achievement

The results for regression runs for percent mathematics achievement gains are presented in Tables XIX through XXI. As Table XIX indicates, all but one of the parameters have the expected regression sign, and six of those with correct signs were statistically significant at the .01 level or better. The predicted values of ESL and bilingual hours both showed positive impact on mathematics achievement. The former was moderately significant at the .10 level, while the latter was statistically significant at the .05 level. Both variables appear to benefit the LEP students in increasing their mathematics achievement. The strong association of predicted values of ESL and bilingual hours (Tables XX and XXI) may suggest that using one to supplement the other is helpful in achieving gains in mathematics.

Mathematics has the strongest and most robust results among the subject areas examined in the present dissertation. No matter what set of characteristics was introduced into the regression, the effect of ESL and bilingual hours basically remained unchanged. The regression coefficients do not vary signs and level of significance; the results are robust.

One can at least have some confidence that the ESL/bilingual program really helps in some important areas represented by mathematics achievement. Mathematics is a value for a lot of other academic subjects which are not language related. This might imply that the ESL/bilingual programs are also helpful in other areas that were not tested for because reading and language are directly related to the 
TABLE XIX

REGRESSION RESUUTS FOR PERCENT MATHEMATICS GAINS WITH AIL VARIABLES

\begin{tabular}{|c|c|c|c|}
\hline Independent Variables & $\mathrm{b}^{1}$ & $s^{2}$ & $t^{3}$ \\
\hline Time in Portland Public Schools & -0.19 & 0.12 & $-1.61 * \star \star$ \\
\hline Neighbor percent little or no Eng. & 0.04 & 1.21 & 0.03 \\
\hline Neighbor. percent high school grad. & 5.30 & 2.38 & $2.25^{\star \star}$ \\
\hline Male dummy variable & 0.49 & 0.28 & $1.74 * \star \star$ \\
\hline Students' race & -0.44 & 0.44 & -1.00 \\
\hline Students' grade level & 0.13 & 0.23 & 0.56 \\
\hline Home language & -0.35 & 0.36 & -0.98 \\
\hline Neighborhood family size & -0.27 & 0.84 & -0.33 \\
\hline Students' language group & 0.04 & 0.32 & 0.15 \\
\hline Eng. prof. less than native language & -2.87 & 2.03 & -1.41 \\
\hline Neighbor. percent below poverty level & -1.06 & 2.96 & -0.35 \\
\hline Percent Asian per school & -2.68 & 2.15 & -1.24 \\
\hline Predicted values of bilingual hours & 0.87 & 0.43 & $2.00 * \star$ \\
\hline Age of student & -0.83 & 0.25 & $-3.28 *$ \\
\hline Predicted values of ESL hours & 0.86 & 0.51 & $1.67 * \star \star$ \\
\hline $\begin{array}{lr}\text { Constant } & 10.67 \\
\text { Sample size } & 640 \\
\mathrm{R}^{2} & 0.094\end{array}$ & & & \\
\hline
\end{tabular}

$l_{\text {The parameter estimate. }}$

2 Standard error of the estimate.

${ }^{3}$ The $t$ statistic.
*Significant at the .01 level. **Significant at the .05 level. $* \star \star$ Significant at the .10 level. 
TABLE XX

REGRESSION RESULTS FOR PERCENT MATHEMATICS GAINS WITH DIFFERENT SETS OF VARIABLES

\begin{tabular}{|c|c|c|c|}
\hline Independent Variables & $b^{1}$ & $\mathrm{~s}^{2}$ & $t^{3}$ \\
\hline Predicted values of bilingual hours & 1.00 & 0.42 & $2.36 *$ \\
\hline Male dummy variable & 0.51 & 0.28 & $1.79 * * *$ \\
\hline Neighbor. percent high school graduate & 5.46 & 2.37 & $2.29 \star \star$ \\
\hline Age of student & -0.85 & 0.25 & $-3.32 \star$ \\
\hline Students' language group & 0.04 & 0.32 & 0.13 \\
\hline Neighbor. percent little or no Eng. & -0.24 & 1.13 & -0.21 \\
\hline Eng. prof. less than native language & -3.00 & 2.03 & -1.47 \\
\hline Students' race & -0.41 & 0.44 & -0.94 \\
\hline Neighbor. percent below poverty level & -1.02 & 2.82 & -0.36 \\
\hline Home language & -0.52 & 0.34 & -1.52 \\
\hline Percent Asian per school & -2.83 & 2.15 & -1.31 \\
\hline Students' grade level & 0.11 & 0.23 & 0.48 \\
\hline Predicted values of ESL hours & 0.96 & 0.51 & $1.85 * \star \star$ \\
\hline $\begin{array}{l}\text { Constant } \\
\text { Sample size } \\
\mathrm{R}^{2}\end{array}$ & & & \\
\hline
\end{tabular}

$1_{\text {The parameter estimate. }}$ 2 Standard error of the estimate. 3 The $t$ statistic.
*Significant at the .01 level. **Significant at the .05 level. $\star \star \star$ Significant at the .10 level. 
TABLE XXI

REGRESSION RESULTS FOR PERCENT MATHEMATICS ACHIEVEMENT

WITH VARIABLES FOR PERSONAL, SCHOOL, NEIGHBORHOOD, AND PROGRAM CHARACTERISTICS

\begin{tabular}{|c|c|c|c|}
\hline Independent Variables & $b^{1}$ & $s^{2}$ & $t^{3}$ \\
\hline Time in Portland Public Schools & -0.23 & 0.11 & $-2.02 *$ \\
\hline Male dummy variable & 0.46 & 0.28 & $1.65 * \star \star$ \\
\hline Neighbor. percent high school grad. & 5.37 & 2.01 & $2.67 *$ \\
\hline Age of student & -0.51 & 0.07 & $-6.50 *$ \\
\hline Predicted values of ESL hours & 0.16 & 0.08 & $1.94 * \star$ \\
\hline $\begin{array}{l}\text { Constant } \\
\text { Sample size } \\
\mathrm{R}^{2}\end{array}$ & & & \\
\hline
\end{tabular}

$l_{\text {The parameter estimate. }}$

2Standard error of the estimate.

${ }^{3}$ The $t$ statistic.

* Significant at the .01 level.
$\star \star$ Significant at the .05 level.
$\star \star \star$ Significant at the .10 level.

ESL/bilingual approaches. For the less intensive language subjects, the only subject examined is mathematics. And mathematics, science, social studies, and geography are all represented by mathematics since there are no standardized testing results for them.

From the results presented here it can be emphasized that the less intensive language area, the substantive area is the one in which ESL/bilingual programs seem to have a consistent, persistent, positive impact. Therefore, one can argue that the real benefits of an ESL/bilingual program are not in the language acquisition necessarily 
but in the acquisition of the less intensive language academic subjects.

Regression Results for Language Usage Achievement

The results of the regression runs for percent language achievement are presented in Tables XXII and XXIII. Of the 15 variables for which results are presented in Table XXII, 5, including the major variables (EHAT and BHAT), had unexpected signs, and none of these variables were statistically significant. Similarly, nonstatistically significant results were found with a different set of characteristics in Table XXIII. In one regression result (Table XXIV) ESL hours had moderate to significant positive correlation with language achievement. The predicted values of ESL hours were statistically significant at the .05 level. This is the only case in which predicted values of ESL hours appear to have a positive and statistically significant effect on language achievement. There were one or two other results which were positive, but they were not statistically significant. In essence, one cannot have much confidence in this result because of the variations in the regression signs, coefficients, and levels of significance.

REGRESSION RESULTS OF SOME OTHER VARIABLES WHICH MAY INFLUENCE LEP STUDENTS' ACHIEVEMENT

Age

Age of the student is used as personal characteristics. The empirical results indicate that the age variable has a statistically significant correlation with all the dependent variables 
TABLE XXII

REGRESSION RESULTS WITH ALL VARIABLES FOR PERCENT IANGUAGE USAGE GATNS

\begin{tabular}{|c|c|c|c|}
\hline Independent Variables & $b^{1}$ & $s^{2}$ & $\underline{t}^{3}$ \\
\hline Time in Portland Public Schools & -0.11 & 0.11 & -0.99 \\
\hline Neighbor. percent little or no Eng. & 0.04 & 1.18 & 0.04 \\
\hline Neighbor. percent high school graduate & 2.32 & 2.33 & 0.99 \\
\hline Male dummy variable & -0.32 & 0.28 & -1.14 \\
\hline Students' race & -0.34 & 0.43 & -0.79 \\
\hline Students' grade level & 0.63 & 0.23 & $2.70 *$ \\
\hline Home language & -0.12 & 0.35 & -0.36 \\
\hline Neighborhood family size & -0.53 & 0.83 & -0.64 \\
\hline Students' language group & 0.47 & 0.31 & 1.50 \\
\hline Eng. prof. less than native language & 1.22 & 1.99 & 0.61 \\
\hline Neighbor. percent below poverty level & 1.65 & 2.91 & 0.56 \\
\hline Percent Asian per school & 3.33 & 2.11 & 1.57 \\
\hline Predicted values of bilingual hours & -0.67 & 0.42 & -1.58 \\
\hline Age of student & -0.51 & 0.25 & $-2.26 * \star$ \\
\hline Predicted values of ESL hours & -0.13 & 0.50 & -0.26 \\
\hline $\begin{array}{lr}\text { Constant } & 5.53 \\
\text { Sample size } & 640 \\
\mathrm{R}^{2} & 0.041\end{array}$ & & & \\
\hline
\end{tabular}

$l_{\text {The parameter estimate. }}$ 2 Standard error of the estimate. *Significant at the .01 level. 3 The $t$ statistic. 
TABLE XXIII

REGRESSION RESUITS FOR PERCENT IANGUAGE ACHIEVEMENT WITH DIFFERENT SETS OF CHARACTERISTICS

\begin{tabular}{|c|c|c|c|}
\hline Independent Variables & $\mathrm{b}^{1}$ & $s^{2}$ & $t^{3}$ \\
\hline Neighborhood family size & -0.49 & 0.78 & -0.63 \\
\hline Predicted value of bilingual hours & -0.58 & 0.41 & -1.38 \\
\hline Male dummy variable & -0.30 & 0.27 & -1.09 \\
\hline Neighbor. percent high school grad. & 3.04 & 2.29 & 1.33 \\
\hline Students' grade level & 0.66 & 0.23. & $2.87 \star$ \\
\hline Eng. prof. less than native language & 1.24 & 1.99 & 0.62 \\
\hline Percent Asian per school & 3.02 & 1.96 & 1.54 \\
\hline Neighbor. percent below poverty level & 2.00 & 2.87 & 0.69 \\
\hline Home language & -0.20 & 0.33 & -0.60 \\
\hline Age of student & -0.11 & 0.24 & $-2.16 * \star$ \\
\hline Predicted values of ESL hours & -0.11 & 0.50 & -0.22 \\
\hline $\begin{array}{l}\text { Constant } \\
\text { Sample size } \\
\mathrm{R}^{2}\end{array}$ & & & \\
\hline
\end{tabular}

$1_{\text {The parameter estimate. }}$ ${ }^{2}$ Standard error of the estimate. ${ }^{3}$ The $t$ statistic.
*Significant at the .01 level. **Significant at the .05 level. 
TABLE XXIV

REGRESSION RESULTS FOR PERCENT IANGUAGE ACHIEVEMENT

USING SELECTED PERSONAL, SCHOOL, NEIGHBORHOOD, AND PROGRAM CHARACTERISTICS

\begin{tabular}{|c|c|c|c|}
\hline Independent Variables & $b^{1}$ & $s^{2}$ & $t^{3}$ \\
\hline Male dummy variable & -0.27 & 0.27 & -0.98 \\
\hline Percent Asian per school & 1.29 & 1.22 & 1.07 \\
\hline Students' grade level & 0.63 & 0.23 & $2.74 *$ \\
\hline Neighbor. percent high school grad. & 2.58 & 1.98 & 1.30 \\
\hline Home language & -0.48 & 0.27 & $-1.73 * * \star$ \\
\hline Age of student & -0.60 & 0.21 & $-2.8 .1^{\star}$ \\
\hline Predicted values of ESL hours & 0.17 & 0.08 & $2.12 \star \star$ \\
\hline $\begin{array}{lr}\text { Constant } & 4.45 \\
\text { Sample size } & 640 \\
\mathrm{R}^{2} & 0.032\end{array}$ & & & \\
\hline
\end{tabular}

lThe parameter estimate.

2Standard error of the estimate.

${ }^{3}$ The $\underline{t}$ statistic.
*Significant at the .01 level. **Significant at the .05 level. $* * *$ Significant at the .10 level.

(reading, mathematics, language usage). The fact that age is negative and statistically significant $(p<.05$ or better) may indicate that LEP students continue to have problems academically even with the help they receive from ESL/bilingual classes. When many LEP students first enrolled in U.S. schools, they were below their grade level in comparison with their agemates because of their low initial achievement and language problems. Thus they were selected to receive ESL/bilingual instruction. 
The fact that the coefficient of age was consistently negative and statistically significant is important. It confims Collier's (1987) study of the relationship between LEP students' age at arrival, prior education, and acquisition of academic skills. Collier reported that LEP students who had entered the ESL/bilingual education program between the ages of 8 and 11 had taken 2 to 5 years on the average to approximate the 50th percentile on national standardized tests of reading, language arts, and science. He indicated that those who entered the program at age 12 and above were only at about the 40th percentile on most tests after 4 years of ESL and mainstream instruction. The average age of LEP students in the present study was 11.9 years. This is the age group that collier found to encounter heavy cognitive academic demand.

\section{Time in Portland Public}

Schools (TIPPS)

The length of time LEP students spent in the PPS system was negatively correlated with their academic gains in all subject areas. However, the variable was not statistically significant in any of the reading and language usage regressions. Thus not much can be said about the effect of time in the PPS system on student achievements in reading and language usage.

Time in the PPS system has a negative and statistically significant correlation with students' mathematics achievement. In most of the regression results for mathematics achievement (see Tables XX and XXI), the coefficient of time in the PPS system is statistically significant ( $\mathrm{p}<.05$ or better). The fact that TIPPS is negative and 
statistically significant is important because it further explains the substantial problem of the selection issue. Students who were preselected into the ESL/bilingual program on the basis of their low initial achievement and language problems continue to have problems and, therefore, are spending a longer time in the program.

The mean time for LEP students in the PPS system is 3.5 years, and if most of the students are 12 years and over, it follows, then, that they would likely encounter problems with cognitive academic language demands (Collier, 1987). What this implies is that these students will take a much longer time than 3.5 years to show progress on standardized achievement tests. This finding supports what many researchers, including Cummins (1984, 1986), have discovered: There is a time lag between the development of social interactive language skills, promoted by ESL/bilingual education programs, and the full development of academic language skills.

Percent Neighborhood High

School Graduates (PHSG)

This variable is a proxy for a broader set of neighborhood characteristics that may individually affect students' achievement. Its coefficients show positive associations with all subject areas in the regression results. But one cannot explain the variable's effect on reading and language usage achievement since none of the coefficients for these subjects were statistically significant. The relationship with academic gains in mathematics was statistically significant ( $p<$ .05 or better) in most of the regressions for this subject. This 
result may mean that there is same set of neighborhood characteristics that may be contributing to students' achievement in mathematics.

\section{Students' Grade Level}

The independent variable, grade level, contributes positively and significantly $(\mathrm{p}<.01)$ to gains in language usage. The coefficient of this variable was statistically significant for language achievement whether in the full regression model or the reduced model with whatever sets of characteristics. This indicates that students in the higher grade levels learn language skills more quickly in L2. This finding is consistent with the findings reported by Burnham and Pina (1986) and Krashen and Biber (1988). Other surrounding factors might also contribute to improvement in language achievement. For example, Westlander and Stephany (1983) have observed that LEP students' experiences, such as socializing, sports activities, travelling, shopping, listening to the radio, and watching television, may contribute to English learning.

The empirical results presented here indicate that the ESL/bilingual education program in the PPS system has strong support for nonlanguage academic achievement, such as in mathematics. The program appears to have minimal effect on language usage, and no effect was found on reading achievement. 


\section{CHAPTER V \\ SUMMARY AND CONCLUSIONS}

\section{SLMMARY}

One of the major purposes of this dissertation was to assess the impact of the PPS district's ESL/bilingual education program. Another purpose was to determine the extent to which time, neighborhood, and personal characteristics explain LEP students' gains in English and other academic subjects.

Chapter I began by examining the broader issues on which ESL/bilingual education has been debated for the past 15 to 20 years. It discussed the growing population of LEP students in the U.S. educational system, and the need for school districts and state educational policy makers to be aware of the implications of this growth. The increasing need, combined with the diminishing financial resources, makes it imperative to evaluate the effectiveness of ESL/bilingual education programs.

Chapter II provided a review of the literature relating to (a) theories and issues relevant to ESL/bilingual education, (b) impact of legislative and judicial actions on ESL/bilingual education, (c) estimating the growing number of LEP children in the school system, and (d) relevant research on the effectiveness of ESL/bilingual education. The third chapter described the methods used to analyze the data. 
Appropriate statistical techniques necessary to deal with the problem of selection bias were presented. Chapter IV presented the empirical findings as they relate to the effectiveness of ESL/bilingual education programs. The final chapter provides a summary and the conclusions of the study.

\section{General Issues on IEP Education}

An increasing number of United States public schools during the 1990s face the challenge of educating LEP students. The challenge has become even greater as the number of LEP students continues to grow in most of the United States (Casas \& Furlong, 1986; Olsen, 1991). There have been efforts during the last 15 years by many educators to establish and implement effective ESL/bilingual education programs for LEP students. However, many practitioners in the field have found that solid empirical evidence evaluating the effectiveness of their ESL/bilingual education programs has been unavailable for use when making decisions affecting instructional practices (Medrano, 1988; Rossell, 1988; Willig, 1985, 1987). The present dissertation is an attempt to provide answers to scme of the most pressing questions regarding the effectiveness of ESL/bilingual education programs in improving LEP students' achievement skills in reading, mathematics, and English language usage. School, neighborhood, and personal characteristics were also included to examine and control for their effects on student achievement. 


\section{Hypotheses}

Several hypotheses were generated regarding school, neighborhood, and personal characteristics as they relate to achievement skills in reading, mathematics, and English language usage. The first set of hypotheses was related to percentage gains in reading achievement. The second set was related to percentage gains in mathematics achievement. The final set was related to percentage gains in English language usage.

Several variables and proxies representing characteristics of the neighborhood, school, and background information were used to explain the academic progress of LEP students in reading, mathematics, and English language usage. The variables representing school-related characteristics were weekly ESL hours, bilingual hours, time in PPS system, student's grade level, percent Southeast Asians per school, and whether the student's school had an ESL/bilingual program. Recent research in this area has shown that school-related characteristics may affect the academic achievement of some LEP students (Krashen \& Biber, 1988; Ramirez, 1986). The variables examined under neighborhood characteristics included percent high school graduate, percent little or no English, percent below poverty level, and neighborhood family size. There may be other important family or personal characteristics that individually may have significant influence on LEP students' academic achievement. Sinœ data on such family factors were not available, proxies for certain neighborhood characteristics were used. Ovando and Collier (1985) have indicated that the amount of social interaction within the daily community with L2 speakers may influence the rate of 
academic achievement of LEP students. In other words, IEP students' neighborhood environment may influence rates of progress in reading, mathematics, and English language usage.

The variables representing personal characteristics included the student's age, home language, gender, race, level of English language proficiency, and language group. These variables may interact to influence the academic progress of LEP students.

The sets of hypotheses mentioned earlier were tested using (a) the PPS district's achievement data, (b) the ESL/bilingual education program's records on background information, and (c) tract data from the 1980 census. The census data were used to identify certain general characteristics of the population in the census tract where a particular student lives. The sample consisted of 1,136 LEP students from a total of 1,223 identified LEP students fram Grades 3 through 8 who were enrolled in the PPS district's ESL/bilingual program in Portland, Oregon.

In analyzing these data, the researcher attempted to address three major concerns. The first was the effectiveness of the PPS district's ESL/bilingual education program. The second concern was control for biases of likely correlations. Finally, the concern about possibility of specification and selection biases was examined. To address these concerns, the methodology suggested by other researchers was used. Wonnacott and Wonnacott (1984), Kennedy (1984) and others have suggested using the instrumental variable technique to solve statistical problems relating to possible biases. The use of the instrumental variable estimation technique is more appropriate to correct biases 
associated with assigning LEP students to ESL/bilingual hours than alternative methods. Since the variables (ESL and bilingual hours) used were contemporaneously correlated with the disturbance term, other variables were found from among the variable list to act as instruments for these regressors. Using these new instruments, predicted values of both ESL and bilingual hours were generated. These new values became the new instrumental variables which were included in the regression models.

\section{SUMMARY FINDINGS FOR ACHIEVEMENT GAINS IN READING, MATHFMATICS, AND LANGUAGE USAGE}

\section{Reading Achievement}

The empirical findings for this study do not show that the PPS district's ESL/bilingual education program is effective in improving its LEP students' reading achievement. None of the regression results for this subject were statistically significant. There may be one or two cases where minor positive impact of ESL was found, but none was statistically significant. After going through all the analysis, the ESL/bilingual characteristics and the estimates of their coefficients changed signs and level of significance (Tables XVII and XVIII and Appendix K). From these results it is difficult to estimate the real impact of the ESL/bilingual program on students' reading achievement.

\section{Mathematics Achievement}

There is ample evidence suggesting that the PPS district's ESL/bilingual education program has been effective in significantly 
increasing the rate of progress that LEP students make in mathematics achievement. The coefficients for predicted values of both bilingual and ESL hours showed positive impacts with achievement gains in mathematics. The two variables were found to have a statistically significant correlation ( $\mathrm{p}<.05$ or better) with mathematics (Tables XIX and $\mathrm{XX})$. The consistent, persistent, positive correlation was found even when different subsets of variables were used in the regression model (Appendix L). With this result, one can confidently say that the ESL/bilingual program is beneficial to the LEP students in increasing their achievement gains in mathematics skills. The stronger, statistically significant ( $\mathrm{p}<.05$ or better) correlation of bilingual hours, in comparison to ESL hours, may indicate that the students' native languages were used, where possible, to explain mathematics concepts. One may conclude from these results that the use of LEP students' native languages is useful in assisting them to increase their academic gains in mathematics.

The finding reported here parallels that of Gonzales (1990, p. iii) and Medrano (1988), who indicate that bilingual education programs seem to be effective in producing superior academic achievement in mathematics. This result also confirms the study by Gersten, Woodward, and Moore (1988) that shows statistically significant effects on mathematics problem solving and mathematics concepts.

On the basis of the analysis presented here, one can conclude that the effectiveness of the Portland (Oregon) Public School district's ESL/bilingual program may not be in language usage and reading but 
in the less intensive language academic subjects as represented by mathematics results.

\section{Language Usage Achievement}

The result for language achievement indicates negative and not statistically significant coeficients for both ESL and bilingual hours in the full and reduced regression models.

On only one occasion (see Table XXIV) were the predicted values of ESL hours statistically significant $(\mathrm{p}<.05)$, which appear to indicate that the ESL/bilingual program had a positive effect on LEP students' language gains. This result is really not as strong as it may appear since in other regression results with different subsets of characteristics (Appendices $\mathrm{K}$ through $\mathrm{M}$ ) both negative and positive coefficients were reported for predicted values of ESL hours. None of the coefficients were statistically significant. With these mixed results, it is difficult to say with certainty, one way or the other, that the ESL/bilingual program is effective in promoting language achievement.

OTHER VARIABLES INCLUDED TO ASSESS THETR INFLUENCE

ON LEP STUDENIS' ACHIEVEMENT

The students' time in PPS was included to assess its influence on LEP students' achievement. The variable was found to have a negative and strong association with mathematics achievement. Because this variable is negative and statistically significant, it may explain why some students with initial language problems are still in ESL/bilingual program while those without leave it. 
Age of the student was examined and found to have a negative correlation and statistically significant coefficients with all subject areas. This result indicates that if an older LEP student enters the PPS system from another country and is placed in a class based on his or her age, the student may be behind academically when compared with the other students of the same age. It is a different situation when a younger student enters the PPS system.

The proportion of students' neighborhood population who are high school graduates and students' grade level were also examined. The first of these variables had a positive and statistically significant correlation with mathematics achievement, indicating there may be other community factors influencing mathematics gains. The grade level was strongly related to language usage gains.

The reader must interpret the results presented here with caution. Although the major variables showed positive and statistically significant effects on the less intensive language subject area, the combined effects of the variables in explaining superiority in achievement gains $\left(R^{2}\right)$ were minimal.

\section{CONCLUSIONS}

At the beginning of this dissertation some major questions were asked regarding LEP students' academic achievement in reading, mathematics, and language usage. The questions are restated here and brief answers provided.

First, is an ESL/bilingual education program an effective approach for improving LEP students' reading, mathematics, and language usage 
achievement? Based upon the data presented here, the ESL/bilingual education program has a strong effect in improving mathematics achievement. The program's effect on language usage is weak, and it appears to have no effect on reading achievement.

second, does the amount of ESL/bilingual instruction influence the academic achievement of LEP students in reading, mathematics, and English language usage? The amount of ESL/bilingual instruction has a positive and strong influence on LEP students' mathematics achievement, minor influence on language usage, and no statistically significant influence on reading.

Third, do the personal background characteristics of LEP students influence their academic gains in reading, mathematics, and English language usage? The age of the student was the personal background characteristic examined here. Age was negatively and strongly correlated with all the subject areas identified here. It has strong influence in explaining LEP students' academic progress.

Fourth, what neighborhood factors influence LEP students' achievement gains in reading, mathematics, and English language usage? The percentage of LEP students' neighborhood population who are high school graduates showed a strong influence on mathematics achievement regardless of what sets of variables were used in the regression equation. The variable showed no effect on reading and language usage.

In summary, the results presented here are not so strong. But the author has demonstrated that the ESL/bilingual education program in the PPS system appears to have some benefits in terms of mathematics and language that simpler statistical techniques tend not to show. This 
technique needs to be applied to a larger sample and more refined estimates. This research has demonstrated that the district's program is likely to have positive impact, but because of the continuing statistical problems and the methods used to address them, confidence in the estimated parameters is not high. This simply indicates that the program is valuable and there is room for more research and direction.

\section{LIMITATIONS OF THE STUDY}

This study was limited in the following areas:

1. The researcher was unable to expand this analysis to include current data. Because the data used in this analysis were fairly old, the researcher had intended to collect current data and, using the same methodology, make a comparison of the ESL/bilingual effectiveness in the two time periods. However, the author was unable to make the comparison for the following reasons: (a) the district now uses different data collection methods; they only indicate whether or not LEP students participated in the program. The data analyzed here showed the actual number of hours; (b) there have been changes in the population characteristics, thus making any meaningful comparison difficult; and (c) inability to collect the neighborhood variables because of the time constraint to finish this project.

2. Relevant family characteristics which may further explain LEP students' academic achievement were not analyzed. The author 
was unable to obtain data on LEP students' parents' educational level, occupation/social econamic status, prior schooling, and literacy in Ll. Other factors such as differences in the LEP students' language groups, their access to support systems from churches and resources fram cammunity organizations when they first settled in the U.S., their prior education in both $\mathrm{L} 1$ and $\mathrm{L} 2$, etc. before coming to the United States are factors that can influence LEP students' academic success. Data on these factors were not available; thus they were not examined. Future studies should include them.

3. The study population used in this investigation came from only one urban school district. The results from this study may not be applicable to other; larger school districts and communities with large populations of LEP speakers.

4. As in most other LEP educational programs, the district's ESL/bilingual education students are reclassified or moved out of the program as they are thought to be sufficiently proficient in oral English or as they reach a certain percentile on a standardized test. This makes the LEP group appear to not perform well because children who know less English always join the group, while the top achievers are pulled into the traditional classroom (Willig, 1985, p. 304 ).

5. The study period was only one academic school year. The time may be too short for LEP students to show significant academic progress. Thus long-term effects of ESL/bilingual education could not be determined. 
6. The Portland Achievement Test used to evaluate the outcome of the data focuses only on academic achievement, i.e., mathematics, reading, and language usage. Other outcome measures are not discussed. Additionally, there may be possible culture bias in the reading achievement tests.

7. This study only analyzed and discussed quantitative effects of ESL/bilingual education; the qualitative characteristics were not examined.

IMPLICATIONS FOR POLICY AND PRACTICE

One of the major objectives of this dissertation was to provide additional empirical data that policy decision makers and practitioners in the field could use in designing, implementing, and refining educational programs for LEP students. Specifically, the question of the effectiveness of the Portland Public School district's ESL/bilingual education program was addressed. Based on the data, the conclusion can be made that program at the PPS district is effective in increasing the rate of LEP students' achievement gains in mathematics.

Some major implications can be drawn from this finding. First, the data seem to indicate that ESL hours have a negative impact on language gains, and a positive and strong effect on less intensive language academic gains. This is a reasonable result, and its implications of a trade-off between language and other subjects discussed. It seems appropriate when an ESL/bilingual education program is designed or refined to include a way to balance raising students' academic 
achievement in reading and language usage, where LEP students are pulled-out, and mathematics and other areas.

Second, the results seem to suggest that using part ESL and part bilingual education to supplement each other is effective in improving the mathematics achievement. From these results one may say that the policy of using the students' native language to further explain academic concepts taught in classrooms is appropriate.

Third, Cummins (1984) and others have suggested that it takes approximately 5-7 years, on the average, for language minority students to approach grade norms in academic aspects of English proficiency and other subjects. Sometimes a student's language abilities may appear sufficient to get along in face-to-face social interactions, but they are often not developed to the point of being able to succeed academically in reading, mathematics, and language usage. In light of these findings, the average of 3.5 years which LEP students spend in the ESL/bilingual program may seem inadequate.

Finally, Milk (1985) suggested that homogeneous grouping leads to relatively little use of the weaker language and consequently works against the student's obtaining appropriate input for second language learning. The district's decision to move from the pull-out ESL/bil ingual program in which LEP students are taken out of their regular classrooms and given special instruction to a self-contained ESL/bil ingual program, where possible, is highly recommended. 
RECOMMENDATIONS FOR FUTURE RESEARCH

At the outset of this project the researcher had proposed to evaluate four variants of ESL/bilingual education programs. The intention was to find which of the four variants (ESL program, bilingual program, bilingual aide, and basic skills) was most effective in educating LEP students. As the project progressed, it became clear that the main program in the PPS system for LEP students was the ESL program. The other aspects of the program were support services, with bilingual hours being the one with enough data worth examining at that time. The lack of useful data on the other variants led the researcher to focus on the effectiveness of the ESL/bilingual education program. Future research should include analysis of bilingual aide and basic skills hours to assess the effectiveness of ESL/bilingual education programs.

A cost-effectiveness analysis of ESL/bilingual education program was first included in this study, but it was later dropped. The researcher had wanted to know whether or not the ESL/bilingual education program was more or less cost-effective than other alternatives in increasing cognitive development of LEP students. A cost-effectiveness study was found to be useful in making policy decisions in the Honolulu, Hawaii school district (Yap, 1988).

For various reasons, the availability of data for the present study was spotty, but more importantly the district was reluctant to release such data. If cost data can be obtained, future research efforts are encouraged to include a cost-effectiveness of ESL/bilingual education program. 
Although the present study has provided information on the effectiveness of the PPS district's ESL/bilingual education program as well as variables associated with increased academic skills, other aspects of the program require further investigation. For example, there is a need to conduct more research on the longitudinal effects of an ESL/bilingual education program (Medrano, 1988; Saldate, Mishra, \& Medina, 1985). What happens to LEP students' academic performance 4 or 5 years after participation in an ESL/bilingual education program?

Future research needs to investigate classroom situations like pullout versus self-contained classes. Presently there are two Newcomers Centers in the Portland Public School district at Vestal Elementary School and Hosford Middle School. These centers have selfcontained ESL/bilingual education programs. It will be necessary for future research to compare the academic performances of the students in the pullout classes with those in the self-contained classes.

Future investigation should be directed to the interdependencies between the student's native language and the second language. Although this has not been a major consideration in this study, it could have an important bearing on a program's effect. For example, do LEP students who maintain their native language have higher or lower academic achievement gains than LEP students who could not maintain their native language?

While not within the scope of the present dissertation, current research has suggested that teachers and parents play a significant role in the academic progress of their language divergent children. More research that examines these variables needs to be conducted. 
The empirical results presented in Chapter IV show that the model used is reasonably adequate, although it does require modifications in light of some findings, particularly the inability to obtain reasonable predicted values of bilingual hours. Additionally, the measure for ESL/bilingual education program effectiveness should not be limited to only academic achievement. It may include such measures as suspension rate, dropout rate, and high school graduation rate. These variables are recommended for inclusion in future research studies.

The present study does not make any generalization that all pullout ESL/bilingual programs are effective. The conclusion pertains to the Portland case only. Mace-Matluck (1986) cautioned against drawing nationwide conclusions from one study, saying, "the notion that ESL/bilingual education programs are the same everywhere is a fallacy" (p. 474). 
REFERENCES

Anderson, J. L. (1990). Acculturation, adaptive behavior performance of children who are culturally and linguistically different (Doctoral dissertation, University of Minnesota, 1990). Dissertation Abstracts International, 51, 1532A.

Anderson, T., \& Boyer, M. (1978). Bilingual schooling in the United States. Austin: National Educational Laboratory.

Averch, H. A., Carroll, S. J., Donaldson, T. S., Kiesling, H. J., \& Pincus, J. (1974). How effective is schooling? A critical review and synthesis of research findings. Englewood Cliffs, $\mathrm{NJ}$ : Educational Technology Publications.

Baker, K. (1987). Comment on Willig"s "A meta-analysis of selected studies in the effectiveness of bilingual education." Review of Educational Research, 57, 351-362.

Baker, K. , \& de Kanter, A. (1981). Effectiveness of bilingual education: A review of the literature. Washington, DC: U.S. Department of Education, Office of Planning, Budget and Evaluation.

Baker, K. , \& Ramirez, D. (1987, April). Becaming a more frequent speaker of a second language: Some effects of program model on LEP students and their teachers. Paper presented at the annual meeting of the American Educational Research Association, Washington, DC.

Bennett, W. (1986). The condition of bilingual education in the nation, 1986: A report from the Secretary of Education to the President and the Congress. Washington, DC: Department of Education.

Bilingual Education Act of 1978. P.L. 95-561 (Nov. 1, 1978), 92 Stat. 2270 .

Bridge, G. (1979). The determinants of educational outcomes. Cambridge, MA: Bullinger.

Brown, R. (1973). A first language: The early stages. Cambridge, MA: Harvard University Press. 
Burnham, L. , \& Pena, M. (1986). Effects of bilingual instruction on English academic achievement of LEP students. Baldwin Park, CA: Baldwin Park Unified School District.

California State Department of Education. (1982). Basic principles for the education of language minority students: An overview. Sacramento, CA: Author.

Cardenas, J. (1986, January). The role of native language instruction in bilingual education. Phi Delta Kappan, 67, 359-363.

Casas, J., \& Furlong, M. (1986). In search of an understanding and a responsible resolution to the Mexican-American educational dropout problem. California Public Schools Forum, 1, 45-63.

Chamot, A. (1988). Bilingualism in education and bilingual education: The state of the art in the United States. Joumal of Multilinqual and Multicultural Development, $9,11-35$.

Chung, H. (1988). The language situation of Vietnamese Americans. In S. McKay \& S. Wong (EdS.), Language diversity: Problem or resource? (pp. 272-292). Cambridge, MA: Newbury House.

Coleman, J., Campbell, E., Hobson, C., McPortland, J., Mood, A., Weinfield, F., \& York, R. (1966). Equality of educational opportunity. Washington, DC: U.S. Department of Health, Education and Welfare.

Collier, V. (1987). Age and rate of acquisition of second language for academic purposes. TESOL Quarterly, 21, 617-641.

Cramer, J. (1971). Empirical econometrics. Amsterdam: North Holland.

Crandall, J. (1983). Equity from the bilingual education specialist's perspective. Washington, DC: Office of Vocational and Adult Education.

Crawford, J. (1987). Bilingual Education: In center of research and policy debates. Education Week, $6(27), 19-20$.

Cummins, J. (1979a). Cognitive academic language proficiency, linguistic interdependence, the optimal age question, and some other matters. Working Papers on Bilingualism, 19, 197-205.

Cummins, J. (1979b). Linguistic interdependence and the educational development of bilingual children. Review of Educational Research, $\underline{49}, 2$. 
Cummins, J. (1981). The role of primary language development in promoting education success for language minority students. In California State Department of Education, Schooling and language minority students: A theoretical framework (pp. 3-49). Los Angeles: California State University, Evaluation, Dissemination and Assessment Center.

Cumins, J. (1984). Bilingualism and special education: Issues in assessment and pedagogy. San Diego: College Hill.

Cummins, J. (1986). Empowering minority students: A framework for intervention. Harvard Educational Review, 56, 18-36.

Cummins, J. (1987). Bilingual education and politics. Educational Digest, 53, 30-33.

Cummins, J., \& Skutnabb-Kangas, T. (Eds.). (1988). Introduction. In T. Skutnabb-Kangas \& J. Cumins (Eds.), Minority education: From shame to struggle (pp. 1-6). Philadelphia: Multilingual Matters.

Cummins, J., \& Swain, M. (1986). Bilingualism in education: Aspects of theory, research and practice. London: Longman.

Curtain, H., \& Pesola, C. (1988). Ianguage and children: Making the match. Reading, MA: Addison-Wesley.

Danoff, M., Coles, G., McLaughlin, D., \& Reynolds, D. (1978). Evaluation of the impact of ESEA Title VI Spanish/English bilingual educational programs: Vol. III. Year two impact data. Palo Alto, CA: American Institutes for Research.

del Valle, M. (1981). Hispanics' language rights and due process. New York Law Journal, 186, 1-2.

Dulay, H., \& Burt, M. (1973). Should we teach children syntax? Language Learning, 23, 235-252.

Durgan, D. (1991, October). [Informal personal interview, ESt/bilingual Education Office, Portland Public School, Portland, Oregon.]

Durgan, D. (1992, December). [Informal personal interview, ESL/bilingual Education Office, Portland Public School, Portland, Oregon.]

Economic Opportunity Act of 1964. P.L. 88-452. 78 Stat. 508. 
English Language Consultants. (1988). A summary of State reports on the limited English proficient student population: A description of the number and educational condition of IFP students and the programs serving them. [Title VII states Surmary for School Year 1986-87.] Washington, DC: Office of Bilingual Education and Minority Languages Affairs.

Fathman, A. (1975). The relationship between age and second language productivity. Language Learning, 25, 245-253.

Fathman, A. (1976). Variables affecting the successful learning of English as a second language. TESOL Quarterly, 10, 433-441.

Fishman, J. (1976). Bilingual education: An international sociological perspective. Rowley, MA: Newbury House.

Geffert, H., Harper, R., II, Sarmiento, S., \& Schember, D. (1975). The current status of U.S. bilingual legislation (Bilingual Education Series: 4). Arlington, VA: Center for Applied Linguistics.

Gersten, R., Taylor, R., Woodward, J., \& White, W. (1984, April). Structured English immersion for Hispanic students in the U.S.: Findings from a 14-year evaluation of Uvalde, Texas program. Paper presented at the annual meeting of the American Education Research Association, New Orleans, LA.

Gersten, R., \& Woodward, J. (1985). A case for structured immersion. Educational Leadership, 43, 75-79.

Gersten, R., Woodward, J., \& Moore, L. (1988). Alternative educational models for language minority students: Research on structured immersion. Equity and Excel lence, 23, 14-16.

Glazer, N. (1974). Ethnicity and the schools. Commentary, 58, 59-67.

Goldberger, A. (1964). Econametric theory. New York: John Wiley.

Gonzales, L. (1990). Effectiveness of bilingual education: A quasiexperimental comparison of instructional approaches in an elementary school district (Doctoral dissertation, Claremont Graduate School and San Diego State University, 1990). Dissertation Abstracts International, 51, 68A.

Gonzales, R., Schott, A., \& Vasquez, V. (1988, March). The English language amendment: Examining myths. English Journal, pp. 24-30.

Gray, T., Convery, H. , \& Fox, K. (1981). The current status of bilingual education legislation: An update (Bilingual Education Series: 9). Washington, DC: Center for Applied Linguistics. 
Hakuta, K. (1985, September). Generalizations from research in second language acquisition and bilingualism. Testimony presented before the House Education and Labor Committee, Washington, DC.

Hakuta, K. (1986). Mirror of language: The debate on bilingualism. New York: Basic Books.

Hakuta, K., \& Gould, L. (1987). Synthesis of research on bilingual education. Educational Leadership, 44, 38-45.

Harlan, J. (1991). Bilingualism in the United States: Conflict and controversy. New York: Moffa.

Heckman, J. (1990). Selectivity bias: New developments. American Economic Review, $80,313$.

Hernandez-Chavez, E. (1978). Language maintenance, bilingual education, and philosophies of bilingualism in the United States. In J. Alatis (Ed.), Georgetown University round table on languages and linguistics (pp. 527-550). Washington, DC: Georgetown University Press.

Hernandez-Chavez, E. (1984). Inadequacy of English immersion education as an educational approach for language minority students in the U.S. In California State Department of Education (Ed.), Studies in immersion education (pp. 144-183). Sacramento, CA: California State Department of Education.

Hooker, C. (1978). Issues in school desegregation litigation. In C. Hooker (Ed.), The courts and education (pp. 84-115). Chicago: University of Chicago Press.

Huffman, P. (1980). Findings of a seminar on the cost of bilingual education. Santa Monica: The Rand Corporation.

Huffman, P., \& Samulon, M. (1981). Case Studies of delivery and cost of bilingual education. Santa Monica: The Rand Corporation.

Jensen, A. (1969). How can we boost IQ and scholastic achievement? Harvard Educational Review, 39, 1.

Johnson, D. (1983). Natural language learning by design: A classroom experiment in social interaction and second language acquisition. TESOL Quarterly, 17, 55-68.

Johnston, J. (1984). Econometric methods. New York: McGraw-Hill.

Judd, E. (1987). The English language amendment: A case study on language and politics. TESOL Quarterly, 21, 113-133. 
Kamm, M. (1988). A comparative investigation of the effects of ESI instruction, transitional bilingual education (TBE) and English submersion upon English language proficiency and achievement of LEPP students (Doctoral dissertation, Loyola University of Chicago, 1987). Dissertation Abstracts International, 49, $02 \mathrm{~A}$.

Karski, J. (1987). Bilingualism and education in the United States: A resource quide. New York: U.S. Department of Education. (ERIC Document Reproduction Service No. ED 288 355)

Kennedy, P. (1984). A guide to econometrics. Cambridge: The MIT Press.

Kleinmann, H. (1982). External influences and their neutralization in second language acquisition: A look at Indochinese refugees. TESOL Quarterly, 16, 239-244.

Kleven, T. (1988). Cultural bias and the issue of bilingual education. Social policy, 19(4), 9-15.

Krashen, S., \& Biber, D. (1988). On course: Bilingual education's success in California. Sacramento, CA: California Association for Bilingual Education.

Krashen, S., Long, M., \& Scarcella, R. (1979). Age, rate and eventual attainment in second language acquisition. TESOL Quarterly, 13 , 573-582.

Kuhn, T. (1971). The structure of scientific revolutions. Chicago: University of Chicago Press.

Lansing, J., \& Morgan, J. (1977). Economic survey methods. Ann Arbor: University of Michigan, Institute for Social Research.

Lamouth, D. (1987). Does Iinguistic heterogeneity erode national unity? In W. Van Horne \& T. Tonnesen (Eds.), Ethnicity and language (pp. 37-57). Milwaukee, WI: University of Wisconsin System Institute on Race and Ethnicity.

Lau v. Nichols, 414 U.S. 566 (1974).

Long, M. (1983). Does second language instruction make a difference? A review of research. TESOL Quarterly, 17, 359-382.

Long, M. , \& Crookes, G. (1992). Three approaches to task-based syllabus design. TESOL Quarterly, 26, 27-35.

Mace-Matluck, B. (1986). New study supports bilingual programs using child's native language. Phi Delta Kappan, 67, 474. 
Macia, R. (1979). Language choice and human rights in the United States. In J. Alatis \& G. Tucker (Eds.), Language in public life: Georgetown round table on languages and linguistics 1979 (pp. 86101). Washington, DC: Georgetown University Press.

Maddala, G. (1977). Econometrics. New York: McGraw-Hill.

Madrid, A. (1990). Official English: A false policy issue. The Annals of the American Acadermy of Political and Social Science, 508, 62 .

Marshall, D. (1986). The question of an official language: Language rights and the English language amendment. International Journal of the Sociology of Language, $60,7-25$.

Mackey, W. , \& Beebe, V. (1977). Bilingual schools for a bicultural community. Rowley, MA: Newbury House.

Multnomah County (OR) County Auditor. (1991). Ballot measure 5: Tax Savings for property owners. Portland, OR: Author.

McGroarty, M. (1988). Second language acquisition theory relevant to language minorities: Cunmins, Krashen, and Schumann. In S. McKay \& S. Wong (Eds.), Language diversity: Problem or resource? (pp. 295-337). Cambridge, Newbury House.

McKay, S. (1988). Weighing educational alternatives. In S. McKay \& S. Wong (Eds.), Ianguage diversity: Problem or resource? (pp. 338-366). Cambridge: Newbury House.

MCKay, S., \& Freedman, S. (1990). Language minority in Great Britain: A chal lenge to current U.S. policy. TESOL Quarterly, 24, 385-404.

McLaughlin, B. (1985). Second language acquisition in childhood: Vol. 2. School age children. Hillsdale, NJ: Lawrence ErIbaum Associates.

Medrano, M. (1988). The effects of bilingual education on reading and mathematics achievement: A longitudinal case study. Equity and Excellence, 23, 17-19.

Michelson, S. (1970). Do teachers make a difference? Washington, DC: Office of Education, Bureau of Education Personnal Department.

Milk, R. (1982). Language use in bilingual classrooms: Two case studies. In M. Hines \& W. Rutherford (Eds.), On TESOL '81 (pp. 181-191). Washington, DC: TESOL.

Milk, R. (1985). The changing role of ESL in bilingual education. TESOL Quarterly, 19, 657-672. 
Molesky, J. (1988). Understanding the American Iinguistic mosaic: A historical overview of language maintenance and language shift. In S. McKay \& S. Wong (Eds.), Lanquage diversity: Problem or resource? (pp. 29-68). Cambridge: Newbury House.

Moore, F., \& Parr, G. (1978). Models of bilingual education: Comparisons of effectiveness. The Elementary Journal, 79, 93-97.

Northcutt, L., \& Watson, D. (1986). Sheltered English training handbook. Carlsbad, CA: BINET.

Ogbu, J. (1982). Cultural discontinuities and schooling. Anthropology and Education Quarterly, 13, 290-307.

Ogbu, J., \& Matute-Bianchi, M. (1986). Understanding sociocultural factors: Knowledge, identity and school adjustment. In California State Department of Education (Ed.), Beyond language: Social and cultural factors in schooling language minority students (pp. 73-142). Los Angeles: University of California, Evaluation, Dissemination and Assessment Center.

Olsen, R. (1989). A survey of limited English proficient student enrol lments and identification criteria. TESOL Quarterly, 23, 469-488.

Olsen, R. (1991). Report of the 1991 LEP student enrollment survey. San Francisco: U.S. Department of Education. (ERIC Document Reproduction Service No. ED 335 907)

Orfield, G. (1986, November). Hispanic education: Challenges, research and policies. American Journal of Education, pp. 1-25.

Ovando, C., \& Collier, V. (1985). Bilingual and ESL classrooms: Teaching in multicultural contexts. New York: McGraw-Hill.

Oxford, R., Pol, L., Lopez, D. , Stupp, P., Gendell, M. , \& Peng, S. (1981). Projections of non-English language background and limited English proficient persons in the United States to the year 2000: Educational planning in the demographic context. NABE Journal, $5,1-30$.

Padilla, A. (1980). Acculturation: Theory, models and some new findings. AAAS Symposium Series 39. Boulder, CO: Westview.

Paulston, C. B. (1978). Bilingual/bicultural education. In L. Shulman (Ed.), Review of research in education (pp. 37-55). Washington, DC: Peacock and American Educational Research Association.

Paulston, C. B. (1980). Bilingual education: Theories and issues. Rowley, MA: Newbury House. 
Paulston, R. G. (1976). Conflicting theories of social and educational change: A typological review (Monograph). Pittsburgh University, PA: University Center for International Studies. (ERIC Document Reproduction Service NO. ED 130 921)

Pearson, C. (1988). Cognitive differences between bilingual and monolingual children on Kauffman Assessment Battery for Children. Journal of Psychoeducational Assessment, 6, 271-279.

Perl, L. (1973). Family background, secondary school expenditure, and student ability. Journal of Human Resources, $\underline{8}$, 156-180.

Phi Delta Kappan. (1986). New study supports bilingual programs using child's native language. Phi Delta Kappan, 67, 474.

Portland Public Schools ESL/bilingual Education Department. (1983). Initial identification and assessment of flow chart of English proficiency test. ESL/bilingual staff handbook: 1982-83 school year (pp. 1-2). Portland, OR: Portland Public Schools.

Portland Public Schools ESL/bilingual Education Department. (1991). ESL/bilingual staff handbook: 1990-91 school year. Portland, OR: Portland Public Schools.

Ramirez, D., Yuen, S., \& Ramey, D. (1991). Executive summary, final report: Longitudinal study of structured English immersion strategy, early-exit and late-exit transitional bilingual education programs for language-minority children. San Mateo, CA: Aguirre International.

Ramirez, J. (1986). Comparing structured English immersion and bilingual education: First-year results of a national study. American Journal of Education, 95, 122-148.

Ravitch, D. (1986). Letter to U.S. General Accounting Office. In U.S. General Accounting office (Ed.), Bilingual education: A new look at the research evidence (p. 74). Washington, DC: U.S. Government Printing Office.

Reder, S. (1981, April). A Hmong conmunity's acquisition of English. Paper presented at the Hmong Research Conference, University of Minnesota, Northwest Regional Educational Laboratory, Portland, OR.

Roman, I. (1987). A study of bilingual education in the United States and related national laws, issues, and problems (Doctoral dissertation, Boston College, 1986). Dissertation Abstracts International, 47(11), P4004-A. 
Rossell, C. (1988). The problem with bilingual research: A critique of the Walsh and Carballo study of bilingual education projects. Equity and Excellence, 23, 25-29.

Rotberg, I. (1982). Some legal and research considerations in establishing federal policy in bilingual education. Harvard Educational Review, 52, 149-168.

Rotberg, I. (1984). Bilingual education policy in the United States. Prospects, 14 (I), 133-147.

Ruiz, R. (1988). Orientations in language planning. In S. MCKay \& S. Wong (Eds.), Language diversity: Problem or resource? (pp. 3-25). Cambridge: Newbury House.

Saldate, M., Mishra, S., \& Medina, M. (1985). Bilingual instruction and academic achievement: A longitudinal study. Journal of Instructional Psychology, 12(1), 24-30.

Schumann, J. (1978). The acculturation model for second language acquisition. In R. Gingras (Ed.), Second language acquisition and foreign language teaching (pp. 27-50). Arlington, VA: Center for Applied Linguistics.

Schumann, J. (1986). Research on the acculturation model for second language acquisition. Journal of Multilingual and Multicultural Development, $7,379-392$.

Skutnabb-Kangas, T. (1981). Guest worker or immigrant: Different ways of reproducing an underclass. Journal of Multilingual and Multicultural Development, 2 , 89-113.

Skutnabb-Kangas, T. (1988). Multilingualism and the education of minority children. In T. Skutnabb-Kangas \& J. Curmins (Eds.), Minority education: From shame to struggle (pp. 9-44). Philadelphia: Multilingual Matters.

Smith, M., \& Heflin, J. (1988, April). An analysis of ESL/bilingual education policy in Oregon school districts. Paper presented at the annual meeting of the American Educational Research Association, New Orleans.

Snow, C. (1986). The development of definitional skill. Cambridge, MA: Harvard University Press.

Spener, D. (1988). Transitional bilingual education and the socialization of immigrants. Harvard Educational Review, 58, 133-153.

Stacy, G. , \& Iutton, w. (1985). The immigration time bomb. Alexandria, VA: The American Immigration Control Foundation. 
Stalker, J. (1988). Official English or English only. English Journal, $\underline{77(3), 18-23 .}$

Strouse, J. (1988). Immigration and education policy in the United States. NABE Journal, 12, 113-132.

Sugai, G. (1988). Educational assessment of the culturally diverse and behavior disordered student: An examination of critical effect. In A. Ortiz \& B. Ramirez (Eds.), Schools and the culturally diverse exceptional student: Promising practices and future directions (pp. 63-75). Reston, VA: The Council for Exceptional children.

Teitelbaum, H., \& Hiller, R. (1977). Bilingual education: The legal mandate. Harvard Educational Review, 47, 138-170.

Theil, H. (1957). Specification errors and the estimation of economic relationships. Review of International Statistical Institute, 25, $41-51$.

U.S. Department of Health, Education, \& Welfare. (1975). Task-force findings specifying remedies available for eliminating past educational practices ruled unlawful under Lau v. Nichols. Washington, DC: Office for Civil Rights.

U.S. General Accounting Office. (1987, March). Bilingual education: A new look at the research evidence. GAO briefing report to the chaiman, Committee on Education and Labor, House of Representatives. Washington, DC: Author.

Valdes, G. (1988). The language situation of Mexican Americans. In S. McKay \& S. Wong (Eds.), Language diversity: Problem or resource? (pp. 111-139). Cambridge: Newbury House.

Vargas, A. (1986). Bilingual education: The need for reform. PIA Today, 2 , 24-25.

Vomin, T. (1.981, January). Adjustment problems of Indochinese refugee students. Paper presented at seattle school district's policy analysis seminar, seattle, WA.

Waggoner, D. (1986). Estimates on the need for bilingual education and the proportion of children in need being served. NABE NewS, 9, 6-9.

Walsh, C. \& Carballo, E. (1986). Transitional bilingual education in Massachusetts: A preliminary study of its effectiveness. Boston: Massachusetts Department of Education, Bureau of Transitional Bilingual Education. 
Westell, A. (1981, August 2). Is the United States becoming a multilingual land? The Boston Globe, pp. B54, 60.

Westlander, D., \& Stephany, G. (1983). Evaluation of an English as a second language program for Southeast Asian students. TESOL Quarterly, 17, 473-481.

Willig, A. C. (1981-1982). The effectiveness of bilingual education: Review of a report. NABE Journal, $\underline{6}, 1-19$.

Willig, A. C. (1985). A meta-analysis of selected studies on the effectiveness of bilingual education. Review of Educational Research, 55, 269-317.

Willig, A. C. (1987). Examining bilingual education research through meta-analysis and narrative review: A response to Baker. Review of Educational Research, 57, 363-376.

Wonnacott, T., \& Wonnacott, R. (1984). Introductory statistics for business and economics (3rd ed.). New York: John Wiley \& Sons.

Wong, S. (1988). Educational rights of language minorities. In S. McKay \& S. Wong (Eds.), Language diversity: Problem or resource? (pp. 367-386). Cambridge, Newbury House.

Yap, K. (1988, April). SLEP student achievement: Same pertinent variables and policy implications. Paper presented at the Annual Meeting of the American Educational Research Association, New Orleans.

Yates, J., \& Ortiz, A. (1983). Baker and de Kanter review: Inappropriate conclusions of the efficacy of bilingual education. NABE Journal, $7,75-84$. 
APPENDIX A

PRIMARY LANGUAGES OF ESL/BILINGUAL STUDENTS, PORTLAND PUBLIC SCHOOLS, 1990-1991 


\begin{tabular}{|c|c|c|c|}
\hline Language & ESL/Bil. & Language & $\mathrm{ESL} / \mathrm{Bi}$. \\
\hline American Indian & 0 & Mandarin (Vietnam) & 5 \\
\hline Amharic & 4 & Mien & 129 \\
\hline Arabic & 12 & Norwegian & 1 \\
\hline Armenian & 0 & Pashtu & 2 \\
\hline Cambodian & 87 & Persian & 4 \\
\hline Cantonese (China) & 107 & Polish & 9 \\
\hline Cantonese (Vietnam & 31 & Portuguese & 8 \\
\hline Chau Chu & 1 & Romanian & 89 \\
\hline Czechoslovakian & 2 & Romany (Gypsy) & 1 \\
\hline Danish & 0 & Russian & 538 \\
\hline Dari & 1 & Samoan & 5 \\
\hline Dutch & 0 & Serbo-Croatian & 0 \\
\hline English & 20 & Spanish & 399 \\
\hline Fijian & 3 & Swedish & 1 \\
\hline Finnish & 0 & Tagalog (Phil.) & 25 \\
\hline French & 1 & Thai & 7 \\
\hline German & 0 & Tigrinya & 8 \\
\hline Greek & 1 & Turkish & 1 \\
\hline Hebrew & 1 & Ukranian & 27 \\
\hline Hindi & 17 & Urdu (Pakistan, India) & 0 \\
\hline Hmong & 122 & Vietnamese & 689 \\
\hline Hungarian & 1 & Vietnamese Chinese & 30 \\
\hline Italian & 1 & Other Languages & 19 \\
\hline Japanese & 17 & Other African Languages & 7 \\
\hline Korean & 28 & Other Indian Languages & 1 \\
\hline Lao & 156 & Other Pacific Isl. & 12 \\
\hline Malay Indonesian & 1 & Other Slavic Languages & 0 \\
\hline Mandarin (China) & 18 & Missing & 173 \\
\hline Mandarin (Cambodia) & 0 & TOTATS & 2,822 \\
\hline
\end{tabular}

Note: From Portland Public Schools ESL/Bilingual Staff Handbook, 19901991 (p. 2). 
APPENDIX B

PRIMARY LANGUAGE OF ESL/BIIINGUAL STUDENTS, PORTLAND PUBLIC SCHOOLS, 1982-1983 
1. American Indian

2. Amharic

3. Arabic

4. Armenian

5. Bengali

6. Burmese

7. Cambodian

8. Cantonese Chinese

9. Cantonese Vietnamese

10. Chau Chu

11. Czechoslovakian

12. Danish

13. Dari

14. Dutch

15. English

16. Fijian

17. Finnish

18. French

19. German

20. Greek

21. Hebrew

22. Hindi

23. Hmong

24. Hungarian

25. Ilocano (Philippines)

26. Italian

27. Japanese

28. Korean

29. Lao
30. Malay (Indonesian)

31. Mandarin Chinese

32. Mandarin Cambodian

33. Mandarin Vietnamese

34. Mien

35. Norwegian

36. Pashtu

37. Persian

38. Polish

39. Portuguese

40. Romanian

41. Romany (Gypsy)

42. Russian

43. Samoan

44. Serbo-Croatian (Yugoslavian)

45. Slovak

46. Slovian (Yugoslavian)

47. Spanish

48. Swedish

49. Tagalog (Philippines)

50. Thai

51. Tigrinya

52. Turkish

53. Ukranian

54. Urdu (Pakistan, India)

55. Vietnamese

56. Vietnamese Chinese

57. Yiddish

58. Others

Note: Adapted from the Portland Public Schools ESL/Bilingual Staff Handbook, 1982-1983 (p. 4). 
APPENDIX C

1983 PERCENT OF SOUTHEAST ASIAN ENROLIMENT PER TOTAL SCHOOL POPULATION 


\begin{tabular}{ccc}
\hline School Asian & Total & Percent Asian \\
\hline
\end{tabular}

Elementary and Middle

\begin{tabular}{|c|c|c|c|}
\hline Abernethy & 74 & 354 & 20.9 \\
\hline Ainsworth & 15 & 474 & 3.2 \\
\hline Alameda & 12 & 649 & 1.9 \\
\hline Applegate & 19 & 230 & 8.3 \\
\hline Arleta & 26 & 436 & 6.0 \\
\hline Astor & 11 & 415 & 2.7 \\
\hline Atkinson & 44 & 368 & 12.0 \\
\hline Ball & 11 & 233 & 4.7 \\
\hline Beach & 50 & 586 & 8.5 \\
\hline Beaumont & 19 & 649 & 2.9 \\
\hline Binnemead & 51 & 609 & 8.4 \\
\hline Boise $\mathrm{BCBC}$ & 20 & 157 & 12.7 \\
\hline Bridger & 19 & 219 & 8.7 \\
\hline Bridlemile & 32 & 486 & 6.6 \\
\hline Brooklyn & 14 & 157 & 8.9 \\
\hline Buckman & 54 & 348 & 15.5 \\
\hline Capitol Hill & 13 & 321 & 4.1 \\
\hline Chapman & 3 & 332 & 0.9 \\
\hline Chief Joseph & 11 & 353 & 0.3 \\
\hline Clarendon & 18 & 369 & 4.9 \\
\hline Clark & 22 & 416 & 5.3 \\
\hline Creston & 27 & 378 & 7.1 \\
\hline Duniway & 18 & 369 & 4.9 \\
\hline Edwards & 4 & 266 & 0.4 \\
\hline Eliot ECEC & 17 & 604 & 2.8 \\
\hline Faubion & 15 & 334 & 4.5 \\
\hline Fernwood & 24 & 528 & 4.6 \\
\hline George & 107 & 531 & 20.0 \\
\hline Glencoe & 24 & 454 & 5.3 \\
\hline Glenhaven & 118 & 250 & 47.2 \\
\hline Gray & 18 & 542 & 4.0 \\
\hline Gregory Heights & 50 & 551 & 9.1 \\
\hline Grout & 45 & 367 & 12.2 \\
\hline Hayhurst & 10 & 383 & 2.6 \\
\hline Hollyrood & 5 & 200 & 2.5 \\
\hline
\end{tabular}


(continued)

\begin{tabular}{|c|c|c|c|}
\hline School & Asian & Total & Percent Asian \\
\hline Hosford & 93 & 669 & 13.9 \\
\hline Humboldt ECEC & 12 & 514 & 2.3 \\
\hline Irvington $\mathrm{ECEC}$ & 21 & 539 & 3.9 \\
\hline James John & 54 & 470 & 11.5 \\
\hline Kellogg & 51 & 602 & 8.5 \\
\hline Kelly & 10 & 605 & 1.7 \\
\hline Kenton & 16 & 302 & 5.3 \\
\hline King ECEC & 12 & 629 & 1.9 \\
\hline Lane & 18 & 421 & 4.2 \\
\hline Laurelhurst & 51 & 424 & 12.0 \\
\hline Lee & 16 & 394 & 4.1 \\
\hline Lent & 39 & 415 & 9.4 \\
\hline Lewis & 16 & 297 & 5.4 \\
\hline Llewellyn & 29 & 455 & 6.4 \\
\hline Maplewood & 5 & 281 & 1.8 \\
\hline Markham & 19 & 561 & 3.4 \\
\hline Marysville & 16 & 383 & 4.2 \\
\hline Meek̂k & 40 & 297 & 13.5 \\
\hline Metro. Learning Center & 6 & 248 & 2.4 \\
\hline Mt. Tabor & 30 & 502 & 6.0 \\
\hline Ockley Green & 55 & 674 & 8.2 \\
\hline Peninsula & 6 & 465 & 1.3 \\
\hline Portsmouth & 21 & 380 & 5.5 \\
\hline Rice & 84 & 157 & 53.5 \\
\hline Richmond & 30 & 326 & 9.2 \\
\hline Rieke & 10 & 138 & 7.2 \\
\hline Rigler & 79 & 471 & 16.8 \\
\hline Rose City Park & 53 & 497 & 10.7 \\
\hline Sabin $B C B C$ & 4 & 582 & 0.7 \\
\hline Scott & 41 & 453 & 9.1 \\
\hline Sellwood & 58 & 533 & 10.9 \\
\hline Sitton & 11 & 485 & 2.3 \\
\hline Smith & 12 & 320 & 3.8 \\
\hline Stephenson & 8 & 364 & 2.2 \\
\hline Sunnyside & 47 & 333 & 14.1 \\
\hline
\end{tabular}


(continued)

\begin{tabular}{|c|c|c|c|}
\hline School & Asian & Total & Percent Asian \\
\hline Vernon $\mathrm{BCBC}$ & 25 & 586 & 4.3 \\
\hline Vestal & 52 & 346 & 15.0 \\
\hline West Sylvan & 10 & 501 & 2.0 \\
\hline Whitaker & 82 & 978 & 8.4 \\
\hline Wilcox & 30 & 187 & 16.0 \\
\hline Woodlawn & 13 & 488 & 2.7 \\
\hline Woodmere & 7 & 205 & 3.0 \\
\hline Woodstock & 34 & 486 & 7.0 \\
\hline Youngston & 10 & 166 & 6.0 \\
\hline \multicolumn{4}{|l|}{ TOTAL ELEMENTARY AND } \\
\hline MIDDLE SCHOOLS & 2,367 & 33,445 & 7.1 \\
\hline \multicolumn{4}{|l|}{ Secondary } \\
\hline Benson & 147 & 1,583 & 9.3 \\
\hline Cleveland & 218 & 1,395 & 15.6 \\
\hline Frankl in & 162 & 1,501 & 10.8 \\
\hline Grant & 140 & 1,756 & 7.9 \\
\hline Jefferson & 98 & 1,427 & 6.9 \\
\hline Lincoln & 101 & 1,385 & 7.3 \\
\hline Madison & 289 & 1,561 & 18.5 \\
\hline Marshall & 102 & 1,190 & 8.6 \\
\hline Roosevelt & 114 & 1,142 & 9.9 \\
\hline Wilson & 61 & 1,880 & 3.2 \\
\hline TOTAL SECONDARY SCHOOLS & 1,432 & 14,820 & 9.7 \\
\hline
\end{tabular}


APPENDIX D

1982-1983 LANGUAGE, READING, AND MATHEMATICS GOALS

FOR PORTIAND ACHIEVEMENT IEVETS TESTS 
Goals

Language

Reading

Mathematics
1. The student can recognize and use fundamental sentence and paragraph structure.

2. The student can use basic grammar correctly.

3. The student can punctuate correctly.

4. The student can capitalize correctly.

5. The student can spell correctly.

6. The student can write with coherence, clarity, economy, and consistency.

1. The student can interpret meanings of commonly used words.

2. The student can comprehend the literal meaning or explicit content of written materials.

3. The student can interpret implied and related meanings from the content and presentation of written materials.

4. The student can evaluate the intent, validity, and worth of written materials.

1. The student can add whole numbers.

2. The student can subtract whole numbers.

3. The student can multiply whole numbers.

4. The student can divide whole numbers.

5. The student can order, compare, rename, and represent whole numbers.

6. The student can order, compare, rename, and represent functional numbers (fractions, decimals, and percents).

7. The student can compute with fractions.

8. The student can compute with decimals and percents.

9. The student can use knowledge of geometry.

10. The student can use knowledge of measurement.

11. The student can interpret and use graphs, statistics, and probability.

12. The student can solve story (word) problems.

13. The student can use the strategies and processes of problem solving. 
APPENDIX E

FIOW CHART OF IDENTIFICATION, ENROLLMENT AND

ASSESSMENT OF ALL CHIIDREN WITH HOME

LANGUAGE OTHER THAN ENGLISH 


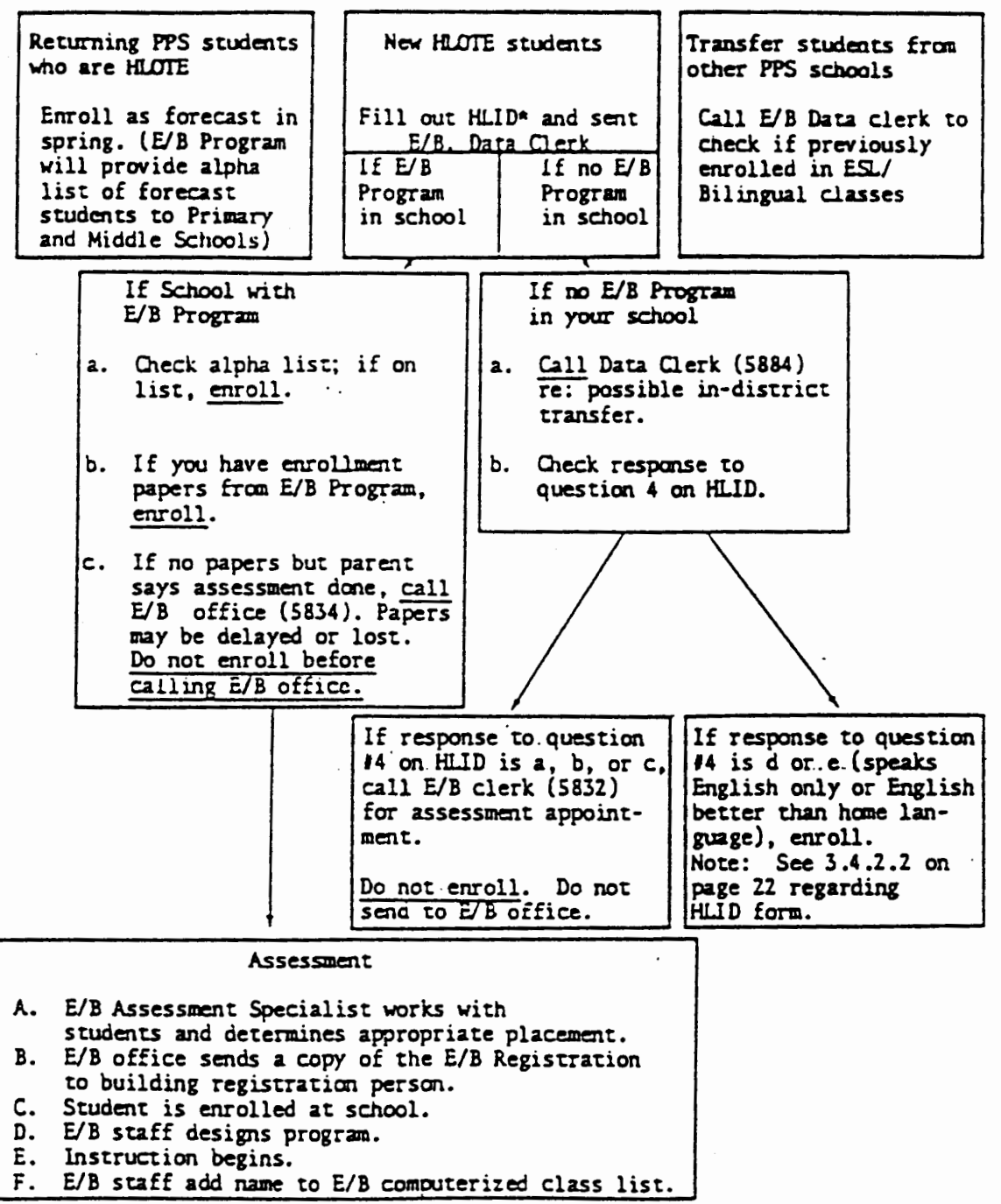

Hone Language Identification form (HLID)

Acronyms

HLOTE: Abbreviation for Home Language Other Than English

HLID: Home Language Identification Form

SDT: Student Data Transfer: The Portland Public Schools' Registration Form 
APPENDIX $F$

PERCENT TOTAL HIGH SCHOOI, SOUTHEAST ASIAN STUDENTS

BY CITY IOCATION DURING 1982-1983 SCHOOL YEAR 
Percent Southeast

High School Asian

City Location

\begin{tabular}{lrl} 
Benson & 9.3 & Northeast \\
Cleveland & 16.0 & Southeast \\
Franklin & 11.0 & Southeast \\
Grant & 7.9 & Northeast \\
Jefferson & 6.9 & North \\
& 7.3 & \\
Lincoln & 18.5 & Southwest \\
Madison & 8.6 & Northeast \\
Marshall & 9.9 & Southeast \\
Roosevelt & 3.2 & North \\
Wilson & & Southwest \\
\hline
\end{tabular}


APPENDIX G

AGE DISTRIBUTION OF STUDENTS IN THE STUDY 


\begin{tabular}{|c|c|c|}
\hline Age in Years & Percent & $\underline{\mathrm{n}}$ \\
\hline 8 & .1 & 1 \\
\hline 9 & 10.3 & 117 \\
\hline 10 & 15.1 & 171 \\
\hline 11 & 15.1 & 171 \\
\hline 12 & 13.6 & 154 \\
\hline 13 & 14.2 & 161 \\
\hline 14 & 13.6 & 155 \\
\hline 15 & 6.5 & 74 \\
\hline 16 & 2.8 & 32 \\
\hline 17 & 3.3 & 37 \\
\hline 18 & 2.4 & 27 \\
\hline 19 & 1.5 & 17 \\
\hline 20 & 1.4 & 16 \\
\hline 21 & .3 & 3 \\
\hline TOTAL & 100.0 & 1,136 \\
\hline
\end{tabular}


APPENDIX $\mathrm{H}$

PERCENT DISTRIBUTION OF STUDY

POPULATION BY GRADE LEVEUS 


\begin{tabular}{ccc}
\hline Grade Level & Percent & $\underline{\mathrm{n}}$ \\
\hline 3 & 15.1 & 172 \\
4 & 15.4 & 175 \\
5 & 14.1 & 164 \\
6 & 14.0 & 159 \\
7 & 14.8 & 168 \\
8 & 12.9 & 146 \\
9 & 4.3 & 49 \\
10 & 4.4 & 50 \\
11 & 4.7 & 53 \\
\hline TOTAL & 100.0 & 1,136 \\
\hline
\end{tabular}


APPENDIX I

DISTRIBUTION OF STUDENTS BY THEIR

LEVEU OF ENGLISH PROFICIENCY 


\begin{tabular}{lcr}
\hline \multicolumn{1}{c}{ Level of Proficiency } & Percent & $\underline{\mathrm{n}}$ \\
\hline $\begin{array}{l}\text { 1. Not proficient in English } \\
\text { 2. Proficient in English } \\
\text { (is less than native language) }\end{array}$ & 4.2 & 48 \\
$\begin{array}{l}\text { 3. English proficiency is as good } \\
\text { as proficiency in native } \\
\text { language }\end{array}$ & 55.8 & 654 \\
\hline & & \\
TOTAL
\end{tabular}


APPENDIX J

NUMBER OF YEARS STUDENTS HAVE BEEN IN PORTLAND PUBLIC SCHOOL SYSTEM 


\begin{tabular}{ccr}
\hline $\begin{array}{c}\text { Number of } \\
\text { Years }\end{array}$ & Percent & $\underline{\mathrm{n}}$ \\
\hline 1 & 13.2 & 150 \\
2 & 20.2 & 229 \\
3 & 23.9 & 272 \\
4 & 22.9 & 260 \\
5 & 13.2 & 150 \\
6 & 6.6 & 75 \\
\hline TOTAL & 100.0 & 1,136 \\
\hline
\end{tabular}


APPENDIX K

SUPPLEMENTARY REGRESSION RESULTS FOR READING ACHIEVEMENT WITH DIFFERENT SUBSETS OF VARIABLES 


\begin{tabular}{|c|c|c|c|}
\hline Independent Variables & $b^{1}$ & $s^{2}$ & $t^{3}$ \\
\hline Neighborhood family size & -0.03 & 0.94 & -0.03 \\
\hline Home language & 0.38 & 0.33 & 1.14 \\
\hline Students' grade level & 9.57 & 0.27 & 0.003 \\
\hline Male dumy variable & -0.30 & 0.33 & -0.90 \\
\hline Percent Asian per school & 3.04 & 2.27 & 1.33 \\
\hline Neighbor. percent high school grad. & 1.62 & 2.76 & 0.58 \\
\hline Eng. prof. less than native language & 1.28 & 2.40 & 0.53 \\
\hline Neighbor. percent below poverty level & 2.13 & 3.46 & 0.61 \\
\hline Age of student & -0.50 & 0.30 & $-1.68 * * \star$ \\
\hline Predicted values of ESL hours & -0.14 & 0.61 & -0.24 \\
\hline $\begin{array}{lr}\text { Constant } & 7.65 \\
\text { Sample size } & 640 \\
\mathrm{R}^{2} & 0.073\end{array}$ & & & \\
\hline
\end{tabular}

IThe parameter estimate. 2 Standard error of the estimate. 3 The $t$ statistic.

$\star \star *$ Significant at the .10 level. 


\begin{tabular}{|c|c|c|c|}
\hline Independent Variables & $b^{1}$ & $s^{2}$ & $\underline{t}^{3}$ \\
\hline Time in Portland Public Schools & -0.15 & 0.13 & -1.12 \\
\hline Neighborhood family size & 0.02 & 0.93 & 0.02 \\
\hline Male dummy variable & -0.30 & 0.33 & -0.89 \\
\hline Percent Asian per school & 2.14 & 1.47 & 1.45 \\
\hline Neighbor. percent high school grad. & 1.60 & 2.75 & 0.58 \\
\hline Students' grade level & 0.003 & 0.27 & 0.01 \\
\hline Home language & 0.46 & 0.34 & 1.34 \\
\hline Neighbor. percent below poverty level & 1.90 & 3.47 & 0.54 \\
\hline Age of student & -0.57 & 0.26 & $-2.22^{\star}$ \\
\hline Predicted values of ESL hours & 0.11 & 0.11 & 1.07 \\
\hline $\begin{array}{lr}\text { Constant } & 9.00 \\
\text { Sample size } & 640 \\
\mathrm{R}^{2} & 0.074\end{array}$ & & & \\
\hline
\end{tabular}

$1_{\text {The parameter estimate. }}$

2Standard error of the estimate.

3 The $t$ statistic.

*Significant at the .05 level. 
APPENDIX L

SUPPIEMENTARY REGRESSION RESULTS FOR MATHETMATICS ACHIEVEMENT USING DIFFERENT SUBSETS OF VARIABLES 


\begin{tabular}{|c|c|c|c|}
\hline Independent Variables & $b^{1}$ & $s^{2}$ & $t^{3}$ \\
\hline Strudents' language group & 0.07 & 0.32 & 0.23 \\
\hline Male dummy variable & 0.47 & 0.25 & $1.65 * \star \star$ \\
\hline Neighbor. percent little or no Eng. & -0.32 & 1.14 & -0.28 \\
\hline Age of student & -0.86 & 0.25 & $-3.35^{\star}$ \\
\hline Neighbor. percent below poverty level & -1.29 & 2.83 & -0.45 \\
\hline Home language & -0.09 & 0.29 & -0.31 \\
\hline Eng. prof. less than native language & -2.92 & 2.04 & -1.43 \\
\hline Students' race & -0.36 & 0.44 & -0.82 \\
\hline Neighbor. percent high school grad. & 5.11 & 2.38 & $2.14 * *$ \\
\hline Percent Asian per school & -1.47 & 2.08 & -0.70 \\
\hline Students' grade level & 0.15 & 0.23 & 0.66 \\
\hline Predicted values of ESL hours & 0.98 & 0.51 & $1.89 * \star \star$ \\
\hline $\begin{array}{lr}\text { Constant } & 9.48 \\
\text { Sample size } & 640 \\
\mathrm{R}^{2} & 0.082\end{array}$ & & & \\
\hline
\end{tabular}

lThe parameter estimate. 2 Standard error of the estimate. 3 The $\underline{t}$ statistic.
*Significant at the .01 level. **Significant at the .05 level. $\star * *$ Significant at the .10 level. 


\begin{tabular}{lccc}
\hline \multicolumn{1}{c}{ Independent variables } & $\mathrm{b}^{\mathrm{l}}$ & $\mathrm{s}^{2}$ & $\underline{\mathrm{t}}^{3}$ \\
\hline Neighborhood family size & -0.25 & 0.79 & -0.32 \\
Predicted values of bilingual & 0.97 & 0.42 & $2.27^{\star *}$ \\
Male dummy variable & 0.51 & 0.28 & $1.79 * * *$ \\
Neighbor. percent high school grad. & 5.53 & 2.33 & $2.36^{*}$ \\
Students' grade level & 0.11 & 0.23 & 0.47 \\
Eng. prof. less than native language & -2.99 & 2.03 & -1.47 \\
Percent Asian per school & -3.03 & 2.00 & -1.51 \\
Neighbor. percent below poverty level & -0.41 & 2.92 & -0.14 \\
Home language & -0.55 & 0.34 & $-1.61 * * *$ \\
Age of student & -0.83 & 0.25 & $-3.29 *$ \\
$\begin{array}{l}\text { Predicted values of ESL hours } \\
\text { 9.46 }\end{array}$ & 0.95 & 0.51 & $1.85 * * *$ \\
\hline $\begin{array}{l}\text { Constant } \\
\text { Sample size } \\
\mathrm{R}^{2}\end{array}$ & & & \\
\hline
\end{tabular}

$l_{\text {The parameter estimate. }}$

*Significant at the .01 level. 2Standard error of the estimate. **Significant at the .05 level. 3 The $t$ statistic. $* * *$ Significant at the .10 level. 
APPENDIX M

SUPPLEMENTARY REGRESSION RESULTS FOR IAANGUAGE ACHIEVEMENT

USING DIFFERENT SUBSETS OF VARIABIES 


\begin{tabular}{|c|c|c|c|}
\hline Independent Variables & $b^{1}$ & $s^{2}$ & $\underline{t}^{3}$ \\
\hline Time in Portland Public Schools & -0.08 & 0.11 & -0.69 \\
\hline Neighborhood family size & -0.36 & 0.77 & -0.46 \\
\hline Male dummy variable & -0.27 & 0.27 & -1.00 \\
\hline Percent Asian per school & 1.40 & 1.22 & 1.15 \\
\hline Neighbor. percent high school grad. & 3.25 & 2.28 & 1.42 \\
\hline Students' grade level & 0.63 & 0.23 & $2.76^{*}$ \\
\hline Home language & -0.42 & 0.28 & -1.48 \\
\hline Neighbor. percent below poverty level & 1.97 & 2.87 & 0.68 \\
\hline Age of student & -0.60 & 0.21 & $-2.78^{*}$ \\
\hline Predicted values of ESL hours & 0.14 & 0.09 & 1.59 \\
\hline $\begin{array}{lr}\text { Constant } & 5.05 \\
\text { Sample size } & 640 \\
\mathrm{R}^{2} & 0.034\end{array}$ & . & & \\
\hline
\end{tabular}

$l_{\text {The parameter estimate. }}$ ${ }^{2}$ Standard error of the estimate. 3 The $t$ statistic.

*Significant at the .01 level. 


\begin{tabular}{|c|c|c|c|}
\hline Independent Variables & $b^{1}$ & $\mathbf{s}^{2}$ & $t^{3}$ \\
\hline Neighborhood family size & -0.39 & 0.77 & -0.50 \\
\hline Home language & 0.46 & 0.28 & -1.65 \\
\hline Students' grade level & 0.63 & 0.23 & $2.76 *$ \\
\hline Male dummy variable & -0.28 & 0.27 & 1.00 \\
\hline Percent Asian per school & 2.24 & 1.88 & 1.19 \\
\hline Neighbor. percent high school grad. & 3.21 & 2.28 & 1.40 \\
\hline Eng. prof. less than native language & 1.18 & 1.99 & 0.59 \\
\hline Neighbor. percent below poverty level & 2.07 & 2.87 & 0.72 \\
\hline Age of student & -0.53 & 0.24 & $-2.13 * \star$ \\
\hline Predicted values of ESL hours & -0.12 & 0.50 & -0.24 \\
\hline $\begin{array}{lr}\text { Constant } & 4.41 \\
\text { Sample size } & 640 \\
\mathrm{R}^{2} & 0.033\end{array}$ & & & \\
\hline
\end{tabular}

1The parameter estimate. 2 Standard error of the estimate. 3 The $t$ statistic.
*Significant at the .01 level. **Significant at the .05 level. 